Portland State University

PDXScholar

Spring 7-25-2013

\title{
Metaphor Use in Interpersonal Communication of Body Perception in the Context of Breast Cancer
}

Jennifer Mary Fillion

Portland State University

Follow this and additional works at: https://pdxscholar.library.pdx.edu/open_access_etds

Part of the Health Communication Commons, and the Oncology Commons Let us know how access to this document benefits you.

\section{Recommended Citation}

Fillion, Jennifer Mary, "Metaphor Use in Interpersonal Communication of Body Perception in the Context of Breast Cancer" (2013). Dissertations and Theses. Paper 1014.

https://doi.org/10.15760/etd.1014

This Thesis is brought to you for free and open access. It has been accepted for inclusion in Dissertations and Theses by an authorized administrator of PDXScholar. Please contact us if we can make this document more accessible: pdxscholar@pdx.edu. 
Metaphor Use in Interpersonal Communication of Body Perception in the Context of Breast Cancer

by
Jennifer Mary Fillion

A thesis submitted in partial fulfillment of the requirements for the degree of

\author{
Master of Science \\ in \\ Communication
}

\begin{abstract}
Thesis Committee:
David Ritchie, Chair

Jeffrey Robinson

Lauren Frank
\end{abstract}

Portland State University

2013 


\begin{abstract}
Female breast cancer patients as well as familial caregivers are often confused, frustrated, and devastated by changes occurring in their bodies and the treatment process. Many women express frustration with the inability to know what the next phases of their life will bring. Previous research also states that many women struggle to communicate with nurses and physicians about treatment as well as side effects. This research examined how woman are use metaphors to describe their experience with breast cancer, specifically throughout the treatment period related to body image struggles. I qualitatively conducted interviews with women who were either currently in treatment or just finishing. My interview questions related to their uncertainties, as well as the changes occurring to their bodies. After conducting the interviews I transcribed the conversations and coded for specific metaphors. The results were consistent with previous research, in that that the interviewees used at least four major metaphors to describe what they are going through. The four most prominent metaphors were (1) journey, (2) game, (3) struggle/fight, (4) grasping. The findings could benefit patients, nurses, physicians as well as family and friends to reduce stress and help with coping. The findings may also help female patients struggling with identity issues due to lumpectomies or mastectomies. Understanding how patients comprehend the disease can ultimately help others to understand and hopefully reduce some of the concerns of all those involved in such situations.
\end{abstract}




\section{Dedication}

This thesis is dedicated to the amazing women who contributed their beautiful and empowering stories, I am truly in awe of your strength and love of life. Also thanks to my supportive family, none of this would have been possible without you. 


\section{Table of Contents}

Abstract..........................................................................

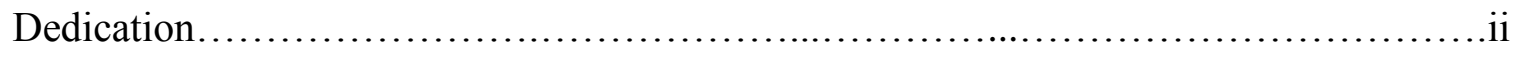

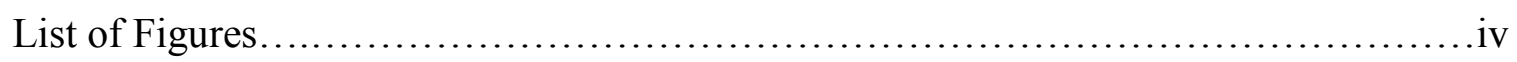

Chapter 1: Introduction ...................................................

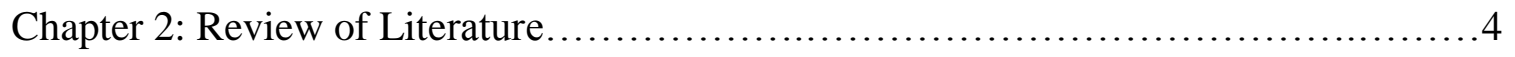

Chapter 3: Methods.......................................................19

Chapter 4: Analysis and Results............................................... 31

Chapter 5: Discussion................................................47

References...........................................................63

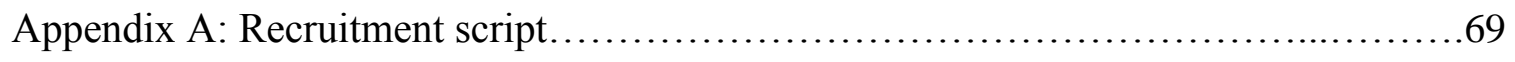

Appendix B: Consent form............................................... 70

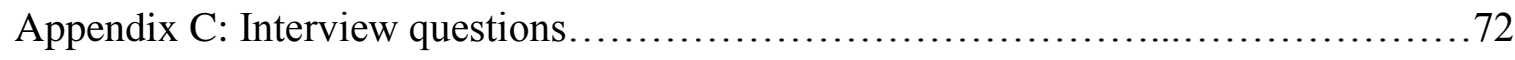

Appendix D: Metaphor coding instructions.................................. 73

Appendix E: Transcripts................................................. 76 


\section{List of Figures}

Figure 1.1: Metaphor frequency......................................... 30 


\section{Chapter 1: Introduction and Review of Literature}

According to the National Cancer Institute (2010) breast cancer is the most common form of cancer amongst women. Breast cancer can cause a number of physical changes to the human body ("National Cancer Institute." 2010). Changes to the female body during cancer do not occur at one specific time, but instead throughout every step of the disease, including treatment (Cassell,1991). As these changes occur in a woman's body, research suggests that women begin to see a new physical self (Bellinir, 2002). Past research has shown that breast reconstructive surgery can cause insecurities about body image and appearance (Moyer, 1997; Stark 2000). In order for women to understand the changes in their body and physical appearance, they may begin to describe their self image in terms of something else in order to create a better personal understanding (Nelson, 1996).

Studies have shown that patients routinely employ a wide range of metaphorical expressions as they talk about specific diseases and their subjective experiences of illness (Gibbs \& Franks, 2007; Gibbs, 2006; Reisfield, 2004; Cameron, 2008). In order to identify how women talk about breast cancer treatment in general and with regards to body image it is important to identify specific patterns of word usage. This paper will be particularly concerned with metaphor usage.

The following paragraphs highlight some of the major problems women face regarding body image while dealing with breast cancer. These changes in body image can create an entirely new identity for some women and sometimes this can be hard to comprehend. The specific aim of this study is to examine the ways in which women who 
have been diagnosed with breast cancer talk about the disease in order to make sense of their experience specifically related to changes in body image.

\section{Justification}

Since cancer is such a common problem amongst women today and impacts their understanding of personal body image it is important for research to focus on the issue. For example, research can identify patterns of talk that are not necessarily covered in medical research, but may have a major impact on the patient's ability to cope with disease. Interviews previously conducted with female breast cancer patients show that extreme stress and anxiety can be caused by a cancer diagnosis and treatment decisions (Hampton, 2005). Patients feel overwhelmed and are dealing with a number of factors with regard to internal and external stressors right from the first doctor's visit. These stressors can range from emotional coping problems to difficulties discussing disease and bodily issues with family members and friends. When patients begin to verbally express their life and concerns as a breast cancer patient, conversations about cancer become particularly important. Women discuss cancer with metaphors to help them understand the somewhat unpredictable physical encounters with the disease (Gibbs \& Franks, 2007). Much of our everyday talk happens spontaneously, and we pay little attention to what we are actually saying and how why we are using specific language. The goal of this study is to identify patterns of metaphors women use to describe their experience and how these metaphors are used to discuss body image. Stories and metaphors provide insights into the underlying thought processes of diagnosed women (Gibbs \& Franks, 2007). 
Since we know that breast cancer can cause extreme anxiety and stress for patients concerned about treatment and changes to the body, it is important for researchers to consider how certain patterns of talk, such as metaphor use, might help patients better understand their complex experience and identity issues. If findings prove that there are in fact patterns related to metaphor use in talk of body image, healthcare professionals and researchers can begin to implement methods of communicative coaching for patients and physicians to use certain types of talk to help women understand their disease. Physicians may also use findings to help patients adjust to the situation and new way of living by using some metaphors over others.

The goal of this study is to provide qualitative data from female breast cancer patients representing linguistic patterns of metaphor use related to body image. This goal will be achieved by first reviewing literature related to breast cancer treatment, metaphor and body image. The following pages will highlight the academic importance of this study and pre existing research. The major justification is embedded in the review of literature and will identify the existing findings related to this topic. 


\section{Chapter 2: Review of Literature}

Cancer is unfortunately becoming more and more common amongst women today (National Cancer Institute, 2010). According to the National Cancer Institute, breast cancer forms in tissues of the breast, usually the ducts (tubes that carry milk to the nipple) and lobules (glands that make milk). In 2011 there were 230,480 new cases of breast cancer found in women. There were also nearly 40,000 deaths among females from breast cancer (“National Cancer Institute," 2010).

\section{Breast Cancer and Body Image}

Women experiencing breast cancer often struggle when coming to terms with the idea that their bodies will be changing physically (Pikler \& Winterowd, 2003). Often breast cancer treatment can leave women with scars, tissue damage, and sometimes reduction or complete removal of one or both breasts ("National Cancer Institute," 2010). The loss of hair can also cause extreme stress and discomfort for women.

Recently diagnosed women usually have a number of treatment options including surgery, radiation therapy, hormone therapy, chemotherapy and targeted therapy (Bellenir, 2002). It is common for patients to receive more than one of these treatments. Usually treatment options are discussed with the doctor and decisions are made based on the severity and stage of the cancer (http://www.cancer.gov/statistics). According to the National Cancer Institute, surgery is the most common choice for patients. Breast-sparing surgery is an operation to remove the cancer but not the breast. It's also called breastconserving surgery. It can be a lumpectomy or a segmental mastectomy (also called a partial mastectomy). In some cases, a skin-sparing mastectomy may be an option. For this 
approach, the surgeon removes as little skin as possible. Sometimes an excisional biopsy is the only surgery a woman needs because the surgeon removed the whole lump. Many women feel that the more breast they can conserve the better, possibly leaving fewer issues related to body image.

A mastectomy is an operation to remove the entire breast. Doctors will often prescribe that patients also have radiation therapy (National Cancer Institute, 2010). Following the surgical treatments, it is common for women to undergo post-surgical treatments. For many patients radiation therapy is the most trying because of its extreme side effects. External radiation therapy is when radiation comes from a large machine outside the body. Patients will go to a hospital or clinic for treatment usually five days a week for four to six weeks. External radiation is the most common type used for breast cancer. Internal radiation therapy is when the doctor places one or more thin tubes inside the breast through a tiny incision. A radioactive substance is loaded into the tube. The treatment session may last for a few minutes, and then the substance is removed, leaving no radioactive substance in the patient's body.

It is important to get a good understanding of the intensity of medically treating breast cancer. The body goes through some extreme changes during treatment and often leaves some temporary, but also some permanent changes to the body. These changes to the body can certainly change the way women see themselves and this will be identified through the use of metaphors in conversations about breast cancer.

Diagnosed women must learn how to understand and interpret the changes in their bodies. Although previous research has highlighted some of the types of metaphors used 
to describe illness experiences (Gibbs and Franks, 2007; Moyer 1997), there has not been much focus on the metaphors patients use or how patients experience and talk about their bodies' physical change during treatment. This study aims to identify the types of metaphors women use to describe the treatment process and will shine light on the way women talk about their struggle with breast cancer, with particular focus on how they talk about the changes to their bodies and their body images.

\section{Body image, dating, and marriage}

Among the most distressing aspects of breast cancer are the changes to the body, such as breast amputation or hair loss, (Lemieux et al. 2008; White 2000), and the resultant changes in women's body images. Pikler and Winterowd (2003) reported that those patients who felt better about their bodies had a stronger belief in their ability to cope with the disease and its treatments.

Many women experience breast cancer in the context of a marital or dating relationship. In a cross-sectional study, Canavarro \& Dattilio (2011) analyzed the links between marital quality and intimacy, body image, and psychological quality of life of breast cancer patients, as well as the moderating role of cancer phase (treatment, survivorship) on the aforementioned links. They also evaluated whether body image mediated the associations between marital relationship variables and psychological quality of life. Results suggested that many women struggle with body image issues with their intimate partners due to post treatment changes to the body.

When the body undergoes extreme surgery, it is no surprise that women may become insecure and concerned about their new appearance. Loss of a breast or poor 
breast appearance is distressing to women who have high expectations for physical beauty (Schover, 1994). It is also likely that issues related to body image and identity differ based on relationship status and age. Schover (1994) interviewed young adult females and found that seeking new dating relationships after breast cancer treatment is a special stressor for single women.

\section{Metaphor Theory}

Metaphor is especially important in mapping experiences of the body to help structure abstract ideas that are fundamental to how people speak and think (Gibbs, 2005). Ortony (1975) describes three communicative functions served by metaphor. First, metaphors allow for expression of inner states that are difficult or impossible to describe literally (as opposed to figuratively). Next, metaphors serve as an economical means of expression, allowing for a more efficient use of language. Finally, metaphors communicate the richness and vividness of experience that is not captured by the use of literal language.

A metaphor is most commonly described as the use of some symbol or word to describe something else. As Ortony (1975) describes above, people often use metaphors to describe things that are rather difficult to literally describe, such as dealing with physical body changes from breast cancer. Metaphors are often used by patients undergoing treatment or experiencing disease, to describe their situation and current state (Bowker 1996; Gibbs and Franks 2002). Clinicians can also use metaphors to inform and empower patients (Harpham, 2010; Golden, Whaley \& Stone, 2011). Patient 
comprehension of health explanations and retention of illness information are enhanced when metaphors are used (Whaley, 2000; Golden Whaley \& Stone, 2011).

Orientational metaphors are defined by orientation. Some of these metaphors are described by Lakoff and Johnson (1979) as "up" and "down" metaphors. Most commonly health and life are described in terms of "up" whereas death and sickness are referred to as "down." These types of metaphors are very common in everyday language. When researching an issue like cancer, orientational metaphors play an important role in understanding health and wellness. Words give individuals a way of describing embodied experiences so that they themselves, as well as others, can understand what they are feeling. For example, a sick individual could state, "The disease broke me down," "I felt distanced from myself," "I felt on top of things," "I had no choice but to stay up ... but one day I was kinda down." (Gibbs and Franks, 2007). Since up is connected with the feeling of happiness and satisfaction and down is connected with feelings of sadness and discomfort, a patient feeling physically well might use metaphors like the ones listed above relating to higher orientation as opposed to low and feelings of sadness.

\section{Cognitive and Embodied Theory}

Cognitive linguistics does not view language as arising from an autonomous part of the mind/brain, but seeks to discover the ways in which linguistics structures are related to and motivated by human knowledge, bodily experience, and the communicative functions of discourse (Croft \&Cruse, 2004; Lakoff \& Johnson, 1999).

The cognitive mind and physical body are connected and function based on experiences with the world (Gibbs, 2005). Philosophers refer to this as "coupling" of the 
self and the world (Leder, 1990, p. 165). The way we conceptualize events or words depends on our bodies' interactions during the present time of the event. Metaphors help individuals give words to their experiences. According to Lakoff and Johnson (1999) metaphorical concepts arise from our bodily experiences. Take for example walking down a path outside and coming to some sort of barrier in the road like a fallen tree, we physically cannot move past this tree so we are forced to turn around or choose another path. Lakoff and Johnson argue that we describe that physical encounter as "the end of the journey." Because of these experiences we describe actual thoughts or feelings with words originating from our physical lives. As the following pages will explain, disease and pain are often the source of bodily discomfort making it difficult for individuals to explain their feelings. This is where metaphors can assist women after treatment. Metaphors can give women a way to describe an extremely traumatic event, or changes in their body. Language is often expressions of emotional, physical, and social change in an individual's life. Because emotional, physical, and social change are all present postsurgery, understanding the language surrounding these issues is important.

\section{Embodied Metaphor Theory}

Previous research suggests that our abstract concepts are connected with our physical experiences and body awareness (Lakoff and Johnson, 1979). Metaphors are often an outlet for describing our understanding of our bodies in the world and the experiences we encounter, hence the embodied view of metaphor theory (Gibbs, 2005). According to current research, our bodies influence the way we talk, so we might expect 
that a breast cancer patient undergoing serious surgery may describe the situation terms of other experiences.

Some of the most prominent hypotheses related to embodiment are as follows: (1) Embodiment plays a role in the development of and change in the meanings of words and expressions over time, (2) Embodiment motivates the linguistic meanings that have currency within linguistic communities, or may have some role in an idealized speakers/hearers' understanding of language, (3) Embodiment motivates contemporary speakers use and understanding of why various words and expressions mean what they do, but does not play any role in people's ordinary on-line production or comprehension of everyday language, (4) Embodiment functions automatically and interactively in people's on-line use and understanding of linguistic meaning (Gibbs, 2005, p. 159). Gibbs (2005) uses these hypotheses to describe how language and communication correlate with embodied experiences. These hypotheses, especially hypothesis number four, suggest that embodied experiences are in fact described by words, and these words give us a better understanding of our embodied experience. This same idea that Gibbs is describing can be thought of with the embodiment of breast cancer. As we saw earlier, many female patients use metaphors to describe the physical changes happening to their bodies.

As stated earlier, people often use orientation metaphors to describe their state of health. People feeling "up" are usually in good health whereas people feeling "low" or "down" are often sick or not feeling well. Gibbs (2006) claims that part of our ability to make sense of narratives and metaphors used within narratives resides in the automatic 
construction of simulation whereby we imagine performing the bodily actions referred to in the excerpt. In a sense, metaphors commonly used in narratives about grief or healing are often understood by simulating what it must be like to perform these specific activities. For Gibbs, (2006) metaphoric language is rooted in the bodily process that people may imaginatively recreate during their ordinary use of such language (Gibbs, 2006, p. 436). With regards to women dealing with a recent cancer diagnosis, embodiment of metaphors could prove to be extremely important in understanding the disease and the healing process. The mind cognitively chooses to recall certain words for certain situations, those words could provide insight into how cancer patients understand their disease. Identifying patterns of metaphor use could help physicians better understand some major concerns for women during the entire breast cancer process.

The process of categorization, putting experiences into certain conceptual categories (Lakoff \& Johnson, 1999), is important when beginning to think about embodied metaphors. "Philosophically, the embodiment of reason via the sensorimoter system is of great importance. It is a crucial part of the explanation of why it is possible for our concepts to fit so well with the way we function in the world" (Lakoff and Johnson, 1999, p. 43). According to Gibbs and Matlock (2008), simulation plays a central role in the comprehension of metaphor: People understand metaphors by creating an imaginative simulation of their bodies in action that mimics the events alluded to by the metaphor (p. 162). Essentially our mind is so strongly linked to our embodied experiences that we can ultimately create connections between experiences and words. Because of the strong connection between bodily experiences and modes of 
understanding these experiences, we can begin to consider the connection that might exist between cancer and words. This is an important argument for metaphor research because it claims that the metaphors we are use are a direct reflection of what our bodies are experiencing, meaning women undergoing breast cancer treatment use metaphors specific and personal to their experience. The metaphors they are using could be highlighting feelings not otherwise spoken about and unique to that specific embodied experience.

This project will identify specific metaphors that women with breast cancer use to describe their experience of their body after diagnosis and treatment and may provide a foundation for future research that examines the utility of metaphor for adaptive coping and understanding.

\section{Metaphors in Talk of Illness}

Cancer and tuberculosis are often discussed in metaphoric terms as a way for individuals to understand a somewhat mysterious disease (Sontag, 1977). A disease like cancer is not always curable. This leaves patients confused and unsure of their fate. For many women the concern might be the thought of extreme physical change, specifically the possibility of cancer removal or reconstruction surgery, leaving their breast looking drastically different than previously. Cancer is often thought of as an "invasion of the body" (Sontag, 1977). This “invasion" can leave patients feeling insecure and uncomfortable. The diagnosis will affect all parts of their life, not just physical, but also their careers, love lives, family life and more. Sontag (1977) provides a close look at the way cancer and disease is understood through metaphorical terms. This research points out some of the many ways cancer is described in figurative language through multiple 
outlets including books, television, and narratives. In almost all facets cancer is thought of as a taboo disease and is often described in terms of invasion and corruption of the body (Sontag, 1977). Some associated metaphors that describe cancer are: "aggressive," “invader," "call to war," and "cancer is a plague." Because of this type of aggressive talk regarding cancer, upon diagnosis women already feel ostracized and different, as if they no longer socially "fit in" (Sontag, 1977). Once they have completed treatment that feeling may worsen. If researchers can better identify how this "invasion and corruption" of cancer is described and processed through patients physical understanding of body image, they can then begin to understand how it is that women simply understand and experience diagnosis and treatment.

Metaphors provide the intellectual and linguistic tools for communication about senseless suffering, and yet also offer a plan for personal transformation in coping with illness (Gibbs, 2002; Guinjoan \& Ross, 1999; Jenny \& Logan, 1996; Mallinson, Kielhoftner, \& Mattingly, 1996). Metaphors of pain are commonly found in narratives regarding disease and illness. Bowker (1996) analyzed the metaphors in her own writings and tape-recordings about her cancer experience and found that five metaphors were central to her narratives: insanity and chaos, natural disasters, cancer as an animate character, battle, and splitting apart or dividing. Physicians and other medical workers tend to use a small set of metaphors in thinking about disease, such as "the body is a machine" and "illness is a battle within the body" (Kirmayer, 1988; Martin, 1994; Taussig, 1993). 
Physical pain or discomfort will be felt at some point during the cancer experience. However, people do not often say "I am in pain," instead they will use metaphors to describe pain. Metaphors give people a richer, more vivid way to explain life. An example of a pain metaphor is, "I was in pain, I felt like someone was stapling my skin." Gibbs and Franks (2002) also found that patients use the metaphor "cancer is war" throughout their entire experience with cancer including treatment. This metaphor highlights that patients feel they are fighting with the disease, and fighting enacts pain and suffering. Kövecses (2008) observed that 'the most important metaphors provide the phenomenological character of pain' involve source domains that correspond to the most salient causes of pain. Kövecses (2008) borrows metaphors from the McGill Pain Questionnaire (hereafter the MPQ), which was devised at McGill University. The list of relevant metaphors includes the following: "pain is a sharp object," "pain is a tormenting animal," "pain is fire." More specifically, patients have stated pain in the following phrases: "Ifeel a sharp pain," and "Pain is fire that can devour the whole body." These examples show that for many, understanding pain comes in the form of describing other painful experiences. "Even when pain does not directly result from tissue damage, it tends to be described metaphorically in terms of a variety of causes of physical damage" (Semino, 2010, p.10). Semino suggests that different metaphorical descriptions of pain vary in terms of the extent to which they are likely, other things being equal, to trigger a simulation, and in the intensity, richness, and complexity of the simulation they may facilitate (p. 19). Semino also argues that pain is described and understood by calling on previous embodied experiences of discomfort resulting in 
damage to the human body, meaning our past experiences of bodily pain informs us of what we might be feeling. Because of these experiences we are then afforded the opportunity to describe new instances of pain with words once used to describe other instances of pain.

Gibbs and Franks (2002) found that female breast cancer patients sometimes use contradictory metaphors in order to conceptualize their experience with cancer (p. 10). They point out that women's embodied experiences are not of the illness itself, but of more general bodily sensations and knowledge as the primary source domains in many of the metaphors used in their narratives. For many women cancer simply allowed them to stress less and enjoy life more so than they had prior to diagnosis. Gibbs and Franks found that their six participants used a total of 23 metaphors. Some of these metaphors included the following (Gibbs and Franks, 2002, p. 12):

\section{CANCER IS AN OBSACTLE IN LIFES JOURNEY}

"Cancer was something I needed for me to get through."

"And it has transported me to a place."

"It kinds brings ... it brought me to the kind of ... the edge of the abyss."

\section{CANCER AND ITS TREATMENT IS A GAME}

"One option was to do nothing and just live with the odds."

"Cancer is so unpredictable."

\section{CANCER IS WAR}

"The disease was an aggressive opponent that I had to fight." (Gibbs and Franks, 2007) 
Lastly, an important finding by Gibbs and Franks (2002) suggests that women do not use just one single metaphor to describe their experience with cancer. Instead, women use a number of metaphors. Gibbs and Franks point out that some linguists might argue with the idea that multiple metaphors can be used to describe one single entity. However, this research posits that all people are different, therefore they use a number of different metaphors to describe their experiences opposed to just one single, universal metaphor.

Brody (1987) contends that "storytelling as an activity is central to medicine" (p. 12). "Narratives serve as a method of working through the anguish and suffering brought on by life-threatening illness" (p. 3), "Not only are narratives told and heard among families while coping with the illness, but also narratives are a primary means of learning about illness in the research process (Anderson and Martin, 2003, p. 9). In sum, not only do women often use metaphors in discussions about cancer, but these narratives may also help patients as well as families to cope with the disease.

Gibbs (1994) explains that a problem with the research on metaphor relating to illness is that researchers have primarily focused their attention on highly personal, idiosyncratic metaphors and downplayed the importance of conventional metaphorical expressions. Conventional metaphors are typically viewed as "dead" metaphors or merely clichés. Although research has been done regarding metaphors and narrative coping methods, there are still great gaps existing in current research. Authors solely focused on metaphor usage in cancer narratives don't take into account other possibilities for reasoning. For example women may be using specific metaphors to describe only certain portions of the entire cancer treatment process. Instead of researching the metaphors used 
throughout the entire cancer experience, it may be beneficial to focus on just one aspect of the process like treatment.

While Gibbs and Franks (2002) offer a strong outline of some of the most prominent metaphors used by cancer patients, they do not examine how metaphors are used by women when discussing their body image following surgery. It is important to understand some of the most common types of metaphors, but further research could potentially point out language exercises for females to feel more confident and comfortable in their own skin after major surgery has been performed.

\section{Language of Journalists and Practitioners}

For patients, metaphors can impose order on a suddenly disordered world, helping them to understand, communicate, and thus symbolically control their illness. "For the physician, metaphors can be time-efficient tools for helping patients understand complex biologic processes" (Gibbs and Franks, 2007). "And for the therapeutic relationship, the language of metaphor can serve as the basis for the shared understanding of clinical reality" (Reisfield and Wilson, p.1, 2004). For physicians and patients alike, war is a dominant metaphor. There are several reasons for this: (1) The metaphor is ubiquitous in our society (witness, for example, the "wars" on drugs, poverty, illiteracy, and teen pregnancy). (2) It is easily adaptable to cancer, wherein there exists a seemingly perfect metaphoric correspondence: there is an enemy (the cancer), a commander (the physician), a combatant (the patient), allies (the healthcare team), and formidable weaponry (including chemical, biological, and nuclear weapons). (3) It connotes an unmistakable seriousness of purpose. (4) War has an exceptionally strong focusing 
quality, and its images of power and aggression serve as strong counterpoints to the powerlessness and passivity often associated with serious illness. With physicians on the "front lines," using their "armamentarium" in search of breakthroughs, and where "brave" patients "soldier on," basic science has only reinforced our appreciation of the “attack” (Annas, 1995 p. 4). Without a common language, patients and physicians risk not having a shared understanding of the situation (Cassell, 1991). Metaphors offer both the patient and the physician a common language and shared understanding, offering both simplification and connection.

RQ 1: What metaphors do women diagnosed with breast cancer use to talk about treatment?

RQ 2: What metaphors do women use to talk about the effects of breast cancer treatment on their body image? 


\section{Chapter 3: Methods}

The previous review of literature highlights the connection between health issues and the way in which women talk about their disease (Caughlin, et. al, Gibbs, 1998, $2005,2008)$. The focus of this research is how women are using metaphors to describe their bodily experience. Although the potential effects of metaphor use are beyond the scope of this study, this study will strengthen the basis for further research on the topic.

This is a qualitative research design using transcribed conversations of female breast cancer patients as the main form of data. The overall goal is to identify patterns of metaphor use that relate to body image and general conversation about breast cancer treatment. A research partner and I coded the transcribed conversations and used a code list based on previous research to identify and classify the metaphors. All of the research steps will be discussed in greater detail below.

\section{Participants}

This research is based on face-to-face interviews with four women in their 50's who had been diagnosed with breast cancer and had either completed or were still in treatment. All four participants were living in Oregon in the greater Portland area. Oneon-one interviewing is important because it allows the interviewee to feel comfortable with the researcher (Wengraf, 2004).

Participants were recruited using a mixture of both snowball sampling and convenience sampling. All participants were from a breast cancer research institute in Portland, Oregon. The coordinator of the cancer support group was contacted and asked 
if the support group could be visited during one of the meeting times. I visited the support group and this is where I met my first participant.

"In snowball sampling, the researcher collects data on the few members of the target population whom they happen to know" (Babbie, 2004, p.184). The "snowball" effect occurs when one of the located subjects suggests another subject. Once the first participant was recruited three more were recruited by way of snowball sampling, however only the initial participant was present at the support group on that particular night.

At the beginning of the meeting I read the recruitment script and invited interested members of the group to stay after the meeting for further explanation and details. One participant stayed for information. Other possible participants, who were referred by the support group leader and initial participant, were contacted via email. Potential participants were given an overview of the study and asked if they were willing to participate further. If participants confirmed that they were still interested a meeting time and place was arranged. At the meeting time consent was given. The informed consent process is explained in further detail in the following paragraphs.

Participants gave consent before becoming involved in any aspect of the interview process. In the consent process individuals signed a consent form indicating that they were aware of any harm or danger that may come of the study. Participants will remain anonymous by the use of pseudonyms and elimination of all references to specific geographic locations or place names (e.g., street names, hospital names) in the transcripts. 
The sample size for this study was four women who were diagnosed with breast cancer $(n=4)$. Four participants provided enough data to represent some patterns of metaphor use, however this sample size was not enough to reach theoretical saturation. Because of the small sample size and configuration of the IRB application the data collected can only be used for the purposes of this specific research study.

Each of the four interviews lasted one hour or more, yielding a total of over four hours of data. The interview question guide (discussed later) assured that the participants stayed on topic. The recruited participants were selected based on commonalities of age and stage of treatment in order to centralize findings and relate them to females of a specific demographic of breast cancer. As the findings will later reflect, a sample size of four women produced enough data to reflect some specific patterns of metaphor use, however it is fully recognized that a larger sample size would have resulted in stronger reliability of results.

\section{IRB and Informed Consent}

The study guidelines and procedures were reviewed and accepted by the PSU International Review Board. The recruitment script included an overview and description of the goals of the research study (Appendix A). Once the women were recruited and read the recruitment script they were then given a consent form (Appendix B ). The consent form (a) described the study, including interview procedures and possible risks and benefits, (b) stated that participation is voluntary, (c) stated that participants may elect to withdraw from the study at any time, (d) informed participant that she can contact the 
researcher or the IRB for further information about the study. Before conducting the interviews each participant read and signed the informed consent form.

\section{Interview Protocol and Research Design}

This qualitative study used in-depth interviewing in the emotionalism version (Silverman, 2001). “According to emotionalism, interviewees are viewed as experiencing subjects who actively construct their social worlds. The primary issue is to generate data which gives an authentic insight into people's experiences" (Silverman, 2001, p. 87).

After each participant agreed to partake in the interviews and signed a consent form she filled out a general questionnaire indicating first name, age, sex, occupation and approximate date of cancer diagnosis and treatment. Participants were informed that the interview would take approximately 30 minute- 1 hour. Once the participant was ready to begin the interview I began audio recording. Each participant was asked the same questions (Appendix C). However the participants were allowed to talk freely and I allowed the conversation go in any direction as long as it stayed on the topic of the participant's cancer, treatment, and recovery. The interview questions were as follows:

1. How long ago were you diagnosed with cancer?

2. How would you describe yourself? What type of personality traits best describe you?

3. How has your life changed since being diagnosed with breast cancer?

4. How has cancer changed your body?

5. What type of changes in your body were the most difficult for you to accept?

6. How do you cope when you begin to feel upset?

7. How do you cope with treatments?

8. Can you discuss your experiences living with cancer?

9. What has been the biggest struggle thus far for you when living cancer? And treatment?

10. How has your body felt since being diagnosed with breast cancer? 


\section{Measures}

Interviews were coded for 17 different metaphors previously identified by Gibbs and Franks, (2007), who focused on metaphors used by cancer patients, and Golden, Whaley and Stone (2011), who focused on metaphors used by family members of Alzheimer patients. What follows is a definition and description of each metaphor. Note that not all of the 17 metaphors were found in both studies, and three additional metaphors (project, criminal and food) were identified in this project. Metaphors found in both Gibbs and Franks (2007) and Golden, Whaley and Stone (2011) are: journey, machine, orientation, game, image, struggle/fight and hand. While coding the transcripts from this study we relied heavily on the definitions from Gibbs and Franks and Golden, Whaley \& Stone. Their definitions gave us (myself and second coder) a clear understanding of what to look for. A few metaphor categories were created simply based on the initial conversations with the participants and were important because they offered a different perspective and understanding of breast cancer that the previous studies. These metaphors include project, food and criminal. The definitions and examples used for coding are listed below.

1. Life is a journey. Life is a journey and cancer is an obstacle on the path of life's journey. For this metaphor cancer(Gibbs \& Franks, 2007) and dementia (Golden, Whaley \& Stone, 2011) are conceptualized as physical things that interrupt the path. . Example: "Cancer was something I needed for me to get through."

2. The body is a machine or circuit. The body is a machine that can break down or stop working. The body is also a machine that can be fixed (Gibbs \& Franks, 2007). In 
order to code for the machine metaphor in conversations about breast cancer we looked for language describing problems with machines or elaborate engineering. Example: "My body's working really hard for me ... it's responding and doing well" (Gibbs \& Franks, 2007). "System is beginning to shut down" (Golden, Whaley \& Stone, 2011).

3. Orientation. Happy is up and sadness is down - one must stay up to heal (Golden, Whaley \& Stone, 2011). Orientation metaphors reflect spatial positions (e.g., up, down, over, under; Lakoff \& Johnson, 1980). We looked for metaphors simply using direction as feeling, most commonly this was the up and down metaphor.

Example: "I felt on top of things" (Gibbs \& Franks, 2007).

4. Game. Cancer and its treatment is a game (Gibbs \& Franks, 2007). "Care giving is a game; but the games that caregivers describe have an air of negativity, fear, and uncertainty (e.g., "Russian Roulette"; “when's my number coming up?”)" (Golden Whaley \& Stone, 2011).

Example: "One option was to do nothing and just live with the odds."

5. Container. Cancer is a fluid within the self container (Gibbs \& Franks, 7007). For us a container metaphor could be described as something being empty or full, such as a glass or a bowl. Women could feel full of life or energy.

Example: "All of a sudden, it was like the plug had just been pulled in me and I was empty." "I couldn't absorb what was going on."

6. Image. Cancer clears vision and allows for new understanding. This metaphor was mostly identified by patients using language associated with vision or seeing. 
Example: "It was like putting on a new pair of glasses." "At the age of $40 \mathrm{I}$ had the chance to look at what was really important and make sure I didn't miss it" (Gibbs \& Franks, 2011). "A person with dementia is an image” (Golden, Whaley \& Smith, 2011).

7. Struggle or fight. Emotional effect is physical contact.

This metaphor was identified by language associated with bodily harm, hurt, wrongdoing, or violence (Golden, Whaley \& Stone, 2011).

Example: "I wasn't prepared for the impact it would have on me." The idea of that therapy really struck me as something I wanted (Gibbs \& Franks, 2007).

8. Cancer is war. Cancer is war between two opposing forces, there is most commonly a winner and loser (Gibbs \& Franks, 2007).

Example: "The disease was an aggressive opponent that I had to fight."

9. Cancer is a teacher. We can learn from cancer.

Example: "The disease has taught me many things about myself."

10. Cancer is a natural force. Cancer is something that can't be controlled and instead just happens (Gibbs and Franks, 2007).

Example: "I felt overwhelmed."“I was knocked over by the news."

11. Cancer in terms of fiscal value. Sometimes thought of in terms of life as a bank account. Life is a bank account (Gibbs \& Franks, 2007). We understood this metaphor as describing things in terms of currency. Example: "Losing my hair is really, really a small price to pay for my life." "I just wanted to buy time until my surgeon was home" (Gibbs \& Franks, 2007) 
12. Project. This category was not found in either of the articles but was used as a category derived from the interview data. The project metaphor was used when women described cancer as project in which they were working towards a "final draft" or nearing an endpoint. For this metaphor women could also describe their bodies as a project that was being "fixed" or "cut apart."

13. Hand or grasping. Understanding is grasping with the hands (Gibbs \& Franks, 2007; Golden Whaley \& Smith, 2011).

Example: "I was really impressed by how I handled it." "My husband couldn't get a grip on it for quite a while.”

14. Cancer is a criminal. This metaphor category was created for this study to capture instances where women felt that cancer was unwelcomed and left the women feeling threatened, but not in the sense of physical fighting.

15. Cancer is a loss. Examples: "Persons with dementia lose things." "Being a caregiver is losing something" (Golden, Whaley \& Smith, 2011).

16. Emotional as physical. Emotional strength is physical strength (Gibbs \& Franks, 2007).

Example: "You really do believe you are OK and you are as strong as you think you are." "It was ... I just ... I learned my strength."

17. Cancer is food. Anytime women described breast cancer as food or something that could be eaten.

Example: "I feel like a couch potato." 


\section{Coding Procedures}

Once all of the necessary data was collected, the data was then transcribed. I performed all of the transcription as a way to get more familiar with the data. In order to transcribe all of the conversations I played back the mp3 recordings and typed out the conversations in their entirety. There were a few instances when noise and volume of talk were an issue and the transcripts are missing a few words. A colleague and I then went sentence by sentence using the 17-metaphor scheme as a coding guide (discussed in detail above). When a metaphor was identified using the 17-metaphor scheme it was categorized and counted. In the first reading of the transcripts coders looked for basic structure and themes found within the data. This allowed coders to become familiar with the data and begin to understand what the basis of the conversation was. In a second pass, both researchers coded looking for metaphors derived from past research (Gibbs \& Franks, 2007; Golden, Whaley \& Stone, 2011) (appendix D). Each coder circled the identified metaphor by category and got a total tally for each category at the end of each transcript. In order to ensure valid coding procedures researchers first discussed the code list and instructions and then checked for agreement after the first two pages of each transcript. The reliability was accessed by having myself and the second coder read the first two pages highlighting and categorizing each metaphor found and then comparing the results to ensure we both understood the coding procedures. When there was an instance where we did not agree on the category of metaphor we would discuss our reasoning and decide on what category was the strongest, however we only disagreed once in the initial coding. At the same time as coding from the derived code list, 
researchers also used open coding to identify any new metaphors that have not been highlighted in previous research. Below is an excerpt of our initial review with the metaphors that we agreed on:

...so the clinic where I was, was right across the street from the hospital where I would be...? and so I uh, she asked if I wanted a ride and I said 'no uh its right across the street I can walk there, 'it took me an hour to walk there, I was so uh, I mean I was used to being healthy I was a tri athlete, I was uh ya know not a couch potato someone who was in good shape, so from a body image standpoint to go from one extreme of extreme health to someone not being able to walk more than five feet without stopping was very extreme. Ya know as a woman, I wasn't thinking of it as a woman, I was just thinking about it as a functioning human being at the time. Um something else that I should mention that is probably more related to the fact that I am a woman is that uh, in my early 30 's I was diagnosed with infertility. And he reason that is important is that when you talk about body image and you talk about identity I think for women umm obviously a lot of our identity is tied up self-consciously with the fact 70that we can have children, and so for me having to have gone through the experience of being diagnosed with infertility and going through the treatment for that I had sorta put to rest the idea that I would ever have children and I would have to come to grips with the fact that I was still a woman regardless of if I can have children or not, and so that took several years to work through all of that and so by the time I came to the first cancer treatment and then later the breast cancer I wouldn't say I had become umm desensitized to the whole medical process, but I was pretty familiar with uh doctors and hospitals and test and I guess I'm a pretty direct person to begin with, ya know im not somebody who feels sorry for themselves a lot so partly the way I deal with it from an emotional perspective it as well as how I deal with it as a patient it to learn as much as I can and ask them as many questions as I can, to do whatever research I can and try to be an active member in my care and I think that that um attitude 80goes a long way with whatever you're dealing with and although you kinda have to go through the grieving process and being diagnosed, are you familiar with Kubler-Ross?

The underlined metaphors in this specific passage represent four major categories, journey, fight, food and hand. All of highlighted metaphors were identified using opencoding procedures described below. For example, the first metaphor highlighted in this 
passage was chosen because of its reference to food, more specifically a potato. The journey metaphors that have been highlighted were chosen because of the interviewee's reference to moving though space in order to "get through" something. The use of the word "through" identified something that was on the path that she was traveling. Both coders proceeded to read all of the transcripts and highlight as above. Once both coders completed all four of the transcripts we tallied the total number of highlighted metaphors from each category and compared results. Any metaphors that the coders did not agree on were discussed and placed into a category based off of the overall relevance to the category. Although coders did not agree on five specific instances, these are still relevant. An example of an instance that researchers did not agree was with the phrase "struggle", this could potentially be placed in the criminal category as well as the fight category. The percentage of each category of metaphors was calculated by taking the total number of metaphors coded (248) and dividing it total number we disagreed on initially (5).This process resulted in a final inter-coder agreement of $97 \%$.

In total, two hundred and forty eight metaphors for breast cancer diagnosis and treatment experiences were identified in the four transcripts, using the seventeen categories described in the preceding, and listed in Appendix E. Consistent with Gibbs and Franks (2002), the majority of the metaphors found could be related to real life bodily experience. In the following paragraphs I will discuss the most frequent and dominant metaphors used in the data following a description similar to Golden, Whaley and Stone (2011). Following a synopsis of the findings I will briefly discuss the potential 
impact this type of language can have on patients, physicians as well as family and friends of those affected by breast cancer. 


\section{Chapter 4: Analysis and Results}

Seven of the metaphors were used by all four women: journey, machine, orientation, game, struggle/fight and image. Those seven metaphors are discussed below with an example from each woman. Then the other metaphors, those used by some but not all of the women, are discussed. Following the examples is a discussion of how these metaphors are used to describe body image.

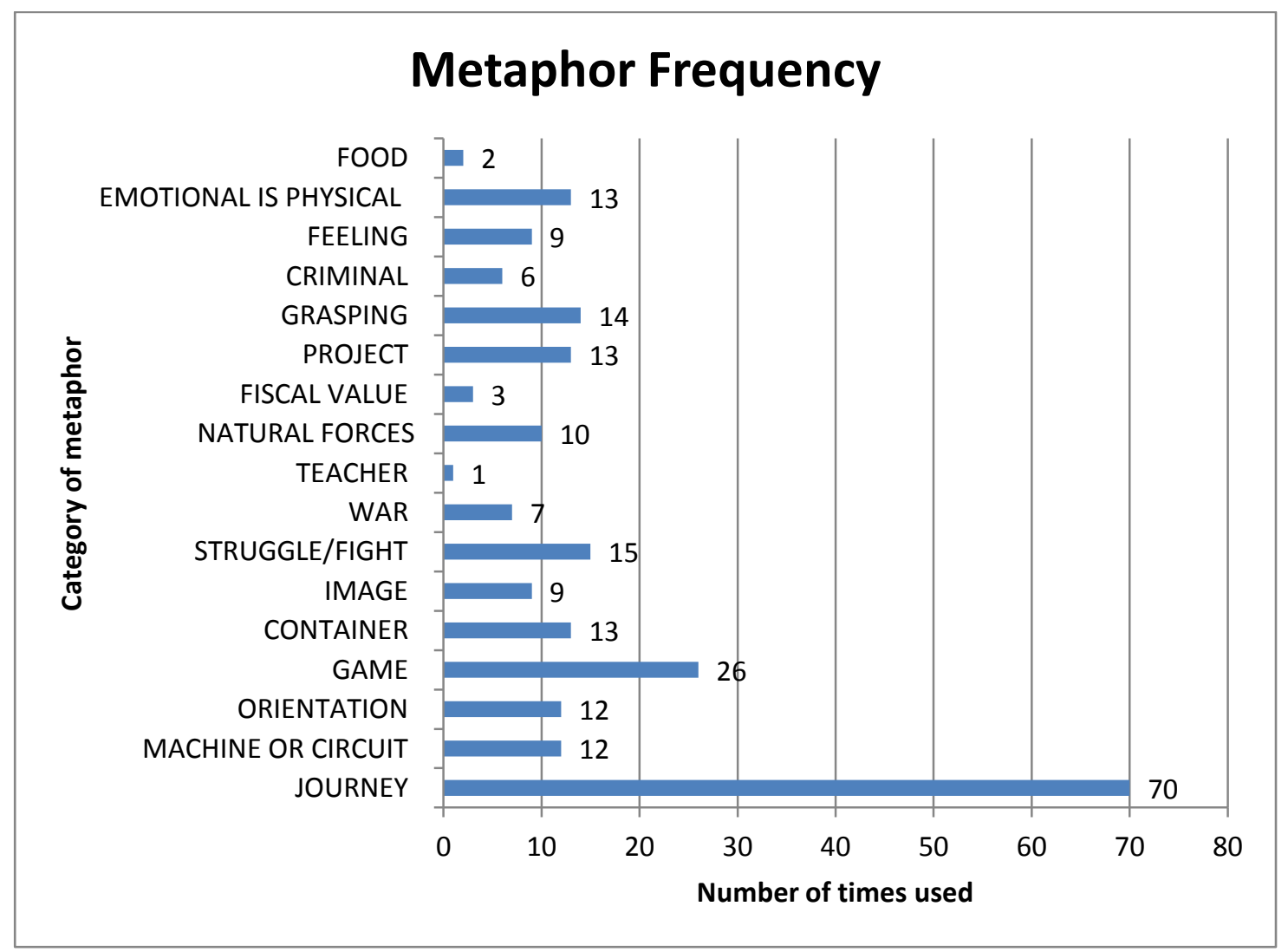

Figure1.1

Although some of the examples listed below are not directly related to portions of the conversation where women are discussing body image issues, they are still closely related to the portion of the research question asking in general how women discuss 
breast cancer. The second portion of the research question is addressed in more detail below the example portion and in the discussion section.

\section{Journey metaphor $(\mathbf{n}=70)$}

Extract $1[$ Ashley \#1, Line 70] "And the reason that is important is that when you talk about body image and you talk about identity I think for women umm obviously a lot of our identity is tied up self-consciously with the fact that we can have children, and so for me having to have gone through the experience of being diagnosed with infertility and going through the treatment for that I had sorta put to rest the idea that I would ever have children and I would have to come to grips with the fact that I was still a woman regardless of if I can have children or not..."

Extract 1 [Cassidy \#2; Line 23] "I had a group of friends to support me prior to going in for this surgical biopsy and we did some personal story telling and um about sort of umm to give me a sense of courage and hope to go forward into this biopsy umm and I can tell $\mathrm{u}$ more about that if you want but I can kinda just stick to the medical and kind surgical stuff."

Extract 1 [Meghan \#3; Line 83] "Yeah no, cause I had done a lot of research and so I kind of knew there were choices along the way. So this is, to show you how much of a project manager I was..."

Extract 1 [Sue \#4; Line100] "I walked everywhere all the time and it sort of just moved through me. And I was having all kinds of weird symptoms, GI symptoms and gross things were happening and I just got right through it and I lost weight, which was good, I needed to." 
One metaphor, journey, was used a total of seventy times, over twice as many as game, the second most frequently used metaphor. The most dominant metaphor used by all four women was the journey metaphor. For the purpose of this research a journey metaphor was best characterized in terms of travel on a metaphorical journey or path often encountering obstacles or road blocks. It is important to note that all four of the participants being interviewed had a relatively positive outlook when recalling their experiences from diagnosis to treatment. That being said, the majority of journey metaphors were used in an uplifting and optimistic manner, especially referring to issue of body image and identity. One woman said, 'I knew I could push through to the end.' This particular participant viewed her diagnosis as a journey with an ending point.

Most commonly patients considered cancer as something that they needed to 'go through,' almost describing cancer as having an entry and ending point at which they would exit and be free of the disease. Again, metaphors such as 'moving forward,' and 'gotta keep moving' showed their determination to keep moving on the journey without stopping, taking 'one step at a time'. One woman referred to her journey as a road that she was traveling on. Although the majority and tone of the metaphors were used in an uplifting description, many of them sounded sure to encounter 'various issues along the way.' If cancer is considered a journey beginning at diagnosis and ending when the patient is cured, then they are sure to encounter a number of issues including sickness, pain, nausea, chemo, radiation etc.. The journey metaphor allows women to express their understanding of cancer as having a beginning and end, but also allows them to comprehend the idea of the unexpected, which may then give doctors the opportunity to 
educate and inform on some of the obstacles encountered on the journey. This finding allows doctors to consider the idea that by molding their communication habits and choosing metaphors that are common in the patients vocabulary they could potentially limit some of the confusion and surprise of 'roadblocks' or 'bumps' along the way. All of the participants identified body image issues as a major problem in terms of treatment. These body image issues are the "road blocks" and "obstacles" that need to be worked through.

Previous research also describes how important embodied metaphorical thought can be in these situations. Gibbs and Franks (2002) explain that a woman's embodied experiences, not the illness itself, but of their more general body sensations and knowledge, served as the primary source domains in many of the metaphors underlying the women's wide range of linguistic metaphors. One of those metaphors described by Gibbs and Franks (2002) is the journey metaphor. This particular metaphor has specific characteristics of physically moving while on a journey. It also has embodied characteristics in that we might often encounter problems or issues along the way. Gibbs and Franks (2002) state that “encountering physical obstacles on life's journey gives cancer patients a wonderful way to think of cancer not just as the end point of life, but as just another obstacle that is temporarily blocking one's plan and goals in life that can be dealt with and overcome to continue living” (p.155). Women used metaphors such as “one step at a time" and "go forward." It was clear that all of the women from this study felt extremely positive that they would see cancer through until they were cured, however metaphors allowed them to understand that there would be obstacles and not to be 
surprised when they arise. Some of those surprise issues included hair loss, weight loss, scaring and other physical discomfort. One woman stated that cancer was something she was "working through." Another felt confident she would encounter "various issues along the way" but it was important to keep "moving forward."

\section{Machine $(\mathbf{n}=12)$}

Extract 2 [Ashley\#1] "I sort of broke down and realized what was happening."

Extract 2 [Cassidy \#2; Line 60] "And she tried to draw a diagram and that was very very helpful, but it was like if you do this and then you do this and ya know it was like one of those very complex engineering, it was like if you do this then yes and no, then you do this and just...yeah yeah."

Extract 2 [Meghan \#3; Line 193] "Yeah so if you think about here this is pressure, this is sending energy in and so there's all different kinds of ways, you can press your stomach, you can press all this sort of stuff, so chemo really kills a lot of stuff so part of what you have to do afterwards is you got get your health back. And So it was interesting as my stomach and all the organs down there started working again and you know." Line 240 "Just like a clot you'd have in your pipes they are trying to push the clot through and break it up."

Extract 2 [Sue \#4; Line 313] "And so what I noticed is I was having kind of a hard time for many different reasons and I was eating too much sugar and I was starting to gain weight and I was starting to feel some soreness around here and the only thing I'm angry about is this all happened when I wasn't working and I go to a lot of breast cancer support groups and people are like my life is falling apart and I'm like all these wonderful 
things already in place and I just have to put it all together so the way that I have dealt with it is I volunteer cause I'm trying to get ready, that's why I just got here today."

All of the women used a machine metaphor at least once in order to describe their bout with breast cancer. In most cases the women were using machine metaphors to describe their struggles with understanding the disease and how it was changing their body appearance and identity. The example used early by one of the participants, "I sort of broke down and realized what was happening" (Ashley) reflects that this patient was processing breast cancer as something that might be momentarily "breaking" her.

Another participant, Meghan, stated "And so it was interesting as my stomach and all the organs down there started working again and you know." These two examples illustrate how women used machine metaphors to describe breast cancer and how they came to terms with the extreme changes occurring in their bodies. This also suggests that, although these women view their bodies as a machine, they also stay optimistic in that they feel the "machine" can be fixed. Never were any of the identified machine metaphors followed by negative feelings or phrases that implied a sense of hopelessness.

\section{Orientation $(n=12)$}

Extract 3 [Ashley \#1; Line 100]" I um have two brothers in law and a brother and they are all physicians, so when I told my brother about it he said look, put this in perspective he said, here's lymphoma at one end and you're at the total opposite end of the spectrum you're in a case where the cancer hasn't spread, they can take care of it, it's very easily treatable and so I sort of down played the whole thing with my parents particularly." 
Extract 3 [Cassidy \#2; Line 250] "I was trying to understand all this technical stuff and I didn't understand it and I had to have the doc go over and over and over because he would sorta not give me a lot of information and then I'd get confused and try to read something and I'd get confused so umm essentially what it came down to he said" Extract 3 [Meghan \#3; Line 202] "I was starting to feel on top of things."

Extract 3 [Sue \#4; Line 12] "And it was his house, his kid I ran out of money and what happened is the week before my diagnosis he ended our relationship, and I had an episode of high blood pressure, this is very weird, I had a panic attack and I went to the ER and my blood pressure was like 190 and my pulse was skyrocketing and of course I had ya know a lot to be panicked about."

Lakoff and Johnson (1980) say that we often use "spatial orientations" conceptually. Spatial orientation is described as locating something somewhere in space, whether that is in front of us, behind us, on top of us. We are constantly aware of things around us and understand location spatially. So we sometimes associate abstract ideas that do not really have a location with a particular place in space. In this way, certain abstract ideas are linked to others that. This kind of thinking in which we "organize a whole system of concepts with respect to one another" is visible in what Lakoff and Johnson call "orientational metaphors"

Although many of the instances when these metaphors are used are quick and sometimes unnoticeable, they still make a statement with regard to body image and identity with regard to breast cancer. Many of orientational the metaphors relate back to a common theme of optimism found with other metaphor use. For example "I was 
starting to feel on top of things" reflects that breast cancer does leave women feeling slightly out of control. However, they feel that they can gain control over the changes that occurred to them. Many instances of orientational metaphor use occurred when women were discussing body image. For example, one woman said she was beginning to "feel on top of things." This example reflects her ability to gain control over the somewhat unpredictable side effects of breast cancer treatment. This language represents some of the metaphors women use to discuss breast cancer, but more than that the language reflects the personal thoughts of breast cancer that these women hold. They are using language that reflects their internal feelings relating to cancer, so when using metaphors like "on top" of things, they are expressing confidence over beating the disease.

\section{Game metaphor $(n=28)$}

Extract 4 [Ashley \#1; Line76] "I'm a pretty direct person to begin with, ya know I'm not somebody who feels sorry for themselves a lot so partly the way I deal with it from an emotional perspective as well as how I deal with it as a patient it to learn as much as I can and ask them as many questions as I can, to do whatever research I can and try to be an active member in my care and I think that that um attitude goes a long way with whatever you're dealing with and although you kinda have to go through the grieving process and being diagnosed, are you familiar with Kubler-Ross?"

Extract 4 [Cassidy \#2; Line 229] "So after the mastectomy, it was a major surgery and again I had this complication with, not only an infection to the incision area but also this built up of fluid and I was exhausted and I just slept for weeks or was on meds or in pain so a lot of this is really fuzzy sorta how this fit together." 
Extract 4 [Meghan \#3; Line 132] "So based on that, I didn't, it was like if something pops up I'll deal with it but I am not going to freak myself out, thinking about the what ifs." Extract 4 [Sue \#4; Line 149] "So I just kept tripping people out because every time they saw me I had different hair.”

Participants describing their treatment, recovery and side effects often spoke with an air of uncertainty and lack of control over the situation. As expected with most medical treatments there is always the possibility of encountering unexpected issues or setbacks. Most of the women repeatedly referred to cancer as 'the cards they were dealt.' As any card game operates, there is most often a process of randomization through shuffling and dealing, which means you will not know what cards you have been given, or how good your chances are until you are able to see your hand. The metaphor also implies that once you're dealt a hand, it's up to you to do as well with it as possible. "Play the hand you're dealt" implies skill not just luck, leaving it up to the patients themselves to take some control over the situation.

In terms of cancer, women feel the same sense of 'gambling' and uncertainty as one might in a card game. For example, you may not know exactly how your body will react to certain treatments until you have actually begun. A few of women also expressed concern while waiting for results after testing. They described cancer as being 'tricky' and leaving them with 'no clue.' Having "no clue" also relates to a puzzle in that breast cancer is something they may be able to solve or find the answer over time. These metaphors suggest that cancer and cancer treatments are an opponent with which they are playing a game. Their ultimate goal is to beat the opponent and be 'awarded the prize." 
This metaphor can also closely relate to the experiences we embody daily. As humans we often participate in games, possibly a board game or a sports competition. We understand there are usually multiple participants and a certain percentage contributing to the overall winner comes down to chance. Many of the women describing breast cancer, especially the decision to get a lumpectomy versus a mastectomy, consider the "chances" of cancer coming back post treatment. Just like in an actual game, the women understand that doctors, like players, can only possess a certain amount of skill, leaving the remainder of the game up to chance. "By conceptualizing life as a game, we are held responsible for what we do with the circumstances we are dealt; there is an understanding that some things are beyond our control, and our fate is often a matter of luck" (Gibbs and Franks, 2002, p. 158).

\section{Image metaphor $(n=9)$}

Extract 5 [Ashley \#1; Line 40] "because my lungs were starting to be affected, my heart was affected, I couldn't go, I could barely go up and down stairs, I could barely do anything and it became clear that it was a pretty extreme situation," Extract 5 [Cassidy \#2; Line 113] "You appeared forty years ago." Extract 5 [Meghan \#3; Line 121]" Yeah, I mean not working was really was really helpful because I had time to focus on it. You know when I had a day that I didn't have the energy, then..."

\section{Struggle/fight metaphor $(n=15)$}

Extract 5 [Ashley \#1; Line 85]" And then it was like, I very very coincidentally remember a moment when I kinda made a decision in my mind that ya know I was either 
gonna fight this with whatever I had and we were gonna do everything we could, or I wasn't, there was no middle ground."

Extract 5 [Cassidy \#2; Line 89] "So apparently we have a lymph node system throughout our body which is a circulatory system and the does about 90 percent of the blood circulation throughout our system but this lymph node system also circulates the last ten percent through our body and its sort of a clear liquid that sort of fights off infection through our body and so umm the second surgery I had some removed and tested." Extract 5 [Meghan \#3; Line 238] "Yeah so if you think about here this is pressure, this is sending energy in and so there's all different kinds of ways, you can press your stomach, you can press all this sort of stuff, so chemo really kills a lot of stuff so part of what you have to do afterwards is you got get your health back." Line 238

Extract 5 [Sue \#4; Line 65] “.... and what that does what they're now discovering and this was in the New York times as well, that breast cancer is about thirty different diseases so they've got, what they used to do is like take a mallet and just hit it the same way, but now they're basically refining the treatment, they need to do a lot more but they're basically specializing in what type of cancer do you have and identifying the onco type or onco gene analysis so we did all those tests and I started and that's basically how it went."

Participants used a variety of metaphors associated with anger and harm towards the cancer and the processes of treatment. Among these, metaphors closely related to physical violence were the most common. Physical violence refers to fighting with weapons or hand to hand combat. Almost all of the metaphors found in this category 
related to fighting were used to describe the period of time between diagnosis and decisions related to treatment choice. For example, many women used phrases such as 'we are going to treat it very aggressively' and 'we decided to fight this.' It's almost as though women were framing their future in terms of a fight between themselves and cancer as the enemy.

Participants described the struggle as though they assumed they would endure some sort of physical pain throughout the experience, "we decided we were gonna fight this." However, they felt they would ultimately succeed over their opponents and "fight off" the cancer and "fight off" the negative physical side effects. Although all of the women were facing issues with regard to body image, it was something they felt they could control. An example of this is when one participant decided to "face" the struggles of hair loss and instead make the situation a humorous one. This particular participants' use of the word "face" in that context show that she was willing to confront the side effects of treatment and combat it with humor. Discussing these issues reflects the idea that metaphors such as the fight metaphor reflect the thoughts in women's minds with regards to their attitudes about breast cancer. The metaphors they use are very specific to their overall mindset when encountering breast cancer and body image struggles.

\section{Grasping/hand metaphor $(n=14)$}

Extract 6 [Sue; Line 294] "Because my hair was down to here. Difficult. It was the only thing I couldn't handle and so I felt a little, kinda sad."

Extract 6 [Ashley; Line 69] "I think for women umm obviously a lot of our identity is tied up self-consciously with the fact that we can have children, and so for me having to 
have gone through the experience of being diagnosed with infertility and going through the treatment for that I had sorta put to rest the idea that I would ever have children and I would have to come to grips with the fact that I was still a woman regardless of if I can have children or not."

Similar to the previous category, grasping or hand metaphors have a specific relation to actual physical movement relating mainly to the hands. Of the four conversations one woman used absolutely no hand or grasping metaphors. However, another woman used a total of ten, showing that this specific choice of words may be more familiar to some opposed to others. In one specific case, a participant referred to her inability to 'get a grasp on the situation,' or expressed frustration for not being able to get 'a hold of their doctor.' Golden, Whaley, and Stone (2011) describe caregivers use of hand metaphors in a similar way to those used by cancer patients. Breast cancer patients may also use physical metaphors involving the hands to describe their emotional experiences in times of change and uncertainty, reflecting a desire for control such as, 'I think its catching on,' and 'it's the only thing I could handle'. Humans physically understand the concept of grasping from birth. As infants we learn to grasp objects and begin to understand our bodies within the world. From past experience, these women know that to "grasp" something is to be in control of it. If grasping commonly leads to control, then women may use these metaphors in order to feel more secure about treatment. Embodied experiences, such as physically grasping something, give women the ability to understand their disease through embodied encounters. 


\section{Project metaphors $(n=13)$}

Extract 7 [Meghan; Line 17] “ And so once I got the diagnoses, it's a matter, I'm an engineer by background so it was like oh, ok, it's a project that I've got to figure out, got to get the data."

One participant in particular used project metaphors to describe her diagnosis and treatment entirely. She viewed her diagnosis as a challenge with an answer that needed a direct and clear plan. She referred to 'cancer as a full time job.' It was clear that this woman needed this type of structure in order to make sense of the disease and the struggles she was going to face. She viewed herself as the 'manager' and felt that this was a 'process that she needed to work through.' This specific category is extremely important because I would argue that without the ability to compare cancer to a project she would have struggled to deal with and cope with the entire situation. This metaphor gave here a sense of control over the disease and allowed her to counteract the feelings of helplessness. Viewing cancer as a project potentially gives women the understanding that they may be incomplete during treatment, however the overall ending product will be a complete project in which they are put back together. One woman also referred to portions of the treatment as being "stapled." Staples are usually used in projects to hold things together, for this woman stapling was being borrowed from her experience of stapling paper and being used to describe cancer treatment. She even described herself as being a very organized and a work minded individual, needing structure and plans. Should she not have had the opportunity to communicate and act in terms of a manager she may have had difficulties during treatment. The same woman was extremely upfront 
and comfortable stating that she felt as though she was the "acting as a manager" over her disease. For this woman in particular, the specific managerial approach allowed her to feel more at ease with the process of cancer.

\section{Emotional as physical $(n=13)$}

Extract 8 [Cassidy; Line 125] "I am numb and shaken to the core."

Participants often talked about needing 'support' throughout their experience with breast cancer. Support is often thought of as a foundation giving participants the opportunity to share their concerns, and fears with others. It was also common for participants to use physical actions to describe a sense of insecurity such as; 'shaken to the core' and 'everything was running around my head.' This type of language was used mostly when talking about the decision-making process regarding treatment. These types of metaphors employ a sense of chaos and feelings of unmanageable situations leaving the women feeling as though they are not in control. The two metaphors above also employ and describe an action committed to the patient by an outside force, this is important because it represents the patients' feelings of defenselessness against cancer. Metaphors from this section differ from grasping and fight metaphors because the majority of these metaphors relate to patients' uncertainty, concerns and needs. Patients using a majority of these metaphors may need extra information and support from family, friends and doctors.

\section{Container/Substance metaphors $(n=13)$}

Gibbs and Franks (2002) describe container metaphors as ideas and emotions within containers. These same ideas and emotions can also be thought of as a substance within a 
container. Participants viewed life with cancer as a container that was either empty or full. The consensus was that the more positive thoughts, the 'fuller' they felt. One participant described her desire to 'live life fully.' However the majority of these container metaphors were also commonly used to describe a sense of emptiness or lack of completeness. For example, one woman described herself as feeling 'less of a woman' because of her loss of hair. In this case the woman may have viewed her femininity as a substance that she had lost during her treatment. Another woman also stated that chemo "completely drained her of energy leaving her to feel very tired and uncomfortable." Energy in this case was thought of as a liquid that could be drained.

Many of the women also saw themselves as a container, something that could be filled or emptied with a substance. For this purpose, if a container could be filled to the top, it could also be emptied leaving nothing. The woman describing herself as "less than a woman" felt that at one point she was full and content wither her femininity and since having breast cancer and going through treatment, some of her container had been emptied. Her femininity was a substance. It is also important to mention that this woman was physically experiencing the empty feeling she was describing. By losing your hair during chemotherapy, or having a breast removed, women are in reality physically experiencing the loss of specific body parts, hence making them "less of a woman" and sometimes feeling empty or less complete. 


\section{Chapter 5: Discussion}

The coding process resulted in the identification of 17 core metaphors. The "journey" metaphor was used the most frequently and "food" metaphors were the most infrequent. The structure of all four conversations began with brief introductions followed by conversation about life leading up to the diagnosis, at the time of diagnosis and throughout treatment to present day. All of the women were between the ages of 5055 , near completion of treatment and in relatively good health. The majority of questions during the interview were related to the women's body image, treatment and whether they felt the breast cancer had changed their concepts of personal identity and their bodies, ultimately having an effect on their identity. The goal was to identify and examine the types of metaphors being used in conversations regarding these specific topics. The following paragraphs will discuss how the seven major metaphors were used in conversation and how they helped participants to communicate and cope with the extreme changes to their life and most importantly their bodies.

Results from the current study were consistent with previous studies finding that the "journey metaphor" was the most commonly used (Gibbs \& Franks, 2002; Golden, Whaley \& Stone, 2011). Gibbs and Franks state that although journeys are often thought of positive experiences, women with cancer describe life as a journey and cancer as an obstacle on that journey. A person with dementia and a familial caregiver's journey are described as difficult and uncertain (Golden, Whaley \& Stone, 2011). This same finding is represented by use of journey metaphors for breast cancer patients. In previous cases metaphors such as the journey metaphors helped nurses explain to caregivers the process 
and progression of dementia (Golden, Whaley and Stone, 2011). Similarly, game metaphors, vision metaphors and journey metaphors gave women diagnosed with breast cancer a better understanding of their disease.

What past research does not quite touch on is the impact that metaphors can have when those diagnosed use them to explain their disease to family or friends. Sometimes the ability to ease family concerns is equally as important as calming the patient herself. One woman specifically recalled being more concerned about the reactions of family members than her own concern. It is possible that doctors and caregivers could ease the patients concerns by giving them certain words to help describe their disease to family and friends. For example the journey and game metaphor are used by cancer patients as well as individuals not diagnosed and in good health. This being said, breast cancer patients may use these metaphors as a way to help loved ones to understand what they are going through. These metaphors can give people a common ground for which to communicate because they have both experienced playing some type of game as well as going on some type of journey.

Also important to mention is that all of the women used at least $\% 75$ percent of the total identified metaphors and all of the women shared the same metaphorical understanding of their disease for at least $\% 58$ of the total metaphors. Gibbs and Franks (2002) feel that people may possess alternative ways of constructing the same experience, such as that for love or cancer. Essentially, people experience everything in their own way and make their own sense of these experiences (Gibbs, 1994). For example, all of the women expressed issues about coming to terms with the possibility of losing one or both 
of their breasts and how this might affect their identity as women. They described this as something they would need to "grasp," something they had not quite gotten a handle on yet, and something they would like to avoid if possible. Their physical embodied experience of grasping items with their hands allowed them to comprehend and communicate how they were feeling about surgery and the possibility of extreme changes to their body as well as entailing control over the disease. This example is interesting because it describes feelings of bodily discomfort by using another embodied experience. Lakoff and Johnson (1999) feel that metaphorical concepts arise from our bodily experiences.

Many of the women also referred to mastectomies as "losing" their breasts or part of them, as if their breast were an object that could be lost and in that sense most likely never found. This metaphor could have come from an experience of misplacing their keys or losing their favorite shirt. Regardless of how they experience losing in the past, they all had a shared common meaning of what losing something meant and because of this they were all able to understand the possibility of removing one or both breasts during surgery. This example represents that we use metaphorical concepts based on embodied experiences. Physically losing keys and finding them, or taking a walk and literally hitting a road block or the end of a path are all things that our body experiences physically and that we then use later to describe another experience, such as the process of breast cancer treatment. Consider a journey that you have experienced in the past, most likely it was either pleasant or unpleasant based on a number of factors. Metaphors are often our outlet for describing our understanding of our bodies in the world and the 
experiences it encounters both good and bad, hence describing the embodied view of metaphor theory (Gibbs, 2005). Whether or not we consciously recognize what's happening to us on a journey or not, our bodies are experiencing things and filing them in

our brain to use as descriptors at another moment. These examples are discussed in more detail in the following pages and identified by three subjects; themes, identity and humor.

\section{Perspectives and Themes}

Cameron (2007) was skeptical of conceptual metaphor theory and stated that "we may also expect that speakers choose and use metaphors that are consonant with their own attitudes, emotions and evaluations, so that examining metaphors can reveal something of speakers' perspectives on what they are talking about, as well as about their social identities" (p. 201). Keeping Cameron in mind, we know that the types of metaphors women are using reflect their attitudes towards their situation. In the case of the journey metaphor, women describing breast cancer as a "trip" or "a road they are traveling" elicits a sense of control over the situation because they understand that journeys have a beginning an end and they are choosing to take that journey by fighting their diagnosis with treatment. The journey metaphor is not the only metaphor that suggests control over breast cancer, the grasping and fight metaphors also imply a sense of control. With these metaphors the patients are active participants in the medical process. The fight metaphor implies that women view themselves as a participant in a fight, while cancer is their opponent. However, in contrast to this, the one metaphor in which the patient is accepting no control is when they use they use game metaphors. Game metaphors reflect that in some sense women understand that they were "dealt a 
hand of cards" and they must do the best they can with that hand. While this metaphor expresses some limited form of control, it is more inclusive with lacking control due to the fact that women have no choice with the cards they are dealt, only how they play their cards. Journey and grasping metaphors reflect a sense of ownership over the situation, while game metaphors do not and instead emphasize some sense of randomness and lack of control.

A discourse dynamics approach to metaphor (Cameron, 2003) identifies patterns of metaphor use in discourse as evidence of thinking and perspective, while at the same time investigating how metaphors are negotiated between speakers at the moment of use. All of the women used journey and grasping metaphors at least once, reflecting a common theme of control and organization. This theme is also heavily supported by one participant who metaphorically perceived her cancer experience as a project in which she was the acting manager. The only contrasting metaphor to the overall theme was the game metaphor. This data implies that women tend to view cancer as something they can control, or at least battle with once they have been dealt their hand, but they first must come to terms with their lack of control regarding the initial diagnosis. By viewing cancer in this way, patients' overall demeanor changes and as demonstrated before, a positive attitude can essentially help patients overcome breast cancer.

This research can help doctors as well as patients frame their language in a way that promotes positive talk and eases the fears of all involved. "Metaphors help health care providers understand patient experiences in ways that are not possible with literal language" (Golden, Whaley and Stone, 2011, p.5). There is some metaphoric similarity 
across illness contexts. Gibbs and Franks (2002) describe journey and machine metaphors in the experiences of women with cancer and found them to be similar to those found in discussion of breast cancer and dementia. Women with cancer also use basic orientation, describing happy as up and sadness as down, with one needing to stay up to heal (Gibbs \& Franks, 2002). Because these findings are similar to those found in previous studies it is arguable that doctors and nurses could potentially use this type of research to understand the verbally communicated concerns from patients.

\section{Body Image and Metaphor}

All of the women discussed at least minor discomfort with the thought or decision of losing one or both breasts. While all of the participants were describing their concerns relating to body image, a few different metaphors were used however the main metaphor was journey. The following paragraphs will identify those metaphors and discuss their relevance. Of the four women interviewed, one discussed extreme concern about losing any bit of her breast while two others felt only minor concern. This woman felt somewhat at ease with the idea of a mastectomy/lumpectomy, but only due to her marital status and described her decisions as that of a journey:

“I um, ya know I'm happily married I have a very supportive husband and we're both in our fifties. So ya know things have begun to sag a bit and we are very accepting of each other, with kinda however we look. And so for me I uh, I did not feel that, even though I knew there was gonna be a scar and sorta a little deformation of the breast tissue under my arm, first of all its in a place where I'd have to wear something really revealing cut to 
show and I know that nothing is gonna ya know change how he feels about me. I uh, I had asked myself the question if I had to have had a double mastectomy ya know uh how I would deal with that and I don't know what the answer is, I don't think anyone can make that decision till you actually go through it." -Ashley transcript lines 144-150

Of the women interviewed, this woman seemed the most comfortable with the idea of a mastectomy, she was married. It is important to note that she was married because previous research suggests that single women stress about breast reduction surgery more than married women. Schover (1994) found that young females seeking new dating relationships after breast cancer treatment is a special stressor for single women. This woman also described the situation as something she had to "go through" to completely understand.

In support of Schover's findings one woman describe her identity and concern in the following terms:

"I think if I was younger, or in a partnership it would be more of an issue of femininity I've sort of grown to the point where I see myself as a woman and human, my humanness is more important to me than my femininity. $Y a$ know, I'm alive (laughs). '- Meghan transcript lines 372-374

Another woman also described the following:

"And the reason that is important is that when you talk about body image and you talk about identity I think for women umm obviously a lot of our identity is tied up self-consciously with the fact that we can have children, 
and so for me having to have gone through the experience of being diagnosed with infertility and going through the treatment for that I had sorta put to rest the idea that I would ever have children and I would have to come to grips with the fact that I was still a woman regardless of if I can have children or not" -Ashley transcript lines 68-72.

One of these women was married and the other had been divorced, both were in their fifties. Both women described minimal concern with issues of identity after surgery. With a larger data set it might be possible to draw inferences about whether women who are married or in a certain age ranges struggle less with the fear of feeling "less of a woman" than single, younger women.

In an opposite situation, when asking another woman about her concerns of female identity she replied:

"Yes! It sounds ridiculous but I was constantly on YouTube and there was a website and I must have watched it about thirty times, my friend from California sent it to me and these women from southern California, its Godiva's secret wigs and they model the wigs and some of the women are bald. I must have watched those videos thirty times and I used to think losing my hair was the hardest thing because I felt like I was an imposter in the world and that it marked me differently. And then when people found out it was so hard for me to talk about the fact that I had been with this guy who was never there for me and I felt weird about it. So umm I think as a woman the concern about the disfiguration because you know my hair and 
my boobs are my best features. " (Laughing) Cassidy transcript lines 285289.

She actually described herself in metaphorical terms as feeling like an "imposter." While this woman was describing in more detail the fear of losing her hair, she actually took out her old driver's license and stated, "see I used to have very long and beautiful hair." This woman had never been married and was dumped by her boyfriend after finding out about her cancer diagnosis.

The previous quotations demonstrate how some women begin to question their identity as an individual within a partnership or as a single identity and describe the decisions for surgery within their relationships using journey metaphors. We've seen that a few women felt more comfortable dealing with changes to their body due to the fact that they were involved in a long term committed relationship or marriage. However, the women who were unmarried felt extremely uncomfortable with the changes to their body and made them feel as though they were a "liability," especially the woman in a shortterm relationship. She stated the following "And I thought well I'm gonna be more of a liability to this guy if I can't even get out of this house.” Another married woman says that she "would likely feel more uncomfortable if she was younger and seeking a partner." This information exemplifies how identity can be challenged due to a number of outside factors. While all of the participants were going through the same type of experience, their identities were affected differently based on their personal, intimate relationships. 
The previous examples rely heavily on the use of journey metaphors. This finding provides evidence that women who have been diagnosed with breast cancer come to terms with their changing bodies by accepting that they are on a metaphorical journey throughout treatment and the experience that is unique to female breast cancer patients only. They also identified that their travel on this journey is affected by a number of factors, but mostly that of their personal relationships.

I previously demonstrated how identity could be impacted by relationship status. The diagnosis of breast cancer can affect other strands of identity as well. One woman in particular used multiple metaphors to mention how breast cancer affected her identity as healthy, athletic individual and as a fertile woman:

"I mean I was used to being healthy I was a tri athlete, I was uh ya know not a couch potato someone who was in good shape, so from a body image standpoint to go from one extreme of extreme health to someone not being able to walk more than five feet without stopping was very extreme.” Ashley transcript lines 62-65

"And he reason that is important is that when you talk about body image and you talk about identity I think for women umm obviously a lot of our identity is tied up self-consciously with the fact that we can have children, and so for me having to have gone through the experience of being diagnosed with infertility and going through the treatment for that I had sorta put to rest the idea that I would ever have children and I would have 
to come to grips with the fact that I was still a woman regardless of if I can have children or not." Ashley transcript lines 68-73

Some women may struggle more with their identity as women throughout the process than others and it is different for every woman, yet they are all experiencing changes to their bodies. The one common thread of their struggles is the way in which they use metaphors to describe their struggles. The research question asked what types of metaphors do women use to discuss body image and the major metaphor used by all women is the journey metaphor. All participants, regardless of their concern for surgery or their relationship status, describe their experience with body image to be a "journey" of some sort.

\section{Control and Predictability}

Toombs (1993) writes that metaphor can bridge the gap between the illness experience and the world of technology and treatment. For many women the thought of breast cancer treatment is scary and they are searching for ways to understand the treatment they will eventually encounter. Metaphors participants were using reflected feelings of control or predictability over insecurities relating to treatment outcomes. Some of the patterns found throughout my conversations with participants identified their overall stance on breast cancer. Some metaphors represent control and predictability more so than others. Women using a large amounts of hand, game and fight metaphors represent feelings of control over the situation and the outcomes relating to treatment. One woman gained control over her feelings of discomfort relating to hair loss by making fun and using game metaphors to overcome her insecurities. This same woman made 
light of her hair loss by trying on various wigs and cutting her hair into a Mohawk. Other participants used journey metaphors to help them cope with the unpredictability of cancer allowing them reframe complex issues and help to provide meaning, "It allows for discussions of goals, direction, and progress" (Reisfield \& Wilson, 2004, p. 6).

"Metaphors can serve as powerful tools for establishing a consensual understanding in the therapeutic relationship, and influencing patient experience in ways that promote adaptation and positive self-regard (Sims, 2005, p. 4). By using certain metaphors patients are expressing their control, or sometimes lack of control over their situation. "By paying attention to patients' metaphoric speech, physicians may gain some insight into the cognitive and affective underpinnings of their illness experience, and this may help make sense of their questions, their demands, their emotional responses, and their treatment decisions" (Reisfiled \& Wilson, 2004, p. 8).

\section{Humor}

This data also lends some interesting instances in which patients used humor while discussing their encounter with breast cancer. While the subject of these conversations is mainly women recalling their experience, many of them stated that humor and a light hearted attitude relating to their struggles helped them to get through the process as well as comfort them presently. One patient stated the following:

"I think it would be funny if they were lopsided, if I got a double I would probably, it seems, it seems, I don't know if it seems funny to you or strange that we can talk about things so matter of factly but you go through so much when you're treated with cancer that if you don't develop 
a sense of humor about it you kind of, you can't stress about it all the time,

it just becomes the new normal." -Ashley transcript, lines 210-216

The majority of instances when women were using humor to help cope with the disease were tied to topics related to bodily change. For example, the previous quote describes one woman's understanding of a mastectomy and post surgery issues. She specifically states that having a sense of humor during the breast cancer experience is almost necessary to survival. Although the research is somewhat older, Cousins (1976) confirms that laughter reduces pain, perhaps by stimulating the production of endorphins, the morphine like substances produced by the brain, as well as the suggestion that laughter enhances immune system functioning.

A second woman I spoke with said, “And I thought well I'm gonna be more of a liability to this guy if I can't even get out of this house (laughs)." She was laughing hysterically regarding a subject that seemed extremely serious. For some reason her laughter helped her to talk about the serious issue. There were a number of other instances where the same woman laughed regarding similarly serious topics. "In this hypothesized stress-moderator mechanism, the cognitive-perceptual aspects of humor would be more important than laughter, and the ability to maintain a humorous outlook during times of stress and adversity would be particularly important; humor during nonstressful times would be less relevant to health" (Martin 2007, p. 315). This quote supports the idea that humor can strongly change ones attitude during stressful times 
related to disease. Many of the women laughed at topics that outsiders may view as serious and sad conversations, such as the following:

"She saw me around the end of the month and I had saw uh, I went in for um a mammogram like august first and umm they were not sure what it was and they did what was called a uh uh, a needle biopsy where uh right then and there they uh, well...its kinda like a staple gun (laughs). ”- Meghan transcript, lines 13-15

This example is interesting because she is describing her procedure as a "staple gun" being used for the human body. The thought of this to an individual who is not experiencing breast cancer treatment seems morbid and painful, however what is interesting is that the woman herself is laughing while describing the experience. This example is also important because of her use of metaphor. She is describing the procedure as though she is a project and the staple gun is the tool for the project. While it may not be obvious, this woman feels that she has essentially been reduced to a piece of paper or something to be stapled.

Another woman was quoted saying, "I mean it was actually when I lost my hair a friend and I went down and picked out a wig and we cut my hair and did a Mohawk and you know all that kind of stuff and just had fun with it basically (Sue Transcript lines 142-143). The previous examples are important because they point out some instances where women use humor and fun to feel more comfortable about some of the agonizing surgeries and experiences they have to deal with. 
Humor is important to consider because similarly to metaphors, laughter and a humorous outlook could be practiced by patients, family members, doctors and nurses. Using humor could potentially make the experience of breast cancer less stressful to patients.

\section{Limitations and Future Research}

It should be acknowledged that although the metaphor coding list allowed for 17 major categories, some metaphors could have fit into multiple categories and were instead placed in the category that the coders felt most applied. In future research it would allow for stronger results to have more defined categories as to not have confusion on where the actual metaphors fit. A larger sample size would have also produced more data, allowing for better examination of metaphors amongst women and relationship status. Future research could go much more in depth relating to humor and identity theory. While I touched on the subject here, there were many more instances in which humor was used to describe breast cancer.

Lastly, many of the metaphors noted were not directly related to body image, but instead related to the women's general discussion of breast cancer treatment. This could have been avoided by asking questions more specifically related to body image, however the open interview protocol allowed for free flowing conversation. The results identify metaphors closely related to the healing process and coping methods. Future research may use similar results to identity the healing powers of metaphors. 


\section{Conclusion}

The analysis represented in the previous pages is entirely consistent with the findings of many scholars within the field of health communications with the major metaphors identified. The findings represent that women do in fact use a number of metaphors to describe their experience with breast cancer, most commonly the journey and game metaphor. Although it was not asked in the initial research questions, it was also found that body image is strongly correlated to relationship status. The data also provides a detailed look into the metaphors women use to describe body image. Participants identify issues with body image, and describe those issues as a "journey." The analysis outlines the importance of metaphors and conversation for female breast cancer patients when trying to cope with such a serious and complex disease. This research may help scholars, doctors, patients, and family/friends of patients better understand how to communicate about such a serious disease.

"Metaphor in both language and thought enables the woman to find that meaning in a deeply personal way, yet also in a manner that can be publically understood by both other cancer survivors and people who have not suffered the same disruption in their lives" (Gibbs \& Franks, 2002, p. 160). These findings also recognized that women struggle with the issues related to identity. Doctors and psychologist may consider some type of pre-surgical analysis to better understand their patient's needs and concerns related to breast cancer. All women differ with what they feel to be the most important characteristic of identity. This should be known by the medical staff surrounding the patient so they can assist and help her to feel more comfortable while struggling with 
treatment. Now that we have identified the major metaphors used by breast cancer patients and the contexts for which they use them, we can begin to mold our communication patterns to better match theirs.

The four women in this study collectively felt that their diagnosis of breast cancer was not a death sentence, but instead an opportunity to embrace life and live it to the fullest. I was truly in awe of the positive outlooks on life that these women represented and feel extremely fortunate to have met each of them. 


\section{References}

Anderson, J., \& Geist Martin, P. (2003). Narratives and Healing: Exploring one family's stories of cancer survivorship. Health Communication, 15(2), 133-143

Annas GJ. (1995). Reframing the debate on health care reform by replacing our metaphors. N Engle J Med ;332:744-747.

Barsalou, L. W. (1992). Cognitive psychology: An overview for cognitive scientists. Hillsdale, N.J: L. Erlbaum Associates.

Babbie, E. R. (1989). The practice of social research. Belmont, Calif: Wadsworth Pub. Co.

Bellenir, K. (2002). Cancer sourcebook for women. Detroit, MI: Omnigraphics.

Boroditsky, L (2000). Metaphoric structuring: Understanding time through spatial metaphors. Cognition, 75: 1-28.

Boroditsky, L., and Ramscar, M. (2002). The roles of body and mind in abstract thought. Psychological Science, 13, 185-189.

Bowker, J. (1996). Cancer, individual process, and control: A case study in metaphor analysis. Journal of Health Communication, 8, 91-104.

Brody, H. (1987). Stories of sickness. New Haven, CT: Yale University Press.

Cameron, L. (2003). Metaphor in educational discourse. London: Continuum.

Cameron, L. (2007). Metaphor in reconciliation talk. Discourse and Society, 18, 197-222.

Cameron, L. (2008). Metaphor and talk. In. R. W. Gibbs, Jr. (Ed.), The Cambridge handbook of metaphor and thought. Cambridge, UK: Cambridge University Press, pp. 3-16.

Cassell E. (1991).The Nature of suffering and the goals of medicine. New York: Oxford University Press.

Canavarro, M. C., \& Dattilio, F. M. (2011). Marital relationship, body image and psychological quality of life among breast cancer patients: The Moderating role of the disease's phases. Contemporary Family Therapy, 33, 2, 161-178.

Dow, K. H. (1999). Pocket guide to breast cancer. Sudbury, Mass: Jones and Bartlett. 
Gibbs, R. W., \& Franks, H. (2002). Embodied Metaphor In Women's Narratives About Their Experiences With Cancer. Health Communication, 14(2), 139-165.

Gibbs, R., \& Steen, G. (Eds.). (1999). Metaphor in cognitive linguistics. Amsterdam: Benjamins.

Gibbs, R. W. Jr. (2006). Metaphor interpretation as embodied simulation. Mind and Language, 21, 434-458.

Gibbs, R. W., Jr. (2008). Metaphor and thought: The state of the art. In. R. W. Gibbs, Jr. (Ed.), The Cambridge handbook of metaphor and thought. Cambridge, UK: Cambridge University Press, pp. 3-16.

Gibbs, R. W., Jr., \& Matlock, T. (2008). Metaphor, imagination, and simulation: Psycholinguistic evidence. The Cambridge handbook of metaphor and thought Cambridge, UK: Cambridge University Press. (161-76).

Glaser, B. G., \& Strauss, A. L. (1967). The discovery of grounded theory: Strategies for qualitative research. Hawthorne, N.Y: Aldine de Gruyter.

Golden, M. A., Whaley, B. B., \& Stone, A. M. (2011). "The system is beginning to shut down": Utilizing caregivers' metaphors for dementia, persons with dementia, and caregiving. Applied Nursing Research.

Hampton, M. (2000). Women's experience of traumatic stress in cancer treatment. Health Care for Women International, 21(1), 67-76. DOI: 10.1080/073993300245410

Harpham, W. S. (2010, March 25). Metaphor as medicine. Oncology Times, 32(6), 16.

Bloom, J. (1982) Social support, accommodation to stress and adjustment to breast cancer, Social Science \&amp; Medicine, 16, 14,1329-1338, ISSN 0277-9536, 10.1016/0277-9536(82)90028-4.

Katz, A. N., \& Taylor, T. E. (2008). The journeys of life: Examining a conceptual metaphor with semantic and episodic memory recall. Metaphor and Symbol, 23: $148-173$.

Kövecses, Z. (2008). The conceptual structure of happiness and pain. Reconstructing pain and joy: Linguistic, literary and cultural perspectives (17-33). Cambridge, UK: Cambridge Scholars Publishing.

Lakoff, George, \& Johnson, Mark (1999). Philosophy in the flesh: the Embodied Mind and its Challenge to Western Thought. New York: Basic Books. 
Landauer, T. K., and Dumais, S. T. (1997). A solution to Plato's problem: The latent semantic analysis theory of acquisition induction, and representation of knowledge. Psychological Review, 104, 211-240.

Leader, D. (1990). The absent body. Chicago: University of Chicago Press.

Louwerse, M. M. (2002). Symbolic or embodied representations: A case for symbol interdependency. Ch. 6, pp. 107-120 in T. K. Landauer, D. S. McNamara, S. Dennis, and W. Kintsch (Eds.), Handbook of latent semantic analysis. Mahwah, NJ: Lawrence Erlbaum.

Martin, R. A. (2002). The psychology of humor: An integrative approach. Burlington, MA: Elsevier Academic Press.

Mallinger, J. B., Griggs, J. J., \& Shields, C. G. (2006). Family communication and mental health after breast cancer. European Journal Of Cancer Care, 15(4), 355-361. doi:10.1111/j.1365-2354.2006.00666.x

Moyer, A. (1997). Psychosocial outcomes of breast-conserving surgery versus mastectomy: a meta-analytic review. Health Psychology : Official Journal of the Division of Health Psychology, American Psychological Association, 16, 3, 28498.

National Cancer Institute at the National Institute of Health. (2010). retrieved from: http://www.cancer.gov/cancertopics/factsheet/cancer-advances-in-focus/breast

Ortony, A. (1975). Why metaphors are necessary and not just nice. Educational Theory $25,45-53$.

Peshkin, B. N., DeMarco, T. A., \& McKinnon, W. C. (2002). Life After BRCA1/2 Testing: Family Communication and Support Issues. Breast Disease, 27(1), 127 136.

Piaget, J., and Inhelder, B. (1969). The psychology of the child. London: Routledge and Kegan Paul.

Pikler, V., \& Winterowd, C. (2003). Racial and body image differences in coping for women diagnosed with breast cancer. Health Psychology, 22(6), 632-637.

Reisfield, M., Wilson G.(2004). Use of metaphor in the discourse of cancer. Journal of Clinical Oncology, 22, 1-4. DOI: 10.1200/JCO.2004.03.136 
Ritchie, L. D. (2009a). Relevance and simulation in metaphor. Metaphor and Symbol, 24, $249-262$.

Schover, LR. (1994). Sexuality and body image in younger women with breast cancer. U.S National Library of Medicine. ;(16):177-82.

Sontag, S. (1991). Illness as Metaphor: AIDS and its Metaphors. London: Penguin.

Street, Richard L. (1995). Increasing patient involvement in choosing treatment for early breast cancer. Cancer, 76 (11), p. 2275.

Shapiro, Lawrence (2010), Embodied Cognition. Hoboken: Taylor \& Francis. 9780203850664

Semino, E (2004). Methodological problems in the analysis of metaphors in a corpus of conversations about cancer. Journal of pragmatics. 36 (7), p. 1271.

Semino, E. (2010). Descriptions of Pain, Metaphor, and Embodied Simulation. Metaphor \& Symbol, 25(4), 205-226.

Silverman, D. (1993). Interpreting qualitative data: Methods for analyzing talk, text, and interaction. London: Sage Publications.

Stark, D., \& House, A. (2000). Anxiety in cancer patients. British Journal of Cancer, 83, 10, 1261-1267.

Toombs S. (1993). The Meaning of Illness. A Phenomenological Account of the Different Perspectives of Physician and Patient. Dordrecht, The Netherlands: Kluwer Academic Publishers.

Whaley, B. B. (2000). Explaining illness to children: Theory, strategies, and future inquiry. Explaining illness: Research, theory, and strategies.: Mahwah, NJ, 195207. 


\section{Appendix Table of Contents}

Appendix A: Recruitment script

Appendix B: Consent form

Appendix C: Interview questions

Appendix D: Metaphor coding instructions

Appendix E: Transcripts

References 


\section{Appendix A}

\section{Metaphors and Cancer \\ Recruitment Script}

Thank you for donating your time to participate in this research study. This study focuses the types and ways in which female breast cancer survivors use metaphors to discuss their experience with diagnosis and treatment of cancer. I am mainly interested in the relationship words can share with everyday lives and experiences. Participants will only include residents of Oregon who have been diagnosed with breast cancer and undergone surgery at any point in their lifetime.

Participants in this study should be 18 years of age or older. Participation in this study is completely voluntary and your responses will remain confidential. If you chose to participate in this study you will be asked to complete the initial consent form and background information questionnaire. Upon signed consent, you will be asked to participate in a video recorded session between you and a researcher while discussing your experience with cancer.

It is my hopes that with the consent of all individuals participating in the support group, sessions will be recorded. It would also be extremely beneficial for any participants interested to follow up the support group session with individual one on one interviews.

If you choose to drop out of the study at any time for any reason your information be discarded and no further questions will be asked.

If you would like to participate in this study, please inform the researcher and I will provide you with all necessary tools. Compensation for participation will include a check for twenty dollars upon the completion of the recorded session.

If you have questions, feel free to contact the primary investigator, Jenny Fillion (503) 507-9179 jfillion@pdx.edu.

Thank you for your time.

Jennifer Fillion

Graduate Student

Department of Communication

Portland State University

503-507-9179

jilllion@pdx.edu 


\section{Appendix $B$}

\section{Consent Form}

Project Title: Cancer and Metaphor: Understanding the use of metaphor in health communication.

Researcher: Jenny Fillion; student in the Department of Communication at Portland State University working on a Master's thesis.

Purpose: $\quad$ This study focuses the types and ways in which female breast cancer survivors use discuss their experience of living with and receiving treatment of breast cancer.

Time: $\quad$ Participation should take approximately ten min for the initial questionnaire and 20-30min for one on one interview.

Risk: Your participation is completely voluntary. This means that you can decide whether or not you want to be interviewed. You may decline to participate at any point. There is minimal risk to you, but there is always the chance that talking about your experiences may be uncomfortable at times. You are free to withdraw from the study at any time and for any reason. Also, you don't have to answer any questions you don't wish to answer.

Benefits: The results of this study may help scholars and instructors understand the relationship between words and real live experiences.

Confidentiality: Although you may choose to share private information, your confidentiality will be strictly protected. If you agree to participate, this means that you consent to having your voice recorded either in the group session or one on one interview. Although your voice is individually identifiable on the digital recordings, we will do our best to make sure that no one can identify you in our publications and presentations. The digital recordings will be transcribed by members of the research team, who will use pseudonyms in the transcription process and in all reporting of data. The digital recordings will be digitally destroyed after five years. Results of this research study may be disseminated via conference presentations, journal articles, or book chapters.

Contact: If you have questions, feel free to contact the primary investigator, Jenny Fillion (503) 507-9179 jfillion@pdx.edu.

Thank you for your participation, Jenny Fillion 
Signing this consent indicates that you understand and agree to the conditions mentioned above.

Signature

Date 


\section{Appendix $C$}

Questions for one on one interviewing

11. How long ago were you diagnosed with cancer?

12. How would you describe yourself? What type of personality traits best describe you?

13. How has your life changed since being diagnosed with breast cancer?

14. How has cancer changed your body?

15 . What type of changes in your body were the most difficult for you to accept?

16. How do you cope when you begin to feel upset?

17. How do you cope with treatments?

18. Can you discuss your experiences living with cancer?

19. What has been the biggest struggle thus far for you when living cancer? And treatment?

20. How has your body felt since being diagnosed with breast cancer? 
Appendix D

Metaphor Coding Instructions

\section{Metaphor Coding List \\ Extracted from (Golden, Whaley \& Stone 2011; Gibbs and Franks 2007)}

\section{Journey metaphor - Life is a journey}

Cancer is an obstacle on life's journey

"Cancer was something I needed for me to get through."

"And it has transported me to a place."

"It kinds brings ... it brought me to the kind of ... the edge of the abyss."

\section{Machine or circuit metaphor}

The body is a machine that can be fixed or break

"My body's working really hard for me ... its responding and doing well."

"The disease broke me down."

"The doctor said we can fix that."

\section{Basic orientation metaphor}

Happy is up and sadness is down - one must stay up to heal

"I felt on top of things."

"I had no choice but to stay up ... but one day I was kinda down."

\section{Game metaphor}

Life is a gambling game- Cancer and its treatment is a game

"One option was to do nothing and just live with the odds."

"Cancer is so unpredictable."

\section{Container metaphors- Cancer is a fluid within the self container}

Ideas and emotions are substances within containers

A caregiver is a container

(The mind of) a person with dementia is a container

Trap or prison metaphor

A person with dementia (or his/her mind) is caught in a

trap or is/could be in a prison

Caregivers are in small spaces

Envelopment metaphor

\section{Image metaphor -}

Understanding is seeing- Cancer clears vision and allows for new understanding "It was like putting on a new pair of glasses."

"At the age of $40 \mathrm{I}$ had the chance to look at what was really important and make sure I didn't miss it."

"It allowed me to see life in a different way." 
7. Struggle/Fight metaphor -

Care giving is fighting or struggling

"I wasn't prepared for the impact it would have on me."

"The idea of that therapy really struck me as something I wanted."

"It's not that it ever was lighter."

Emotional strength is physical strength

\section{Cancer is war}

"The disease was an aggressive opponent that I had to fight."

\section{Cancer is a teacher}

"The disease has taught me many things about myself."

"I learned so much from this illness."

\section{Emotions are natural forces}

"I felt overwhelmed."

"I was knocked over by the news."

\section{Life in terms of fiscal value}

Life is thought of in terms of money

"Losing my hair is really, really a small price to pay for my life."

"I just wanted to buy time until my surgeon was home."

\section{Life is a play}

Cancer offers one new roles, with characters and scenes

"It was a new role for me."

"The dance he has choreographed for me was riddled with mis-matched moves."

"It was role-reversal."

\section{Understanding is grasping}

"I was really impressed by how I handled it."

"My husband couldn't get a grip on it for quite a while."

\section{Cancer is a criminal}

"I felt robbed"

"Suspicious"

\section{Painful feelings}

"burn"

"Stab" 
16. Emotional is physical

17. Food 
Appendix E

DW (Ashley)

Age: 52

October 172012

Ashley arrived at the Starbucks mid-day and was wearing athletic clothing; tennis shoes, black running pants a t shirt and black Nike running jacket. She was very welcoming and kind. She seemed happy to be there and stated that she happy to be helping. Her overall demeanor was extremely positive and friendly.

I: Hopefully this works, ok so first of all do you have any more questions for me before we start

A: Nope, nope

I: Ok so first of all how long ago were you diagnosed?

A: Well I was diagnosed with DCIS which is ductal carcinoma in situ in May of this year

I: Wow so not that long ago

yeah

I: So what type of treatment options were you given initially upon diagnosis

A: The conventional, I don't know if it's the gold standard right now is to do a lumpectomy which is just to take, is a partial, uh, I guess technically it's a partial mastectomy and then following that with

10 radiation. And then five years of tamoxiphin.

I: Ok, and so are you, what stage of the treatment are you at?

A: So I had all of my treatment, I had the lumpectomy in June; I had the radiation in July and I'm on the tamoxiphin. now.

I: Ok, so and you'll do that for five years?

A: five years.

I: Five years?

A: Yup 
I: So then um, do you know, this is kind of a weird question, but do you know what type of cancer?

A: Yeah, so ductal carcinoma in situis stage 0 . It's a pre-cancerous condition that if left untreated could 20 evolve into serious breast cancer. So they treat it very aggressively and something that you should know about me also that's material to your research also is that I am a prior cancer survivor. I was diagnosed with lymphoma in 2006, was treated for that over the course of the year and have been in remission since 2007. So coming to the cancer, the DCIS cancer, I shouldn't call it cancer because technically its not cancerous, um having that happen obviously my oncologist looked at my history and said

" you've gotta, given her history we want to be sure that we are aggressive about how we do it." That being said my understanding is that this is how they treat most women with DCIS. I didn't get anything that was excessive, ya know above and beyond what you would get knock on wood if it ever happened to you.

I: Mmhmm, ok, so these are kinda the questions. When you initially found out back in 2006 ?

\section{Yeah}

I: How did you feel? What were your initial feelings about?

A: Oh gosh, it was an entirely different experience than what with the breast cancer, the DCIS diagnosis. So with the lymphoma umm I presented in a way that was fairly rare so it took them a month to diagnose me and I had had something called superior venocava syndrome. Which was basically, I had a tumor growing in my chest we didn't know about yet, all I knew was that I was short of breath and couldn't walk and I was obtaining a lot of fluid in my face and my neck and my arms. Well what was happening was the tumor was growing and pressing on the vein that returns blood to your heart and so as a result the fluid was backing up in the upper part of my body, but it took kinda a long time for somebody to connect the dots on it, so, by the time I was diagnosed I was, um, it was a life threatening situation 40 because my lungs were starting to be effected, my heart was effected, I couldn't go, I could barely go up and down stars, I could barely do anything and it became clear that it was a pretty extreme situation, when they finally diagnosed it then they moved me very quickly to treatment and so umm that experience, the way that I found out that I had a tumor was that I had been in for a CT scan as a result of one of these follow up visits and they were trying to figure things out and I got a call from a technician who basically said pretty matter of factly; ' you uh, you have a tumor in your chest' what size it was I don't remember off the top of my head, and, and that was it, she basically hung up. And I had been sitting there with my husband in the family room, we had been expecting this call, and I looked at him and the reaction was I knew that the 
words I was gonna speak were gonna change our lives forever and I knew that when I picked up the phone to call my family that that was gonna change things. My entire 50family is very healthy, I was really the first one to get sick, im the oldest of three children, my parents are healthy and still alive in their 80' s and um it was gonna be a, I was very worried about the effect it was gonna have on the people were close to me. Um of course I was also very worried about my own condition, um but I had confidence um that uh the treatment that the doctors would, I was told that, well gosh I wasn't told anything at the time. I was just told that I had a tumor and to come in the next morning. Um so I went in the next morning and was told, well I went to the nurfrology department I think which is the department that oversees kidney functioning which I thought was kind of strange and I met with a nurse practitioner there and she explained a little bit more about what was going on, she explained that I had his massive tumor in my chest and what we wanted to do was umm do additional test to identify ya know what it was exactly and then we would figure out what the treatment plan was. 60And so the clinic where I was was right across the street from the hospital where I would be related and so I uh, she asked if I wanted a ride and I said 'no uh its right across the street I can walk there,' it took me an hour to walk there, I was so uh, I mean I was used to being healthy I was a tri athlete, I was uh ya know not a couch potato someone who was in good shape, so from a body image standpoint to go from one extreme of extreme health to someone not being able to walk more than five feet without stopping was very extreme. Ya know as a woman, I wasn't thinking of it as a woman, I was just thinking about it as a functioning human being at the time. Um something else that I should mention that is probably more related to the fact that I am a woman is that uh, in my early 30's I was diagnosed with infertility. And he reason that is important is that when you talk about body image and you talk about identity I think for women umm obviously a lot of our identity is tied up self-consciously with the fact 70that we can have children, and so for me having to have gone through the experience of being diagnosed with infertility and going through the treatment for that I had sorta put to rest the idea that I would ever have children and I would have to come to grips with the fact that I was still a woman regardless of if I can have children or not, and so that took several years to work through all of that and so by the time I came to the first cancer treatment and then later the breast cancer I wouldn't say I had become umm desensitized to the whole medical process, but I was pretty familiar with uh doctors and hospitals and test and I guess I'm a pretty direct person to begin with, ya know im not somebody who feels sorry for themselves a lot so partly the way I deal with it from an emotional perspective it as well as how I deal with it as a patient it to learn as much as I can and ask them as many questions as I can, to do whatever research I can and try to be an active member in my care and I think that that um attitude 80goes a long way with whatever your dealing with and although you kinda 
have to go through the grieving process and being diagnosed, are you familiar with Kubler-Ross?

Yes

So if you go through those stages, my husband likes to laugh in heinz site, he says from the moment I went though all four stages in about an hour. Ya know you cried about it, you were angry about it, you were in denial initially, how can this be? And then it was like, I very very coincidentally remember a moment when I kinda made a decision in my mind that ya know I was either gonna fight this with whatever I had and we were gonna do everything we could, or I wasn't, there was no middle ground. And so once you decide you are gonna be all in that means that mentally and psychologically you're in as well as physically and so I started orienting all my energy toward what I deeded to get better rather than 90saying woa is me and uh also another thing I kinda did to cope was uh, again I was very concerned about the people around me, it's almost worst to watch people round you reacting to your illness, you feel like rightly or wrongly you have some sort of control over the situation and you really don't, but I mean you do as far as your attitude right and how you approach the whole thing, umm but I was more concerned about the people who felt helpless around me and really couldn't do anything. And so when I came to the breast cancer or the dcis this spring, having been through the lymphoma and that was very intensive, I went through ten rounds of chemo therapy when through surgery, I had a stem cell transplant and radiation, um a diagnosis that might have been daunting to someone else, I mean I wasn't happy about it but I knew I could deal with it because I had been through a really extreme case of varying breast cancer and for all intensive purposes beat it. I um have two brothers in law and a brother 100and they are all physicians, so when I told my brother about it he said look, put this in perspective he said, here's lymphoma at one end and you're at the total opposite end of the spectrum you're in a case where the cancer hasn't spread, they can take care of it, it's very easily treatable and so I sort of down played the whole thing with my parents particularly. $\underline{\mathbf{1 0 : 0 0}}$ minutes

Umm in terms of what was going on I just didn't want them to worry about it. And so my siblings are a great support to me and they're always there for me for lots of support so um the way it was diagnosed in the spring was I went in for a routine mammogram and uh the radiologist saw a series of calcifications on the film and its normal for women to develop calcifications in the ducts of your breast tissues but what they look for is clusters of those or when they're lined up and they saw a line of them and said ok I wanna do another mammogram so they did another mammogram and it looked suspicious enough that 110they wanted to biopsy that area to see what they could find. So I had what is called a stereotypical biopsy which is a biopsy into that area with a needle and they got a 
good sample sent it off to the pathology lab locally and then they also sent it off to another lab in new York to verify what they were seeing and they saw dysplasia which means they were seeing an abnormal growth of cells. It was all still contained in the ducts, it hadn't gotten into the cells or out into the tissue so the diagnosis was DCIS; incitu meaning 'in its original place.' And then from there they wanted to make sure, they wanted to confirm that diagnosis so what they did was an incisional biopsy so they went in tik the tissue around where they did the needle the biopsy and sent that off to the lab. And what they do when they send it to the lab is they look at, they think of it as a little block of tissue they tell you how close to the sides of the block they find anything that's suspicious. And what they're looking for is that there is a least two to 120three $\mathrm{mm}$ of clear tissue around all sides that means that they've gotten a contained lesion. After that biopsy they were able to confirm that A. it is DCIS and B. that on a couple of sides they were too close and that point what we should do is go back in and do a lumpectomy which basically is cleaning up the margin around that area. So um, it was sort of ironic because at the end of May I was seeing my oncologist who treated me for the lymphoma, they followed me, they follow you for five years after you've been treated and he and I were scheduled, we actually had sort of our final graduation appointment and a week later I was back in his office with this laughter. So and I, I really like him as a doctor and a person, so I, we joked that I just couldn't let him go, ya know I had to come back and see him. At one point we sat down, and he uh, he's a Chinese gentlemen and he is uh very empathetic, very knowledgeable. He basically went through med school in china and then came to the states and kinda 130did it all over again. And so a lot of confidence in his work so um we discussed the normal pattern of diagnosis up till this point and it was to do the lumpectomy and the radiation and the temoxiaphin afterwards. In uh breast cancer, and stop me if you know any of this, so he is what is known as a medical oncologist which means he predominately treats using chemotherapy temoxophin and so forth, for the lumpectomy you generally have and oral surgeon do that, he's familiar with working with cancer patients. And then as far as your radiology goes you go to a radiation oncologist, uh oncologists, medical oncologists don't know how to do radiation and radiology oncologists don't know how to do chemo therapy. So your treated by a team of people, so I had three doctors helping me essentially through the surgery and uh, the initial diagnosis, the surgery, the radiation and then the follow up chemo. And so tomorrow I uh go see my medical oncologist for a checkup and next week I'm going to see my radiation 140oncologist for a checkup because we are about six months past what happened. So I said ok, ok let's do it, so I had my lumpectomy and then I went to talk to my radiation oncologist to talk about about the next step area that was um, where they took the lump is under my arm on the side, its almost directly under my armpit, so from a physical image standpoint, I um, ya know I'm happily married I have a very supportive husband and we're both in our fifties. So ya know things have begun to sag a bit and we 
are very accepting of each other, with kinda however we look. And so for me I uh, I did not feel that, even though I knew there was gonna be a scar and sorta a little deformation of the breast tissue under my arm, first of all its in a place where id have to wear something really revealing cut to show and I know that nothing is gonna ya know change how he feels about me. I uh, I had asked myself the question if I had to have had a double mastectomy ya know uh how I would deal with that and I don't know what the 150answer is, I don't think anyone can make that decision till you actually go through it. So um I meant with radiation oncologist and he have me two options for how to do the radiation. The firs was sort of the very traditional well documented mode

\section{$\underline{16: 00 \mathrm{~min}}$}

which was to go through six weeks of daily radiation come in every morning every week and they give you your dose of radiation right to the middle of your chest and it basically radiates the entire chest. Umm, for six weeks every day during the weekday and you basically get off on the weekends, partly because the tissue has to recover a little and you don't wanna damage the tissue partly because of scheduling issues and the second option is considered to be, it's not experimental, its accepted. It's not like its out on a limb somewhere, but its less well documented. It's called braci therapy, you may or may not have heard of it for prostate cancer in men, what they do is they can actually implant radioactive seeds into the prostate and they just sit there and radiate the area that's infected. And braci therapy of the breast is just the idea that you'll just radiate the immediate area, you wouldn't radiate the whole breast. And you raised this issue with me because my lymphoma I had significant radiation to the middle of my chest and the concern there is of course your radiating the heart. So at that point I said to him, he was recommending the traditional method and I said well wait a minute, it makes more sense to me to just radiate that area and he said 'we can I'm just telling you that there's more weight of evidence for the total breast.' And I said this is not a fair question 'but what would you do?' he said 'oh id do the braci therapy.' I said, I'm doing the braci therapy. But its, so the doctors can give you the evidence, and the doctors job, in my view, is to help patients engage their own value systems and their own preferences so that would be medicine, the evidence, to arrive at something the patient is comfortable deciding on and I would say I'm not a risk, a high risk taker, well I shouldn't say that, I climb mountains and do triathlons, my husband would say I'm a risk taker, financially I'm not a risk taker but in my own life, and particularly after the diagnosis of a serious cancer I'm more of a risk taker, why hold back? Ya know live life. So I said id like to think about it, I discussed it with my husband I talked to my brothers and my brothers in law and they did some research and came back and said 'we think it ya know it's a valid approach." What they do is they actually implant a device in you and you get treatment twice a week, sorry 
twice a day for one week, so it also had the added benefit of not having to go two weeks, I would just have to, done sooner and also a side effect of whole breast radiation is fatigue, and I'm very active very busy and I wanted to minimize the fatigue, braci therapy minimizes the fatigue. So it, although the evidence is there, there's growing evidence that its very effective, minimize the fatigue, minimize the radiation to the breast, shorter period of time, I said that it, it all sound good to me let's do it. So at that point they implanted the device and what the device looks like is, it's about this long, it's a series of small plastic tubes that culminate in a balloon, it can be all collapsed so it's just a tube but if you picture the ability to be able to inflate or bend the tubes at the end so that it forms the shape of a bubble, what they do is they insert it and they turn a dial at the end of it and then it balloons to the shape of the cavity that was left. And then what they do is they hook that device up to the radiation machine when you go in for radiation and then the radiation machine sends the radiation into that area and it just radiates the inside of the area where the lumpectomy was done.

I: so you still had to go in twice a day?

A: yes, yes. Right. So it wasn't implanting stuff and me walking away and coming back, it was, cause they have to change the dose every day because the radioactive material they use decays, they get a shipment at the beginning of the month and then that shipment begins to decay so you have to adjust your dose every day for how much radiation they have in the safe is decaying and how much they wanna give you. So I got smaller more frequent doses, more localized and then at the end of the week basically I went in and they gently pulled the device out, umm I don't think he even stitched me up, the incision was pretty short, I mean the incision for the lumpectomy is like that, the incision for the um device is about that long and since its considered a puncture wound they want to let drain and ya know they don't want to let any infection in there, so it didn't cut into any of my chest wall tissue, your boob is basically fat and not a lot of nerve damage, so ya know a week later I had forgotten that...

I: what about the side effects? How did they differ if you had had radiation they way they usually do it? What side effects did you have?

A: I didn't have any side effects. I was a little bit tired the week they did it, but I can't chalk that up to the treatment. It may have been my anxiety about it or the fact that I was having difficulty sleeping, half of the thing is inside you and half of the thing is taped to the side of you about this much is outside and then you have this plastic tube on you, so otherwise I had no side effects at all, no fatigue, no nothing you would normally associate with radiation. Radiation is normally a fatiguing process. 
I: so initially as from a woman's standpoint, when you were initially diagnosed with the breast cancer did anything even go through your mind? I know you had, you talked about having a past, but did anything initially go through your mind as far as how will this affect me as far as being a woman goes? Will it at all? Did you even?

A: ya know it didn't, it really didn't. I think because I had dealt with it in my 30's and kinda put it to rest umm it didn't, but as I said, at one point when I was discussing with the oncologist before we started talking about the different radiation treatments he said ya know you can consider a provalactic mastectomy and my mother doesn't have a history with breast cancer, my sister, I don't have immediate family, I'm not at high risk, I haven't been genetically tested but ya know why would? I mean some woman go right to mastectomy.

I: because they don't want to take the chance it would re-occur

A: yeah so I think the perception of myself as a woman came in as, why not conserve the breast if I can? Umm an I don't I don't uh consider it to be, I mean I do what I need to do ya know, if the consensus was I need to have a mastectomy I would but didn't have to deal with those thoughts. But my thinking was yeah, like keep the breast if I can, if the evidence seems to suggest that I can be as healthy with it as without it, and another reason is I talked to my radiation oncologist and he said ya know deb, if it occurs in another part of your breast we can do the same thing, we don't have to take the whole thing, and if you come back repeatedly, how many times do you want to have that procedure? At some point you may say its better to just do that, but umm I'm not, ya know I'm not huge breasted I'm just average in everything. And it was like, the thought didn't even cross my mind of how would I deal with it if I had to, but I didn't go there cause I didn't have to. I remember one situation if I can digress briefly, I went to the gym one day and I was getting ready to go walk on the treadmill or whatever and a woman came back in a bathing suit in a pool and she took off her bathing suit and she had a double mastectomy and I had never seen somebody that had one before and she was completely self unconscious out it, she was who she was and I was close enough, I was close enough to my lymphoma treatment that I had, one of the things that I find among cancer treatments it that, cancer is, when you get that diagnosis initially there's like a curtain that's drawn and on one side of the curtain your part of a new fraternity with people that have been told their life is being threatened and then there are people on the other side of their curtain that haven't heard that gratefully but, don't know what its like to hear those words and so there's sort of a camaraderie amongst those cancer survivors because they've had to face death in one form or another and they've stared it down or they know somebody who had and so I kind of probably tired in a gentle way to just, it was just the two of us in the area and I said umm; I just kinda looked at her and made eye 
contact and said "I'm a cancer survivor as well and we just kinda started to talk." Very candidly about her mastectomy and what her experience was like and ya know there was yet contact, it wasn't like I as ya know, but she was so free with the information and she was so, happy to talk about from the standpoint, and it was kinda the standpoint that I'm from as well, that's like why not make something good out of it, if you can share your experience with someone else who is going through it and, umm that's a silver lining in my book in terms of something that you can get out of a very bad experience, so umm I just thought it was just, I was so touched by her that she was so willing to talk about it and she was so generous with her information so...

I: one thing ive noticed when interviewing women is that the women that ive talked to that have been younger, cause I uh, the support group that I went to in Albany was a young women's breast cancer support group and there was a young woman who was 18 and she had just been diagnosed and then there was a couple other women, there wasn't anyone older than I think 28 and it was interesting because a lot of the things that they say is completely different than...

A: sure they're concerned about having children, can I breast feed my children, what is this gonna, ya know if you're not yet married, what is that gonna do, is someone gonna be turned off by this? Yea. Different places in life, definitely.

I: it makes complete sense. So you said your husband was huge support system for you and you never once had to worry what he was gonna think or what he was gonna feel about scaring or anything like that, and you never worried about that with him (yeah, yeah). See yea a few of the women who were younger expressed a lot that they were still dating and that, one of them said that she ya know when she takes her shirt off when she goes on a date and she takes off her shirt, she said it takes her a long time to be able to do that because she is not comfortable. A lot of trust and she is just not as confident.

A: a lot of trust and I would say that if I was in my early twenties and unmarried I would also, that would be going through my head as well. Um one thing I, because I have had a couple surgeries that, and I went through this when I met my then boyfriend/future husband I told him, I kind of warned him in advance because I said like I have the scar, the scar you get from a scecirian section and its now, now it's very faded, but at the time it was very noticeable and I didn't want somebody to kind of freak out when you see it so it's important to sit across the table from somebody, if you're getting to that point in your relationship and just say there's some things that you need to know about me and kinda take the chance that they're not gonna get up and walk away and then depending on their kinda reactions tells a lot about you and the type of the person they are. 
I: yes and the woman that I know very closely, she got a double mastectomy and I kinda asked her ya know are you going to get any type of reconstructive surgery and she was $\% 100$ just no, I don't want, it's not that she didn't want to, she just felt comfortable not having it. Because some women, do you know any women that have had reconstructive surgery after a mastectomy?

A: I do I have a colleague and she reached out to me after my diagnosis and I kinda shared my story but we haven't kept up since then.

I: I'm just always interested to hear why some women want to have reconstructive surgery and why some women don't and kind the social stigmas attached to doing it or not.

A: yeah and you do raise a good point, if that had been an option if I do have a mastectomy would i... and I probably, if I had a single mastectomy I probably would.

30:00

I think it would be funny if they were lopsided, if I got a double I would probably, it seems, it seems, I don't know if it seems funny to you or strange that we can talk about things so matter of factly but you go through so much when you're treated with cancer that if you don't develop a sense of humor about it you kind of, you can't stress about it all the time, it just becomes the new normal.

I: yea, the women I interviewed, I will say, every woman that I have interviewed and the support groups that I sat in, every woman has been so so positive about the situation, which was a surprise to me because for someone who has never been diagnosed with breast cancer I imagine it as just being a really really hard...

A: traumatic event...

I: yeah, and it never, it just always feeling upset about it, but ya know its not the case and I think that has been one of the most interesting things, is that most of the women that I have talked to have been like 'ya know it happened and I'm dealing with it and it will be ok.' Ya know I have never actually interviewed a single woman who has sounded negative or down about the situation at all.

A: that's great, that's not entirely, yeah, the thing is there will be bias in your research because if people people are willing to talk to you about it, it will likely be the people who are most positive about it, it would be really great to talk to somebody who is not so positive about it because that would obviously be more representative of the full spectrum of what you can do. But what your saying is definitely the case with me, it goes 
back to that decision to either fight or not and if you're gonna fight its like, 'ok, accept it, move on and do what you need to do.'

I: yeah, Ive been, I have been lucky to interview the women I have. Its, I'm having, I get kind of nervous sometimes, actually maybe you can help me with this, because I will hopefully at some point, because I'm sure I probably will at some point go into an interview with a woman who is maybe not so positive about her experience, is there questions that you think I should stay away from, or questions you think I should ask? Cause sometimes I get nervous I don't know if, ya know.

A: you wanna be sensitive to the situation, lemme think about that a little. Off the top of my head, no, I mean I think you should be prepared for a difficult conversation but I don't know that I would ask any questions differently or not ask any questions, I think you need to ask the hard questions. But just do it in a respectful way. And you are obviously a very caring person and just convey that to them. Just be yourself and I think when people feel like you really care they'll open up to you even if, and they'll tell you whatever as long as they feel like you're doing it in a respectful way which you definitely are.

I: you've touched on pretty much all of my questions but I do have one more. How does your body physically feel? You said that your body feels fatigued but do you have any other pain? Or?

A: Actually I don't feel fatigued, I was I felt a little during the week I was getting the radiation but I think it was because I wasn't sleeping well. Cause I was uncomfortable, but since that nothing. That's not a side effect.

I: and stress? Or anything like that?

A: worry about it recurring? So, when I went in for the one year check up on my lymphoma my transplant doctor said to me; I have good news and bad news, yeah it was the one year check up. I said; ok, he said the bad news is you have a highly aggressive form of cancer, if its gonna come back its gonna come back within two years, so I said what's the good news? He said the good news is if it doesn't come back within two years were gonna consider you cured because ironically the more aggressive your cancer the is the easier it is to treat. Because you can go after it aggressively and the tumor like eats it up, whatever it is you give it and if you give it bad stuff it will eat it. So from that conversation I kinda set up in my mind, I'm living, I live in sort of a two year horizon. When I make choices about how I'm gonna spend my time I think two years from know if I was told I was gonna last, would I feel like I spent those previous two years I had wisely and doing things that I should have been doing, and so umm when you kind of talk 
about worrying about relapse, one of the things that you go through as a cancer survivor is you, and this goes back to the new normal thing too, is once your all in to the situation and you're consumed by when do I go in for my next chemo therapy umm after the chemo have I adjusted my schedule so that after the first few days after chemo do I have a lot of stuff on my calendar cause I am going to feel yucky and when do I call in for my labs for my white counts and you have this whole, there's this whole new schedule that kinda gets imposed on your life and it becomes in a way comforting because it's like structure, something that you know and so as you go through this process you do bond, not only with your doctors, because they have your life in their hands but also with your oncologists and their nursing staff and all these people and when you finish treatment it's like "goodbye" and you go "I'm on my own again." And you have that sort of stepping back into the world feeling like what if something happens, and if something happens we'll deal with it. So I'm going all over the place here, but in terms of worrying again with the lymphoma because it was very serious. Let's see, I had a stem cell transplant in June I went back to work in September and its not that I forgot about the cancer but I sort of receded into the background and one of the things that I found was that I felt like I was living intensely while I was going through the situation, immediate treatment, and as it started to recede I had felt like I had lost that perspective of being able to really appreciate life and I wanted to kind of stay in touch with that a little bit, cause it was a good thing to have that and so I started to get myself into situation where I was volunteering in caner environments just so that I could remind myself where I come from and that I still need to appreciate life and so forth. So, again this DCIS being at this end of the spectrum, the lymphoma being here, much less impact. I mean I certainly went through all those scenarios in my mind and lord knows my poor husband worries every time I get the sniffles and, but my attitude is, and I have a very strong faith also, if umm if got wants me to be here doing something, he'll make it possible for me to be here doing something and umm ya know when ive completed that and it's not my time any more than I'm gonna go and I don't have any control over that. I could walk out here and get hit by a bus so umm I try not to live with that fear and uh because the breast cancer, the DCIS diagnosis was minor compared to the lymphoma thing, not so much a factor this time, umm it was debate about whether I should to back for a mammogram in six months or a year and we decided that I would go back in a year. Breast cancer tends to be relatively slow growing and even if something were there it A. wouldn't likely be seen in six months and even if It was a year when they say something umm it's still treatable. And maybe to some people I sound a little bit more relaxed about the whole thing than I should be, but again, it's like where do you put your energy in life? Do you worry about something that might not ever happen or do you put your energy into doing what I'm doing and I decided as a consequence of my cancer treatment that I wanted to work in health care and I have no healthcare background, I have an MBA, I've worked in 
technology, I've never worked in health care and so I started up at OHSU in the healthcare management program and umm about 2/3 through I learned that there was a whole discipline that dealt with just technology care and it was like the angels started singing and the clouds parted cause I was like, I've been casting around for what I was gonna be when I grow up for thirty years and I finally felt like I found the thing that I was supposed to be doing and what you're doing in informatics is your doing things like helping doctors make better decisions on patient care based on their access to information. Ya know doctors have their hands full taking care of patients, they shouldn't have to be spending hours and hours researching things and trying to find things. There should be a group of support people behind them and technology behind them that makes it easy for them to do this so they can focus on taking care of the person and so that's what attracted me to this whole idea and so the idea is here, it's a second career for me, I'm starting over but then I'm hoping that im gonna have another $25 y$ years of productive time and I better spend it doing something that I, that makes me help people. So that's kinda my story.

I: and your whole experience with all of this is probably the reason why you are, feel so passionate about what you're doing now. You've been a patient, ya know you've talked to doctors; you have doctors in your family, yeah. Well that's very interesting.

A: absolutely. Definitely. Last Friday I went on rounds with a woman from the bone marrow survivorship clinic. She's an oncologist, I'm doing some volunteer work for her group and for this, for one of my classes you need to round with some clinicians and you need to write your observations and so forth, we rounded on patients in the bone marrow, blood and marrow unit at OHSU which would have been, that's where I would have been. It's the floor that I would have been when I had my transplant, I told the doctor at the beginning of rounds; I said; "if it would help for you to tell them that I'm a survivor feel free to use that information." I gave her permission to disclose that about myself and she said there will definitely be some patients we see today who will love that and so I would say maybe $5 / 15$ patients there was an opportunity to, ya know for encouragement, and she could point to me and say, look at Deb, she's here, look how healthy she is. She is starting a new career and she is a five year survivor of this program. And people eyes and faces just lit up and that to me is what it's all about, it's the silver lining. Look at all you can do with this experience.

I: I think I just got the shivers actually. I love

A: hahahah that's why it's fun to do these interviews and other women are willing to talk about it, cause they get to relive that too. 
I: thank you so so much for meeting with me today. I know you have to go but umm in the future, do you want me to keep you up to date on what I'm doing?

\section{A: yeah!}

$42: 3$ 
LK (Sue)

October 19, 2012 3:30 pm Starbuck's next to the sandwich shop and Middle Eastern deli, facing the Park Blocks.

Lauren had dyed dark back hair. She looks nervous and lost when she initially enters the room. Once I make eye contact she is much more comfortable. She orders a chi tea latte.

I: Ok so we'll start how long ago you were diagnosed?

C: That would be April 2011 so that would be about a year and a half ago.

I: And what was the diagnosis like?

C: Uh invasive ductile carcinoma,

5 I: And so leading up till your diagnosis what was your health like? And remember it you don't feel comfortable talking about this you don't have to.

C: my health umm took a dive umm for the worst after I left my job and moved away from my friends and family and my cobra insurance had been discontinued and I had a lump and I knew I was in trouble and I was exhausted. And I had some other health issues, I had anemia too but I was really tired. I knew $\mathbf{1 0}$ something was wrong.

I: and you went to the doctor because?

C: well I went to the doctor because, and this is a very weird story and feel free to edit, I moved to Vermont without a job and I had part of my retirement left and I met a guy while I was there and moved in with him. Which I have never done before. And it was his house, his kid I ran out of money and what 15happened is the week before my diagnosis he ended our relationship, and I had an episode of high blood pressure, this is very weird, I had a panic attack and I went to the ER and my blood pressure was like 190 and my pulse was skyrocketing and of course I had ya know a lot to be panicked about, I was about to be jobless, without a home in a state where I knew like five people, so at that point I believe I had just gotten Vermont medic-aid and I think he was concerned because he could see that I wasn't all 20that well and he wanted me to, he wanted to make sure that he didn't end up absorbing the costs of my medical care so I had just received medic aid and so I went to the doctor because I was afraid my blood pressure was off the charts and I was gonna have a stroke or something. And I thought well I'm gonna be more of a liability to this guy if I can't even get out of this house (laughs). So when I was there I told the doctor about the lump and she was a natural path, a woman and she just said 'go 
now, go to 25the hospital today and she was like I'm calling them now.' And so I went like the very next day and I had known about it for at least six months and I had sort of this feeling of discomfort for probably about eight or nine months before that and I was just scared and I had just lost my health insurance and I was think I just gotta get a job, so that was the story and while I was that clinic, it was actually a midwifery clinic in Vermont just random that I was assigned there and a complete stranger overheard the 30receptionist talking to me about a mammogram and she came up to me and said 'look I was a survivor, I've been through chemo I've been through a lumpectomy and I'm here I'm fine and then she gave me her number and then that's when the whole thing started. And so

I: so when you initially went in and got the diagnosis were you scared, were you calm?

C: well the diagnosis happened about a week and a half later, what happened is that I went to get the 35mammogram and they immediately said this looks bad and then they immediately did the ultra sound and then the ultrasound technicians came over and gave me a hug and then they scheduled I think within three or four days they scheduled a biopsy for me and the surgeon said 'ya know this looks bad.' So they did the biopsy so at that point I knew that I had cancer and I was calm and then he called me on that Friday either April $12^{\text {th }}$ or $13^{\text {th }}$ or something and he called me as soon as the results came in and said 40its cancer and come in and we'll talk.

I: and so from there you went in and talked about what your options were?

C: Well what was really interesting

$5: 34$

C: I was incredibly lucky I've never had that many male doctors. I'd had an amazingly sensitive wonderful man. And the first thing that I did was I contacted the patient care navigator for the cancer center and $\mathbf{4 5}$ this is a new field, oncology social workers, and the oncology social workers are like beacons of light, what this woman did is this is what she said 'this is the surgeon you want to see, this is a support group for you, this is another support group for you this is a physical therapist for you, these are some recourses for you to try and find a place to live and so on.' And so she spent about an hour on the phone with me, and I was so lucky I mean I'm almost crying on the phone talking about it. And she was a 50woman about my age, went back to school and got her master's brilliant woman. so I called this doctor and it turns out that he was only in town a certain part of the month, and he was the guy everybody goes to, so I called him and the first thing he said was 'breast, conserving surgery.' Because he could tell I was young and my ex boyfriend at that point he had completely severed the relationship, I mean he had 
dropped me off, I went to the biopsy all by myself, I went to the surgeon all by myself. I went to 55overwhelming all by myself and theirs nobody, and my mother I mean, well ill put it this way, we don't even want to go there (laughs) so she was in Cali and so what they realized is that in order to do the breast conserving surgery we had to do what's called mio chemotherapy so within a few weeks of my moving out of the house, saying goodbye to my mom and grandma I sort of went back to California packed up my stuff moved in to Lake O, took a room in house and started my chemo three days later. 60And my chemo regiment was slightly less intense than most people, I did what's called sytoxen ataxitire, ill write them down. Sorry I have chemo brain it's hard to remember how to spell them. And a lot of women also get what's called aujudomysin, but anyways I think that's how it's spelled. These are the three common chemo agents. And I had what was called, essentially, at that point we had done the test and it's something that I had found out from a book that I was reading, and threes a new test called 65oncotype DX, and what that does what they're now discovering and this was in the new York times as well, that breast cancer is about thirty different diseases so they've got, what they used to do is like take a mallet and just hit it the same way, but now there basically refining the treatment, they need to do a lot more but they're basically specializing in what type of cancer do you have and identifying the onco type or onco gene analysis so we did all those tests and I started and that's basically how it went.

70I: and were you worried at that point about side effects?

C: I was only worried about one thing, my father, may he rest in peace, my father umm died of a blood cancer called multiple myeloma in 2004 and between the period of when he was diagnosed and when he died he was about three months and he literally went insane, I'm not kidding you. I mean he went over, and there's kind of a history of that in my family, mental illness or whatever you want to call it, and I call 75it extreme state, cause I think that sounds better, I learned that from the alternative psychiatry movement and my father had an adverse reaction to a steroid called adexitron, and the steroids used in cancer treatment have two folds, some types of cancer theyre actually used to treat the cancer itself till it treats itself or shrinks itself.

10:09

The other aspect in my particular situation, the same steroid was used umm because it would suppress $\mathbf{8 0 m y}$ own immune reactions to the taxitire and the sytoxen, so I was very worried because I saw my father flip out, I mean he was hallucinating and not making any sense and ya know making racist comment, and I mean he was not himself. So my boyfriend had left me, I was living at this guys house, these two guys, I didn't know anybody in the whole state but my boyfriends two kids and this other woman I had met 
and I wasn't really that supported so I was basically scared I was gonna lose my mind 85(laughs). And I sort of did but I kept on going, I was very lucky in that a number of things happened. First the woman that reached out to me continued to stay in touch. Two friends of a very good friend of mine that I've known for thirty years, two of her good girlfriends were survivors stayed in touch with me. One of them was like this grateful dead freak, and she's a five year out survivor and she was like calling me all the time the next thing that happened was a friend of mine that I grew up with was stage 90 four she really she was really scared, she waited till she almost died, and I don't fault her for it, she was calling me all the time and sending me cards and letters. So umm it was summer and umm what that meant in Vermont is like night and day difference. So I got a therapist and I connected with a support group. And this particular support group, and I think this is catching on, what they did was they match survivors who are on the other side who were diagnosed so it's called kindred connections, it was $\mathbf{9 5}$ started by this woman who was into Butism, and I had two kindred connections and this is the kind of thing that happened. So I started my chemo and felt like I was completely alive/? And there was this huge flood in Vermont and I didn't know what was going on and people were calling me and I was like not even remembering that they called, but somehow I had gotten through it and ya know I just started, one thing I did was I walked, this is the one thing that people don't do, because I didn't have anything to $\mathbf{1 0 0 d o}$ beside be a patient, I walked everywhere all the time and it sort of just moved through me. And I was having all kinds of weird symptoms, GI symptoms and gross things were happening and I just got right through it and I lost weight, which was good, I needed to. And they say paradoxically we gain weight after our treatment because we are just tired or depressed but somehow or another I had what's called four rounds of three which is four months apart. And the actual inducement itself umm I was in a 105really cozy comfy infusion room and I had my headphones to listen to Garcia or whatever and I had books, and I had aroma therapy and but it was very hard for me because what they did for me was infuse me with deca rather than giving it to me a few days before or a few days after, so each time I went through the infusion I had a tightening in my chest and it was very scary, but I got through it. And so I would take the bus up and people would meet me except one time I just went all on my own and I 110started trying to meditate, trying to be calm. My bother sent me a TV so I'd like watch, what's that show about the teacher that had finds out he had cancer so he makes meth, have you heard about that?

I: oh oh, breaking bad. Yes I've seen every episode. I love that.

C: (laughs) high-five. I got addicted to breaking bad. I mean I was like in David's house, ya know David was a friend of my ex boyfriends family and I was upstairs watching breaking bad till four in the morning 115 then I would get up and ya know go out and 
think can I walk to the café. Can I walk to the therapist, and so I just kept going and this is very interesting. Two weeks to the day after I had started, oh I have to show you, my hair had started, it was long and curly, this is an old picture but I was, this is as long as it's ever been and this is a pic of, and this was like two years before that it was like down to here.

I: oh wow, it was like so curly!

120C: yea, and so what happened is about, well the first thing I did, everyone said you'll wanna shave it off and you'll know when it's time and so the first thing I did was I went and got it cut. And hopefully it went to locks of love, and I don't know if they want grey hair, but they just chopped it and kinda made a bob and so two weeks after that id wake up in the morning and I kinda like ya know and my whole scalp felt tingly and big chunks would fall out, so I called the stylist and said ya know its time. So she was so 125nice, this is Vermont and she said ya know come in at night, because a lot of people on YouTube they have their boyfriends or friends shave their heads, or their friends shave their heads too, I met someone at OHSU and she shaved her head with her sister in solidarity.

$15: 44$

But I was it was just me, so this stylist had come down and uh, anyways sorry and umm...oh wow its Michael Franti (playing in the background) so anyway, sorry obviously my brain is not back to normal. So 130what happened is she said well you can come at night and nobody will be there. But when I got there her peer was there and some teenagers and she said 'are you ok' and I said yes. And she shaved my head but I didn't look, and then she was like are you ready to look. And instead of crying I turned around and it was so funny because my eyebrows were heavy my head was shaped like a jellybean and my ears stuck out and the first thing I said was 'I look like a white Barak Obama.' I mean my face was like 135so oval. And everybody in the place like totally cracked up. And it was hysterical. And so I put on my wig and a hat, and it was so dark and rainy and I was walking around like this and then the hardest part was umm when I first put on the wigs $m$ girlfriend said it doesn't look that bad it's just that your brain doesn't recognize it. Because she and I had both done a lot of grateful dead an all that stuff from the old days so we know what like trippy feelings are. And she says look your brain just doesn't recognize itself. 140But it was really hard at first. I'd go out and I would think people were just like hehehehe, but my friend in Michigan just said had fun with it. So I went and put all these different wigs on my credit card. And not one, not two, I had four different wigs and my best was actually better than with my own hair. It was long and straight and that's all the wigs are straight because my girlfriend said if you 
try to get a curly wig it looks like a Halloween costume, so she said don't even go there. In fact, this is what $\mathbf{1 4 5}$ happened. And I should really write her a letter and thank her again, so she found a wig from California, and I was in Vermont, she said you need to get this one and this color and I was like yes ma'am. And she was right. And then I went to this consultant called the wig goddess and she said the same thing. It was grey and white and it was a bob and it curved around. So that was the one I wore the most. So I just kept tripping people out because every time they saw me I had different hair. So yeah it 150worked out and I got used to it. And the other thing that was different for me and my treatment was that umm a lot of women in Vermont especially if they're out with their husbands or boyfriends they would either go bald or just wear a cap, or they would just wear their scarves, but I really god a lot of support from my friend heather, I was like 'were not that kind of girls.' Even if it was 90 degrees and humid I would wear my wig, I would even wear it to the store, I had all these scarves and we did all 155these wraps and I just didn't feel comfortable. So what I would do is since I lived in a house with guys I would go from the shower to, I would get up and start wrapping all these scarves I had like a glitter scarves and this that and the other and I put this whole thing together and then walk ya know from the bedroom to the shower and then take a shower come all the way back, so that went on for a couple of months and then the next step was the surgery. I was really scared I had never had surgery so I was 160really scared that they gave me two adavant and I went on the bus by myself and they gave me two adavant and I was so hyper nervous that they gave me more. But I was fine. Got up walked out of there and stayed at my one friend's house. My ex boyfriends ex wife who is a friend, I stayed at her house one night got up and put the wigs on, got up and started grocery shopping I thought that ya know this is just, I gotta keep moving and it turns out that research says it's the best thing. I never stop walking; I never 165stop carrying groceries I never stop like helping other people. I took care of this woman's cat and I met this other cancer survivor and I was like cleaning her apartment. What I notices was that it hurts, but if I didn't think about it and focus on other people the only thing that I had and this is not typical I believe, I wasn't working and I had worked for thirty years and I wasn't around my friends and my boyfriend broke up with me because of all those things and I had panic attacks, but I don't think 170everyone has that.

20:40

I: so that was after the surgery?

C: no, the panic attacks started right away and I still have it. And I went through a trauma, because to me it was so shocking but then what I started to hear was that there are a lot of men who are like that, a lot of men bail, especially if it's a new relationship, and I mean this guy pursued me many times, I mean $\mathbf{1 7 5 h e a r}$ we are mileages, were not 
teenagers, were in our 30's 40's or something and he just completely abandoned, abandoned me and so anyway umm I met all these other people and my surgery was uneventful, I felt very little pain and...

I: so what kind of surgery?

C: oh a lumpectomy, yeah I still have both. And what was so cool was that it looks pretty goofy but if you 180don't look at my other, my other old boyfriend who is like around seventy now, I showed him and he said it looked fine. And there's like, my scar is underneath, but this is where it gets tricky, a lot of women in my situation because of my pathology score would have gone for a mastectomy and I met a lot of women who like had husbands and they just have it and they're fine and they look fine they just have reconstruction and you would never know and they're athletic and so my cancer survivor mentor in 185Vermont she had a double mastectomy and if you met her you would never know, she is like a jogger and a skier and a lawyer but ya know I decided to go for the breast conserving surgery so ya know I have a higher risk for reoccurrence compared to my peers but ya know they always say the other thing that is a little tricky, even if you have a mastectomy it can still come back in the chest walls very very common and so yeah, so I had the chemo and surgery...

190I: so why did you decide to get the lumpectomy opposed to the mastectomy?

C: umm a million different reasons. The first is that for example when I look down I can't even see the difference because my scar is hidden. So the other thing is that the mastectomy is a much, much more intrusive operation, you have to have a drain in for several days or a couple of weeks so the recovery period is much more significant. The lumpectomy is really, it's just a little piece of cake, I men they just 195take a little piece out, but with the mastectomy they take, its much bigger than it used to be, but for me I was really lucky cause what they did was they took the sentinel lymph nodes, they took a couple to make sure the cancer hadn't spread. And so the chemo therapy was supposed to technically shrink the cancer and it did they were really happy. So that was the other thing, if a lot of women now, the first thing you do is have your chemo neo agent which is for the other treatment, but that means it can 200shrink the tumor which means your other surgery might not have to be that invasive. And that's what a lot of people do, they do the opposite. And the other thing about having your chemo first is you can see if it's working because they are taking ultra sounds and they can see that it's shrinking. So it's not like if they take off your breast and then they see that the it's shrinking from the chemo they don't really know how that chemo would have worked on that type of tumor. And so you still have the cells in your 205body, that's the other think we all have microscopic cells in our body and so it's just a questions of am I gonna have a healthy 
environment in my body or am I gonna have an environment that's more conducive to what's happening. So as soon as my surgery healed and it was really just a breeze, I was ready to go to radiation (laughs).

$24 ; 30$

And then it wasn't just the same. I had great doctor's great nurses. I went home for 33 days, now they're 210doing something, the more academic hospitals are doing what's called braci therapy where they just put a couple of seeds in and it's just there for a few days but I had a smaller hospital and everybody was really nice, one of the radiology technicians was a guy he was still nice, it was a little uncomfortable, but he was nice, everything was fine and then umm four days after I finished my radiation I moved to Oregon. And can you imagine four days. And (laughs) the other thing I left out of the middle was that I 215moved five times during what I had just described.

I: how did you manage that?!

C: I don't know how I did. I mean it was so crazy.

I: did it help you, ya know moving, and being in new places, or did it?

C: well ya know I think what I learned was that because there was nowhere to hide, because I was 220moving all the time, because I was kind hung out to dry, so to speak I had to accept support from people. And I had to make new friends and meet new people. So for example at one point I was almost homeless if you can believe it and I met this woman who did know me and she just gave me this place to stay just for a week and another really interesting thing happened was that the American cancer society had a special place where people could go called hope house. I believe its national but I don't think 225Portland has one yet. And what was interesting to being a middle class person, living in this guy's house to suddenly on the margin. And so the social worker was trying to refer me to hope house, but she actually accidently said I was virtually homeless because to try to get the space for me, but they said; 'oh no we don't want her, we only want women who have a permanent address.' And so that was, can you imagine how that would feel?

230I: no, that's not very supportive.

C: I mean I had worked for thirty years I had always had sort of insurance, I always paid the rent. I mean I helped my boyfriend, and here I was hung out to dry. But I got over it. And luckily at the end of my treatment the social worker found me some houses that I stayed in a little guest house. So I stayed at this guys house and wasn't clean but I looked after his pets. And what happens after chemo is every 235 spell and every taste is a 
million times stronger and I couldn't, I just couldn't take it so then I moved in with this 90 year old radical woman who had hair down to here and she didn't clean out her refrigerator and she wouldn't let me clean it and the whole house, the smell was getting so bad and I was like oh man I cannot like eat here. And she started yelling at me because I didn't eat there and I thought I gottta bail again. So there we are again, my ex boyfriend his two sons, the whole crowd, his $\mathbf{2 4 0}$ son said disavow. And then I moved into another place and then I left, yeah so finally when I moved here to Portland that's it, I'm living like right over here. It's a little tiny studio, it not the ideal apartment but I'm happy.

I: is this your first time in Portland?

C: yes I love it, I mean it's hard being here alone in these circumstances but I love Portland. Yeah so when 245I got here the first thing I had to do was I had to take all my medical, they took all my medical records and I had to finagle medical care in Oregon because the next part of the treatment it's that after your chemo therapy and your surgery and radiation usually if you have a tumor that's estrogen positive you have to go on hormonal therapy. And so we go on one or two things things. Either amoxophin or aroma tason prohibitor can't understand And that was another thing I went through the 250change just like that it was crazy. So I'm on tomoxaphin for five years so I had to get medical insurance and pester the people at breast and cervical cancer program because I wasn't eligible because I'm getting social security based on my former salary I wasn't eligible for Medicare for OHP, but I thought I have to have medical care, it turns our one visit with an oncologist would be about four hundred dollars just to meet with them, so I had to really push it and just before my tomoxophin ran out 255 the doctors in Vermont gave me a ninety day supply. So I brought it with me and I started here without a doctor, I was all alone. My bother lives here but he's not around the lives in California, so yeah but it's ok and I'm committed to taking it because I know people who stopped and it lessens the reoccurrence and what it does is it reduces the circulation of estrogen in your body it does have side effects. It makes you have hot flashes and kinda jumpy, kinda like you're on the pill. It's just the old 260school pill. Now I think they've refined it but the old school pill used to make people kinda, ya know it just makes people feel funny; you can't put your finger on it. But its umm I'm committed to taking for five years.

I: so you take it for five years?

C: yes, five years.

265I: and how often?

C: every day and then a lot of women if they had already gone through the change when they were diagnosed. And so Portland has been a completely different experience. In 
Vermont I had therapists that Vermont Medicaid paid for me to see twice a week I had social workers at the hospital who helped me apply for disability, I had umm doctor, I had a support group, I had two new friends, survivors that called 270me all the time. And when I got to Portland its harder, ya know when I go to a breast cancer support group its only no maybe only eight months later and I'm only getting to know one of the women in the group. Cause this is a city, people have their own lived, they are adults and other woman my age have adult kids and they have a lot going on and people are just kinda like whoa ya know.

I: how do you stay positive? Because you seem very positive.

275C: oh thank you. Well hopefully I'm not too hyper. Because usually when I get too hyper, sometime when I'm telling these stories I re experience them and I'm like 'why did I end up with that guy.' How do I stay positive? Umm

\section{$31: 23$}

A lot of reading. Umm there was a woman and I'm trying to think of it because I've got your email and she lived 20 years with stage four with a mataticide cancer, she was incredible. She wrote a few books, 280she traveled to India. I think for me it was just completely I was thrown into a completely be here now situation. And umm I just had to go one step at a time.

I: so you just kinda felt like you had to just fight your way through it. And that's what kinda helped you stay positive? What about from a woman's perspective, the whole diagnosis, what were you most concerned about? Were you concerned about appearance?

285C: Yes! It sounds ridiculous but I was constantly on YouTube and there was a website and I must have watched it about thirty times, my friend from California sent it to me and these women from southern California, its Godiva's secret wigs and they model the wigs and some of the women are bald. I must have watched those videos thirty times and I used to think losing my hair was the hardest thing because I felt like I was an imposter in the world and that it marked me differently. And then when people found 290out it was so hard for me to talk about the fact that I had been with this guy who was never there for me and I felt weird about it. So umm I think as a woman the concern about the disfiguration because you know my hair and my boobs are my best features. (Laughing)

\section{I: Well as a women ya know}


C: That was really hard for me and I just thought this wasn't fair. It was my features. Because my hair 295was down to here. Difficult. It was the only thing I could handle and so I felt a little kinda sad. But then I have to make the best of it. And umm I guess just have to stay positive. And umm I would do things like walk down the street. To start smelling, and I know this sounds cliché but I would literally start smelling one lilac tree after another just inhaling the lilacs, going to the movies all the time, ya know I didn't care if I was alone going to the movies because something that happened to my friend and 300this was in Michigan and I'm still having trouble with my concentration, you lose your concentration like trying to read a book you read the same page over and over and over again and it's like 'wait a minute, this is not going to work.' And so I got magazines so I could read those and then not go to the movies, so I feel like ya know focusing on things outside of myself, all of the people that supported me in Vermont and I try to support people now and just learning new things and walking and those are things 305that keep me positive.

I: wow so you've definitely had an amazing story, so you at this point are feeling, your body is feeling better?

C: well it's interesting, I had a really good, you get a mammogram a year later and it was good. Umm the last couple of weeks, and I hope this is just my imagination, I haven't been feeling as well and part of the 310reason is I started, and this is really interesting, and this isn't even on the diet that we have, the diet that is recommended for us survivors is anti flamitory, no sugar no dairy no wheat, no nothing and you know you can have brown rice and salad (laughs). And so what I noticed is I was having kind of a hard time for many different reasons and I was eating too much sugar and I was starting to gain weight and I was starting to feel some soreness around here and the only thing I'm angry about is this all happened 315when I wasn't working and I go to a lot of breast cancer support groups and people are like my life is falling apart and I'm like all these wonderful things already in place and I just have to put it all together so the way that I have dealt with it is I volunteer cause I'm trying to get ready, that's why I just got here today.

I: where do you volunteer?

\section{$36: 13$}

320C: I'm volunteering; well it's kinda hard for me to find an internship, well your age who are tech savvy and social media savvy and to do an internship. So at my age its kinda hard, so I had to kinda poke around till I found the right thing so it turns out that I'm doing four different places so today for example I started out doing data entry for the department of forestry in the GIS systems for the tree survey and umm at first it was really really hard and I couldn't find my place on the page and I just thought ok this is 
325chemo brain I'm gonna get through it and I did, and they asked me to stay and that's why I just got here. And then I also volunteer for sisters of the road which is a homeless organization and they serve lunch to people down in old town china town and then on Tuesdays I just started volunteering for chess for success and then on Thursdays I volunteer I did the summer reading program at the library so I found something, I mean all do anything. I mean I put stickers on books for three or four hours, but people will 330say thank you and I'm like 'no thank you, I'm glad to have a place to be, I'm glad to have something to do.' And when I'm volunteering I push myself as hard as I can to be accurate to be quick to be concise and what I'm trying to do is like train my brain to go back to the way it was in the workplace. But the other unexpected gift is what I notice is that when I'm happiest is when it's not about me. Like I go to a breast cancer support group, and we had this group in Vermont where people would go to a potluck 335every month and we would go to people's houses and people would talk about everything under the planet. When I go to a breast cancer support group to the one in Portland and people are like 'I feel this and I feel that and I am tired and angry and I have lymphodema and I'm' and what I've noticed is that even in the course of that meeting, like and I know I need to open my heart and have compassion, but what I find is that if I start thinking those thoughts I immediately feel tired. So what I realized is that its 340a fine line between having compassion for myself and having compassion for peoples stories and cause I think we have to learn to be, it's a Butist principal, we have to learn how to be with ourselves but we still have to push ourselves out to the world. And that's what I've noticed is that when I'm focusing on what's not right or what could happen in the future or all that, everything falls apart and what I'm focused on is like ya know, for example I'm glad to be here because I'm helping your thesis which is a $\mathbf{3 4 5}$ wonderful honor for me and ya know it's just I'm good, if I'm learning about something if I book reading or taking a walk around so right now I'm a little worried because I'm having a few sensations and I'm telling myself it's just healing and ya know it's not the sensations we have it's what we tell ourselves and hopefully ill make sure that's the case it's just healing. And what I have to tell myself is that if I do have a reoccurrence ill just have to deal with it every possible treatment. But as far as I'm concerned its 350in permanent remission, ya know that's what I think. In the now it's in remission. That's all we can do.

I: do you think that if you had possibly gotten a mastectomy, would you have had reconstruction surgery do you think?

C: yes, absolutely, without a doubt.

I: story about young women's support group in Albany in regards to reconstruction. Well this is a bit off 355subject, but one time I had a lump in my breast and at first they were concerned, and this happened a year ago, and they were concerned so they did a biopsy 
and they found that it was just a cyst, but they ended up taking it out anyway and I ended up having a scar, a long scar.

C: yeah yeah yeah, it does. No no nothings off subject.

C: ohhh I'm sorry.

360I: Well but the thing was it was very small and initially I was ya know kinda a little embarrassed to take my shirt off in front of a guy or whatever but then afterwards I was fine and I noticed that the young women's support group was like this. They start out kind of concerned and then at some point you can tell that they realize ya know if a guy is gonna be judgmental for that than he's not worth it. And do I was really happy.

365C: and I'm sorry you had to go through that.

I: oh no it was fine, it was a little scary initially, but I don't know why it runs in my family. We get like calcium buildups or something because it happened to my mom too. But I wondered that, because the woman that I said was my mentor she had a double mastectomy and she was absolutely against reconstruction. And she had never been married.

370C: did she have a reoccurrence after the mastectomy?

I: She didn't she didn't.

C: oh wow, oh she's still ok now?

I: yeah yeah she's great. She is fin.

C: oh thank goodness I got some stories mixed up.

375I: no no its fine, but yeah she wasn't married she didn't have any kids and she was probably, well she's about sixty and she umm.

C: I'm 54 by the way.

I: yeah but she umm didn't care at all, she said I had the mastectomy and I didn't care at all.

$\mathrm{C}$ : wow that is awesome.

380I: yeah and she was totally comfortable because we waitressed together and she came back actually a, I swear it must have been a week or something right after she had the surgery and was waitressing full time. So I've just been, the coolest thing about this 
research has been interviewing women like you and just hearing your story because I think it's crazy some of the thing that you have been through and yet you remain so positive and it just makes me think ya know, when I start complaining about little 385things it really makes me ya know reconsider

C: laughs, yeah I call it a confluence of events and I'm in the position now as people when I go back to work I've always told the truth in a job and once I really did get fired and I was asked to resign from a position about ten years ago and it was a great responsibility and I worked as hard as I could and this woman just took out after me, she just did not like me

$43: 31$

390And I did good work, I was honest in my job interviews because people knew me where I worked I worded at UC medical center and people knew me, but now I'm in a touch position I'm just not sure, they say 'oh you never tell them, you never tell them that you were sick or that you had an illness, say that you were care giving.' And I'm really, I'm completely confounded because I've always been honest and I feel like if anything it makes me a better worker because now I know that like well, I was in a 395workplace where people were just, it was all politics. I worked for the department of neurology at UC which is just like OHSU for the last five years of my time, and nobody was working collaboratively, people were just trying to hide information from each other and it was really a sad environment and I was always worried that people were not gonna like me or get mad at me, so I always said yes and now I'm to the point where, 'so what?' I mean I don't need to go through that. I mean my personality hasn't 400changed much but I think ya know, I mean if, I mean I'm trying to get myself into that mode where this is small and I don't need to get stressed about certain things and ya know, like for example where I live is over here, village at love joy fountain and I have a neighbor who is always saying its noisy at night and I'm just like 'ya know so what?' I have a roof over my head, it's not the end of the world and I hear all this noise, so what. And ya know, but on the other hand that doesn't mean that I ought not be $\mathbf{4 0 5}$ compassionate with, because everybody is, as my mom's cousin says who is kind of a healer and has been into metaphysics for like forty years or something, literally, she says everybody has their own story. So that's the other thing that I have to tell myself is that if if it comes back, or if my friend heather only lives a few more years, just because we don't live doesn't mean there is a difference between healing and cure. And so maybe we might not be cured but we can heal and be one with the universe 410and be one with who we are and where we are with ourselves even if we don't make it through the journey. Ya know? And a lot of the woman in my groups and I've met woman who are living with cancer and it's like its, their cancer has matatrocized outwards but they're living with cancer and doing what they can and being 
as healthy as they can and that's another thing, to be healthy and lose weight. I've got to get in shape like you are (laughs). You're in great shape!

415I: Well I used to play basketball but now it's hard to uh, in my undergrad I played and now it's hard to bring myself to ya know, cause I feel like I was forced to do it for four years. Ya know I had to be to practice on time and lift at this time, so now it's like wow I'm free! I don't have to do anything.

C: oh wow, (laughs) that's great.

I: yeah now I just want to focus on school and, do you eventually want to go back to work?

420C: yeah, yeah, I have to go back to work umm normally believe it or not, breast cancer itself is not enough of criteria to get disability. What happened with me is that I think I was in the middle of a nervous breakdown so I was awarded it on a combination of different factors. So I was awarded it because of that. And I believe if I had been in Oregon at that time, well that's how it happened, my brother had said you're gonna have to leverage all social services which is really humiliating for me, but I 425 had to go look for help. (laughs) it was awful! And I have always worked, I mean I have like health issues this that and the other, I've been through a lot of different stuff in my life but I've always worked. And so what happened is when I moved to Vermont the economy crashed and my other boyfriend who I've been off and on with for 25 years he was like an old hippy guy like seventy years old (laughs) he decided at the last moment now to come and he didn't know it then, but I think that I was already sick 430 because I was so tired I just, so umm I never thought I'd be out of work for longer than a couple months and it's been four years and I mean I have to go back to work, because my work was my whole life it was my identity, all my friends were from my work and and it was me. So that's my goal and that's gonna be the hardest thing.

I: but eventually do you want to work full time or part time?

435C: I absolutely want to, yeah and believe it or now

I: I mean it sounds like you're really busy anyways right now...

C: I've just started to become really busy and this is another really interesting thing, my oncologist at the hospital they had a tough love strategy, the lawyer that was my kindred connection my mentor and was a cancer survivor she worked during her treatment. Umm the radiation oncology nurse, umm I was 440concerned about, I had a question about surgery and she said 'oh well ya know most women work during their treatment.' She literally said that to me I mean she had no idea that my whole life was coming apart at the 
seams. And umm there were kids involved too, my ex had younger kids but umm so and then I met this woman here in Portland who works through the whole chemo and treatment of radiation and her surgery and so my feeling is that the most that we can do is we just keep pushing 445ourselves and then the other thing is I had the most wonderful experience, I'll try to remember this person, I mean ill send you this persons link umm its back east, its university of Vermont my ex boyfriends friends cousin was the head of oncology at university of Vermont and she is also a survivor of a double mastectomy and she had this long pony tail down to here and obviously her hair had grown back and I went to this seminar that she did and she told the story, and she said that all of her male 450peers, and this was amazing, I'm trying to remember the story, here she was an oncology worker and all her male peers were saying there's no such thing as chemo brain, there's no such thing as cognitive impairment she said that her kids were wondering, here she was a college prof, here kids were saying mom why did you put the milk in the oven? Ya know she put the milk in the oven and when she told me that story I realized I don't have to be ashamed as to what my brain is going through. I might not 455remember how to get around the block, and the other thing is that it does stay with some people so what we have to do is overcome it by literally training our brains to think and pushing ourselves as hard as we possibly can, and this woman patty Obrien she started a and I believe this is gonna happen nationwide, all of the research is showing that immediately after surgery and during radiation the best things that we can do is lift weights, keep walking and keep moving and that is the optimal healing, and 460so she started a umm program that is called steps for success and its gonna be a trend that will take off nationwide because umm she as a survivor knows exactly what she is doing and she is looking at evidence based medicine and they are working collaboratively with other things around the states and all the research is showing that it's the best thing we can do is clean up our diet, ya know people say 'oh you can treat yourself to chocolate.' And it's like 'noooo' laughs

51:28

465I: is it really not good to have

$\mathrm{C}$ : sugar is bad, it's really bad because its coming out more and more and there was an article in the NY times about two years ago it feels, it's a glucose mechanism and it, it's gonna be a big deal in the states because as we know the lobbies, the meat lobby the dairy lobby the corporations that make us eat fruit when we are growing up, all these corporations are going to be very very slow in changing died. But $\mathbf{4 7 0}$ more and more evidence is coming out that the glucose mechanisms of having a lot of white flower or white pastries and then when we get to the large, the larger we are as woman the more estrogen we produce naturally even after menopause and so that's the other thing. So 
those two factors alone those ya know. But anyways so that's another sort of factoid but yeah this prof is amazing and she just put on this huge research conference, I think there is one here but I didn't make it because they wanted a 475 hundred dollars or fifty bucks, Komen did and I feel like as a survivor, I mean I know I sound, this is my only indignity, but I feel like 'excuse me, I've been through this, I need to go to this conference for free and the one in Vermont was free and it was put on by the university of Vermont and it was equally academically rigorous to this conference here which I believe was collaborative with OHSU and all the big wigs were there in Vermont and maybe they just didn't make as much for their honorariums but I 480 feel that it's really really important to absolutely just every single way, every piece of knowledge every piece of, any diagnostics available to women. And Oregon its,...

I: there's not that many

C: no I mean legacy good Sam has incredibly good recourses but they don't really like Medicaid very much and it's really challenging. So my next goal after I go back to work, I have to figure out what can I $\mathbf{4 8 5}$ do to give back to the community because other people gave back to me.

I: well you already are giving back a lot even though it might just be volunteering or be as much as you want to right now I think, I think everyone should volunteer

C: that's so funny cause when you said you did basketball I wondered if you like teach basketball to the kids, ya know to girls. You just seem like you have a natural leader, natural leadership qualities. Well I 490hope this has been helpful for you.

55: 17 
October 22, 2012

University Center Building

520 SW Harrison Street, Suite 440

Portland, OR 97201

Miriam(Cassidy) is a short statured lady who is 53 years old. She wears blue jeans and a blue turtle neck. Her hair is short grey. She comes in wearing a backpack. Initially she has a lot of questions regarding my study and research practices. She is calm. Once we begin talking she starts laughing at and getting more comfortable. She has a folder of article with her to share with me that may help my research.

M: Well I appreciate kinda being in a neutral environment

I: yeah yeah, I think that's good, other women said 'oh that's fine, totally doesn't matter" its just total preference. I would want to be in a quiet room probably. Ok, so do you wanna go ahead and get started.

5M: sure sure

I: So first of all when were you diagnosed?

M: umm, so I was diagnosed. There's even a story about this. But umm sept. 2011.

I: Do you want to share that story about your diagnosis?

M: sure umm, what happened is I found a lump in my breast around mid July. And umm I was 10concerned. But ya know I wasn't freaked out. I um, ya know I had never had a lump and I talked to a women I know and I knew a couple of women who had had lumps that were not cancerous, and umm so my thoughts was that is was not cancerous and $\mathrm{i}$ will go see a doctor. She saw me around the end of the month and I had saw uh, I went in for um a mammogram like august first and umm they were not sure what it was and they did what was called a uh uh, a needle biopsy where uh right then and there they uh, well...its kinda like a staple gun (laughs). They just start putting a staple gun to your tumor and they just staple it and they like, uh uh, well its not comfortable, its not fun, but even then after they got the results they didn't know what it was and so I was told to go see a surgeon to talk to her about getting a biopsy done, surgical biopsy, and so that was scheduled September first and I asked her what the chances were of my 20having cancer were and she said well twenty percent. And I thought well that's not very hight and ya know eighty percent I don't have cancer so I uh was reluctant to even go through with the biopsy, uhh the surgical biopsy. So the day of the surgical biopsy...I'm trying to decide what to tell and what not to tell....so I had a group of friends to support me prior to going 
in for this surgical biopsy and we did some personal story telling and um about sort of umm to give me a sense of courage and hope to go forward into this biopsy umm and I can tell u more about that if you want but I can kinda just to the medical and kind surgical stuff. I umm soo umm I was reluctant to have the surgical biopsy because I had thought it wasn't that high of a surgical risk, 28umm and so even the day of the surgical biopsy I was ya know in the hospital waiting to have the surgery procedure done. I did have a friend who was a former cancer survivor and even a hospital Chaplin with me and umm I was at the point where I was backing out. It was like 'well I don't think I have cancer, why am I here? Do I want to do this?' so she talked to me and then a nurse navigator who I had never met at the time but had t talked to over the phone umm came and talked to me and they convinced me to go ahead. So umm I didn't hear the results for another two weeks and that was also a concern there was also a miscommunication between myself and the surgeon. The surgeon was out of the country, she's um, well I don't know exactly her status, she has dual citizenship or whatever and she ya know has lived in, or is from another country originally and she would umm call me and leave all these messages bus she wouldn't tell me how to get in contact with er. So I finally called this nurse navigator who had been at my bed side the whole time and she said look shes been calling me and doesn't tell me how to get a hold 40of her, I tried to call her office, ya know they're not helping um can you tell me what's going on here. she said yes I can tell you the results, and this was after two weeks, so, normally you should get the results after two weeks so she did tell me at that time I had cancer. And I was pretty shocked and upset and umm yeah. So I didn't quite know what to do at that point time.

I: and when she told you that was it over the phone or in person?

M: it was in person.

I: and so after that did you go in?

\section{$5: 22$}

M: no so what happened was. And this gets really mumbled in my brain because I was in shock and was really upset. And exactly what happened in what sequence I can't remember soon after the diagnosis but I did find out from the nurse navigator, her name is Teresa, that they did have 50umm support groups. And um in support, people I could talk to, so one of the things that I remember doing first was probably calling what's called the breast and outreach, breast and surgical, uh what I'm getting them all mixed up there's so many (laughs). The breast and surgical outreach program or something through Portland providence medical center. And its women who will talk and or meet with you about their experiences so I ended up talking to quite a few women who had been through breast cancer and it was really really helpful. Umm at first the surgeon told 
me that I had three different options. That I could have a lumpectomy, just the tumor removed, but I had already had some of the tumor removed already, the biopsy, so I didn't quite understand that. I could have a partial mastectomy and I mean she gave me all these options. It got very confusing very quickly and all the medical terminology. And she tried to 60draw a diagram and that was very very helpful, but it was like if you do this and then you do this and ya know it was like one of those very complex engineering, it was like if you do this then yes and no, then you do this and just...yeah yeah.

I: that's probably a ton to think about, way to overwhelming.

M: sooo um, my initial thought was that I just wanted the min done because I I had really not, well I had one other major medical issue in the past ok I've had more than one, but his was unusual for me and umm I did not, I've ha some experiences before where I've had a major 67surgery in a leg for instance because of a car accident and it took years to overcome it because it will just never be what it was. So I had some umm real concerns about surgeries and ya know medical ya know very invasive procedures, so umm I wanted to do the least of what she was 70suggesting and she was suggesting everything from ya know the least of removing the lump and maybe going through radiation to having both breasts removed and doing chemo and radiation and reconstructions. I mean ya know there's just all sorts of things you can do. And I mean ya know I had been working with a natural doctor called a homeopathy doctor and that's sorta like a naturopathic but its diff, and so umm so what ended up happening was I had three surgeries within three months, I had the biopsy the first of spet of last year, then I had a second surgery to go in and do sort of a cleaning up of what they call the margins, and what they found was that the tumor had escaped out of the ductal umm I had what's called DCIS, so it escaped the ductile area and had started to move to other areas of the breast so they needed to go in and find out how far it had invaded other areas, so that was ummm mid oct or something and then $\mathbf{8 0}$ when I had got the results form hat the surgeon basically said 'well umm from that surgery I did it had invaded most of your right breast and so the recommendation at this point was to have a mastectomy.' I was not happy about that obviously. And they also did what is called testing of the lymph nodes.

$10: 31$

I don't know are you familiar with some of this?

I: is that when, well you could probably explain better. I know some of the other women have talked about this.

M: ok so, I didn't know anything about his obviously, you almost have to be your best advocate or have somebody else come in and be your advocate to understand what their 
saying because it gets very technical very very quickly. So apparently we have a lymph node system throughout 90 our body which is a circulatory system and the does about 90 percent of the blood circulation throughout our system but this lymph node system also circulates the last ten percent through our body and its sort of a clear liquid that sort of fights off infection through our body and so umm the second surgery I had some removed and tested. They test your lymph nodes to see if its gone into your lymph system and if its gone into your lymph nodes then you may be in danger of the cancer spreading in other parts of the body. So they removed ten nodes and I had three that were positive. And I had three surgeries in three months and when they took out the lymph nodes, I think it was the second surgery or they did no, ok, it ge 3ts confusing. They took out what was 98called sentinel lymph node biopsy, so they only took out two lymph nodes, or three lymph nodes at the time of that surgery to see if ya know there was any indication of cancer in the 100nodes. There's sort of lumps ya know, like gapes, so I did have some spread in the lymph nodes at that time so they recommended the mastectomy and and they also recommended they, well I was concerned with how many lymph nodes they would have to take out and they said that, 'well we don't know we have to go in and find out.' So, umm I did write a poem right before I went in to my mastectomy and did have it with me, would you like to hear it?

I: yeah definitely. And you wrote this before you went in to have your surgery?

M: I umm, sometimes when I'm having a really hard time and I don't know how to express myself I have to write and this is actually my journal so I just write and write and write but even sometime that doesn't do it so I write a poem and I've done this off and on for a long time, umm I did give this to other women who were going through mastectomy's to help them through their 110process. And I have some extra copies, and I wrote two poems when going through my cancer treatment. So i have a copy of one of them but I don't have a copy of the other, so ya know I can always send it to you if you're interested. So call it 'loosing you.'

\section{4:09 SEE ATTACHED POEM}

\section{Losing You \\ Draft}

by Miriam Lange revised 11.20.11

You appeared forty years ago 
As I entered a tumultuous and wonderful time of my life

Awed by the small mounds growing on my chest

"I'm becoming a woman! But what does that mean?"

117At 12 or 13 years old I really didn't know

Maturing into a young woman I was assured by your constant presence

Though I paid little attention nor did little to care for you

You became tender and sore in the rough early days of my periods and pregnancy

121Bitter tears and remorse came when we could not feed my infant son

Today you will be removed by a surgeon

The doctors say that I have cancer and that you must go

How can I lose you after so many years?

125I'm numb and shaken to the core

What does it mean to have cancer?

To re-enter life as a one-breasted women?

How do I mourn the onset of cancer that has invaded my body?

How do I mourn your loss?

130I'll be no less a woman

But profoundly and irrevocably changed ---

I struggle to carry on -

Putting one foot in front of the other

Living day by day, moment by moment --- 
Talking to other women who have traveled this road

Their ordinary strength and courage act as beacons of light

Small glowing circles of light strung along the roadside

Piercing the darkness ---

Mysterious clues guiding me along meandering pathways.

\section{$15: 49$}

140M: So that was a way for me to sort of say what i was feeling because its very overwhelming and very shocking and very hard and umm ya know I remember first going into one of my first umm, well I started going to one of the support group meetings and Krista nelson was leading these and umm also the nurse navigator Teresa who I had been working with. And I kept hearing about these women who had had mastectomy's and I just couldn't imagine, it was just not something I could even imagine experiencing and then ya know it was going to be me. So I remember going in asking these women " how did you cope it emotionally or psychologically?' and ya know I got some very ya know, kinda animated responses umm most of it was around the medical issues and I realized the group was comfortable talking about their medical issues but they were really not comfortable talking about their deep feelings or umm experiences and I 150found that really amazing and sort of disconcerting and I couldn't understand that because yes, the medical things are happening but is also effects me emotionally and psychologically. Ya know I can't kinda cut myself into little pieces like a surgeon does and just not think anything about this, I'm not gonna feel any of this (laughs). Ya know I couldn't do that so this poem was a way to try to relate to it emotionally.

I: so would you say that when you were told that getting a mastectomy was your best option you obviously went through a big part of loosing what is a part of woman, womanhood is their breast, ya kow loosing that, and you can tell through your poem that must have been a scary thing, but when you were told that initially what were thinking? Were you just panicked?

M: well no, what I did was I just talked with these women and that's why at the end of the poem 160I talk about 'talking to other women who have traveled this road, their ordinary strength and courage act as beacons of light, small glowing circles of light growing along the roadway piercing the darkness mysterious clues guiding me along meandering pathways.' So I really felt that these women who had gone before me, if they could do It I could do it, and that they were living examples of proof that there is life after 
that that its not gonna kill me. And I did go talk to a surgeon, I went to get second opinion after the surgeon was recommending all these different options and the surgeon basically said yes you have all these different options and you have an early stage cancer and if you do what the medical people prescribe you'll have a 90 percent chance of recovering after five years and so that really helped too, I knew that basically I wasn't going to be dying that ya know it was a breast and I have a son that is grown and he may be 170about your age right now, he is 26 and he said to me 'well mom its breast and it's better to lose a breast than your life and I was like...oh. (laughs). I guess that makes sense. And I think you can probably relate, it is part of your, part of your body and somebody suddenly says 'well you just have to take this off.' It's like chopping my arm off. It's like well, I need that don't i? but again it's not an arm, it's not a leg, it's not like brain cancer, like you're not taking a part of my brain out. Umm but its intimately a part of who I am or was, and so it was very emotionally traumatic and difficult and I had already some side effects of the second surgery and that has continued even to this day where I developed some really a very sore arm, from the lymph nodes being removed and it was so painful I realized I had overdone it or something had happened and $\mathrm{i}$ had to have people come and help me do everything, and I had to ask people to come and help 180me do everything and that was really hard for me because I'm a single person and not used to asking for help but I just recently got diagnosed and its almost a year later, but it's called lymphodema and its where you have problems with pain in the arm or swelling in the arm because of the removal of lymph nodes, and so I'm not wearing it now but I have a compression arm thing and a hand thing and I have to do physical therapy numerous times a day because I have this condition, where it could swell up, or, ya know it still hurts after a year, umm soo, where was i? so I had that going into the mastectomy and then I did have some problems with the mastectomy, I had an infection umm and uh there's something that, ya just don't know cause 188you've never don't this before, and it turns out there's this umm, because of the lymph nodes being removed you get lymphatic fluids that drain from the surgical areas. And they actually 190 literally put a tube in your side and it literally drains out this lymphatic fluid and ya know never had experience but I heard about tit form other women in the support group, I had heard about it from Teresa the nurse navigator who specifically works with breast cancer people. I had specifically talked to her before but it literally was a situation where I came out of a day surgery and I was on multiple drugs and the nurse was saying oh 'you need to this and this and this,' and I was going huhhhhh (laughs).

23:10

So I had no clue ya know, and it was like I was doing something but I wasn't doing it right cause you have to like do it a special way and I wasn't doing it the special way and 
it was like uhh it turned out that I ended up having a lot of extra fluid building up by the surgical area and that caused complications, ya know complications from the very ya know, within two months of my 200diagnosis, no, well at least a month form my diagnosis and at least the arm complication has still umm gone on and the buildup of fluid had gone on for a long time, at least aq month or more and I literally had to have them come along and take a big syringe and take out the fluids several times. Umm.

I: so did you decided when you were initially told that you needed to get a mastectomy, did you think to yourself, do I want reconstructive surgery or?

M: I was told that I prob needed radiation and this was another thing that I had to learn, and the radiologists said 'it is best if you don't get reconstruction umm right after surgery because that makes radiation to the breast area more difficult. So in a way I was kinda glad not to have to deal with that because I was already overwhelmed and exhausted and dealing with the arm issue and 210as a single person trying to coordinate my own care because I have small support systems but they're very small and so nobody was able and willing to step in and coordinate my care so I was literally not able to do much of anything for a couple of months. And I had to have people come in and do my house cleaning and cooking, so ya know it was just very overwhelming and exhausting from the beginning. I even had (laughs) an old cat who I just recently put down, that I had around the same time I was dealing with this that had a flee infestation and I was having to deal with fleas in and around all of this and I was exhausted, just exhausted, so not having to deal with reconstructions was a blessing in a way. So I had my mastectomy and then a whole other level of complication was weather I do not only radiation but chemo. And so I met my chemo doctor which is called an oncologist early in November for the first time right before I went and 220had my mastectomy and umm I was still sort of in shock and still not clear of what I would be doing or what would happen, but it was a good meeting, he brought in a nurse navigator again who was also a cancer survivor a young woman to our meeting and I had also had a friend who was a cancer survivor with me and I figured out that is what I need to do at these medical meetings because they are so complex and then the emotional and psychological effects are so complex that its really hard to as a person go in and be level headed and hear what they say and 226not be impacted by it or thrown off by it,

$27: 25$

so that was a good meeting but umm I was told that they would do a test on my tumor to see whether I needed chemo and they already had the tumor removed and I said yes go for it. So umm the sequencing is really interesting I'm trying to remember how it all fit together. So after 230the mastectomy, it was a major surgery and again I had this 
complication with, not only an infection to the incision area but also this built up of fluid and I was exhausted and I just slept for weeks or was on meds or in pain so a lot of this is really fuzzy sorta how this fit together.

Were you concerned about side effects?

Oh yeah yeah, those were big big issues o sometime in dec I met with the radiologist and oncologist and tried to understand why I would need either of those procedures because I was skeptical. Ya know I was like 'I don't want to do these if I don't have to do these things' because they are very uhh invasive and dramatic and traumatic to the body and psyche. So I met with them umm and they gave me the technical info and in terms of the chemo I was told I would have to have that first. So that took on some added emergency, ya know emergent priority so uh, 240what I was told was the results from the tumor testing and there's a technical name you don't need to know. There are three categories that you can fall in. One is high risk for reoccurrence of cancer, and that means that you could benefit from chemo. There was the low risk and that meant you shouldn't. well I fell in the middle (laughs). The doctor said 'well you're a special case.' So its like thank god, no thank goodness. So they literally he told me they are doing medical research to determine what to do when women fall in this intermediate category. They're not sure what the benefits are to doing chem. for them or what type is best. And he said the results won't be in for years. So it was like, well if you don't know what's best for me, how do I know what's best for me? And so a lot of very intense discussion with him and I went again with my friend who was a survivor. He had another nurse navigator who I met who ya know was also 250older and I was trying to understand all this technical stuff and I didn't understand it and I had to have the doc go over and over and over because he would sorta not give me a lot of information and then Id get confused and try to read something and id get confused so umm essentially what it came down to he said 'I do recommend chemo, you have two choice for chemo.' So I was like 'oh great I have to choose again' (laughs). You can do eight sessions of chemo every two wks for three months or you can do four sessions for every three weeks for ya know four months. And ya know I didn't want to do chem., essentially I had this conversation with Krista and the nurse navigator Teresa, ya know didn't really want to do really any of these procedures any time, at all. And now I have had a mastectomy and now they're trying to talk me into chemo and radiation umm so essentially I got the doctor to say that he thought in my 260situation that the four sessions of chemo was efficient, that he thought it would kill off any possible cancer cells in my body and at this point it was still an early stage of cancer and they could not tell if there was any cancer throughout my body, but he thought the four sessions were enough. And I thought, 'ok I can do four.' I didn't think, because I was so exhausted and overwhelmed and had so many complications already, I didn't 
think that I could go through eight chemo sessions and come out the other end and not be just ya know a basket case or whatever, and I did have another complication that had to do with my teeth. I had a root canal that was done incorrectly and I had to have a tooth pulled, so I'm still dealing with that. Anyway that's another long story, but I had to have that done before chemo because the risk for infections was high and so just logs of info. Your overloaded with lots of technical information, your 270overwhelmed, and exhausted and many times you may have side effects or other health issues that you're dealing with.

I: so what are you dealing with right now?

\section{$34: 36$}

M: Ok, so I'll tell ya that there are other parts of the story so umm so I had the four sessions of chemo, I actually did write another poem about the chemo, I can read it to you or just give it to 275 you

I: Please can you read it?

M: yeah I do have an extra copy so you're welcome to have it. So this was at the end of my chemo.

I sleep my body is numb

280Gaining what seems like momentary relief

I wake barley able to move

Utter exhaustion permeates every cell

$36: 46$

I: Wow that's very intense

M: Laughs yea it really spoke to me at the time. So I went through the four chemo therapy sessions at the time, and I have to back up because I was doing another test at the time I was told that umm I really should get a genetic test done to see if I have a genetic propensity for other cancers and if it runs in my family so I started chemo in February but dec I went in for genetic testing and counseling with a counselor nurse and there was some probs with the testing and insurance coverage and I don't think I got the results till January so it turned out I was positive 290for the genetic tendency and that was also very upsetting because I knew that I might be at high risk in a way because my mom had ovarian cancer and now what I know it there is a genetic tendency for about four percent 
of the pop to have this genetic default we all have the gene but only four percent of us have the default. So I was hit by this and trying to go into chemo and this arm issue and an engorged so I had multiple, a lot going on, and it was very intense and very difficult emotionally so I actually did get on antibiotics, antidepressants, and I was told by my surgeon when I first asked for this, that a lot of women going into their mastectomy ask for this because its extremely extremely difficult so umm all of this gets mushed and its very intense very overwhelming I was exhausted and all of this medical stuff ya know running around in my head and all the emotional and psychological stuff it just takes over your life and uh there's, 300Krista at one point or the nurse navigator said this becomes your fulltime job because you're always going to doctors or nurses, your trying to figure out how to deal with side effects, your trying to go to support groups because you need them you're talking to other women to find out how they dealt with these kinds of things before and basically I needed all the support I could get and I still had people coming to help me with everything because I really couldn't do much. I did do one very fun thing, well tow, during chemo, it wasn't all horrendous. One of the things was I knew my hair was gonna fall out and I thought well; ' I can freak out about it, or I can do something productive.' And so I decided to have my son shave my hair and he has a son. I have a grandson he was about five at the time and so my sons fiancé suggested that we have my grandson be there so he had a sense for what was going on. And I said well I have all these hats not since I'll be without hair and why don't we do something with my grandson and I with hats and scarves. So that's what we did, my son shaved me and took some pictures then my grandson and I played with hats and scarves and took pics. And it was wonderful, ti just make the whole thing a wonderful experience for me. Because obviously I love my son and my grandson and so it made it fun. And that was one wonderful thing and then another wonderful thing was through a breast cancer support group. And I got a call around the time when I was ya know sitting on the couch doing nothing, so I got a call and it was really funny she says 'well how are you doing?' and I said 'horrible, I'm on chemo what do you want me to say?' and she says 'well how do you 318want to go to a blazer game?' so I went with the other women. It was sponsored by this breast cancer support group and my son and I went to a blazers game, and he loves basketball. Neither of us had been to a professional game in at least ten years and umm yea we got to sit in Paul Allen's box because he donated it to the support group. So we sat in the box we had special food it was really neat. And i got all of these free hats which was really cool. Cause you know I had always admired women that wore had but I had never worn hats other than winter ones, so I got all these cool hats and got to put them all on and even had a cosmologist make up thing and I learned that there are ya know twelve steps to putting on makeup, you have to put your foundations first and I didn't even know what was going on cause I never wear makeup. But that was fun, it wasn't all horrendous but ya know physically emotionally psychologically you're just, 
well poems give a sense for the depths of ya know the sense of dying away. And I met a women who used this term and its very graphic but it speaks to what I felt in a way. She says, 330well the treatments are slash, poison, and burn. And slash is the surgery poison is the chemo and burn is the radiation, so it's very graphic but yet there's a cearnal of truth in that. So after radiation umm after chemo it ended in April then I had about a month off and umm that was great cause you need all the rest you can get then I started radiation and it was thirsty sessions, six weeks, five days a week, very intense, very scary I was not wanting ot do it I had ot really sit down with the radiologist and be convinced that this was the right thing for me and she would sit down and talk about percentages and research and ya know so finally I was realizing that she said well it will help you in the future to cut down your risk of reoccurrence and so I did do it. And one of the things that was really helpful was that I did have people come sit with me at chemo cause it's a four hour ordeal and I had friends come sit with me and one woman was a breast cancer survivor that I had not known before but I had gotten, I had reached out to a support group and said 'ya know I am looking for someone to come sit with me.' And she had volunteered and so she came with me to one of my chemo sessions and a couple of my radiation appointments. And that was really helpful because it's this huge god awful machines and its radiation and it's like burning and I was told ya know certain things from the chemo doc and the radiation doc that was comforting that it would cut down my risk of reoccurrence in the future in terms of the chemo therapy umm the poisons leave your body within forty eight hours and with radiation you're only exposing the area you think is at risk and there's no radiation outside of this area that well be doin and were are only doin it for two three minutes or less. So all of that helped but I did end up having the major burn and issues around that and they had to give me 350special medication ant I had to put all over my breast area and that was horrible and painful and yucky and so then because I was positive for this genetic test I was told I would need to get my ovaries removed so I had to prepare to for another surgery and I did have that surgery in july end of july so its really only been a few months that Ive been out of the cancer treatments. So that's my story so far.

I: ok and so overall, and we can end on this if you want. So overall, and by the way thank you so much everything have been really really good. How do you think the whole cancer diagnosis and treatment had affected your identity as a woman? Or did it, did it have any effect? Cause I know when I went to the young women's support group even minor scars have effected them and they said it makes them feel less feminine, but some women also come from a totally different perspective feeling that it didn't affect them in that way.

47:57 
M: well that's a very good question and I think I'm still sorting it out. I mean literally as I said I just finished my last surgery at the end of july, only three or four months ago. Emotionally and psychologically I am still trying to figure this out. I am older I just turned 53, I'm not married, im not seeking any intimate relationships at this time and if I was married or looking for intimate relationships it would be different. I think that's all I can say about this at the time. And I ya know I think it does uhh there's I think my first poem particularly, how can you lose a part of yourself and not be affected. I have one woman a friend who came with me to these appointments who had a double mastectomy and decided not have reconstruction and I asked how it affected her and she said it didn't. and I could not not believe that. There's no way I could 370lose a part of my body and not be affected. So for me I think that either they're in denial or incapable of dealing with the deeper issues or don't want to deal with them. I think if I was younger, or in a partnership it would be more of an issue of femininity ive sort of grown to the point where I see myself as a woman and human, my humanness is more important to me than my femininity. Ya know, I'm alive (laughs). There's a life ahead of mean and I have to be grateful.

I: well you seem to have remained extremely positive about this. And I'm sure there are times where you don't feel so positive, but right now are you?

M: well I'm still working through things, before uh and I didn't get into this before all this happened, I went through a major move last spring and was even looking for work up till my first chemo session and I was like 'I can't do this and work. And so I do need to get back into a professional role and I'm struggling with that and I'm still dealing with fatigue and he said it could be a year or more. And I asked if there was anything they could do about that and he said get more exercise. And I'm still trying to do that. My body has just been through a hell of a lot for a full year and I can just flip a switch and pretend I'm 20 or 30 . Because I'm not, I can just jump around and pretend. So it's a process. I'm still dealing with that part of work.

I: well I can't thank you enough and I'm so grateful you came here.

$52: 46$ 
Wednesday the 24th at the Starbucks on 6th and Jackson

Kathleen Engstrom (Meghan)

Kathleen is a taller woman wearing jeans, a shirt and a jacket. She has short hair and jewelry. She seems very direct and to the point. She possesses a manila folder with documents from her doctor visits as well as excel spreadsheets composed by her of treatment options and medical side effects. She answers every question very straight forward and direct.

Jenny: Ok that should do it, and you can talk as quite or as loud as you want it picks up everything.

Participant: Sure, okay

Jenny: Why don't we start with, can you just kind of tell me when you were diagnose and what that was like?

Participant: Well what happened is on my baseline mammogram they found a suspicious lump and so at the time, umm I am trying to remember I think I did the original surgery with my original doctor and I got the diagnoses of breast cancer. At which point, I said I don't trust my doctor. Well actually no, I don't actually think, I think what they did is, I got the mammogram 10and they looked at it and they said we think based on this you should go and have surgery. I was really not comfortable with the doctor I had, she had no bed side manor at all. So I started working my network, to say does anyone have breast cancer, do you have doctors, all that sort of stuff. Through that I found a surgeon that I felt comfortable with, so I went to that surgeon for my original surgery where they did the biopsy and also found another doctor through my network and so then once it was confirmed that it was breast cancer then I found an oncologist.

So all three of those the surgeon, the oncologist and my new primary care physician were things that came after I was kind had of received the notice that I had that suspicious lump. And so once I got the diagnoses, it's a matter, I'm an engineer by background so it was like oh ok. It's a project I've got to figure it out got to get the data. So started researching, so actually my mom had 20the year before had been diagnosed with hodchkins lymphoma, so I had been down there and help her to figure out what she wanted to do. She was actually in her seventies when she was diagnosed. And she was, she actually considered not doing anything and just dying. So we spent some time kind of working through that because her father had had thynomoa which is cancer of the thymus. He had had, I mean, this was in the seventies and he ended up getting shingles and so the side effects of things killed him and so my mom just kind of like cancer 
means I am dying and I am done. So I spent the whole, year before working with her to see that there were options and we got her on a regiment and all that sort of stuff. And because of that I already knew the process of researching for cancer, so that was I did.

30Jenny: So you researched a lot yourself?

Participant: Oh absolutely, yeah because I had all sorts of resources and I had a good group of friends, uh that were also kind of, you know would give me ideas and I would process things with. And so based on that I had quite a lot of knowledge before I went into see my oncologist for the first time. And so when I went in, my friend went in with me and we both had a list of questions and we both took notes and you know, and kind of went through and went through that process and decided on a course of treatment and kind of went through the process.

Jenny: So when, when did all that happen, when was the diagnoses?

Participant: So the diagnoses were, so I was actually, I pulled out some stuff because I haven't looked at it in a long time, so I created a timeline for myself. So what I had did, this was my 40original was in October of 2002 so you know ten years ago. it's got the initial mammogram and the fallow up mammogram at this point they said it looked suspicious, so at this point, kind of right in here I said I don't trust her went and found you know another doctor and then based on that, this is the surgeon, so I met with him in February and you know that first surgery was on the 18th, that's when I kinda got the diagnoses that it was breast cancer. So umm between here and here they talked about there was a setonold biopsy clinical trial going on, so I enrolled in that trial. Umm what actually happened, was that I had the cancer had metastasized into my lymph nodes. So they end up taking all of the lymph nodes because you know that's what the trial was designed. So had that and found out that it had indeed that it had started to move out of my breast so I think I that meant that I was stage two. Umm this was my oncologist, so I met with 50him had a great conversation I didn't write down the original date but this was a second opinion, I ended up at Fred Hutchins Center, so based on all these conversations I started chemo in April, went through my chemo. I actually had an interesting thing, you know my umm portacath. you know for the chemo that had been put in I got a blood clot, so I ended up having to have that to be removed. So I got a whole new group of doctors. Then umm, you know because I was having lumpy breasts and assists, so they were fighting over stuff on the table, so they were doing all that. Then I did radiation starting in August. I did that and I was back to work by the end of October.

Jenny: Wow, ok, so when you were initially diagnosed in October your treatment options were to automatically just start... 
60Participant: No, so so it was interesting I pulled this out, what I did is working with my oncologist we said okay here is all my options, so I went through and kinda created this table that said what are my options, what do I have to expect from them. So you can see that I took very analytical, political, umm like a project management approach to it and so it was just like okay. And kinda my thought was if I researched everything up front and really understand it, when I pick something I would have the confidence to just go with it. So I ended up choosing this, which was, you know rather than having chemo every three weeks I'd have it every two weeks, so I had an accelerated chemo and because I was fairly young and in good shape, umm so man I got to get through this in four months verse six months of chemo...

Jenny: So that must have been very intense.

70Participant: Ya, so it was pretty intense but it actually worked fairly well, in terms of I tolerated the chemo fairly well. You know various issues along the way but they were manageable.

Jenny: So were your, did you ever consider a mastectomy or ...

Participant: No umm I mean I pretty much, I talked about it I think with my surgeon, but you know the tumor I had was pretty well defined, they were pretty confident that they had gotten it. And you know I didn't have a history of breast cancer, my family doesn't have a history of breast cancer, we have cancer but not necessarily breast cancer. So it was like...

Jenny: Not... You didn't feel like it was necessary.

Participant: Yeah I didn't, I kind of looked at it, just didn't feel like it was something that 80 would be valuable to me.

Jenny: So when you were initially diagnosed were you concerned about possibly that being an option of you possibly losing your breast... or no?

Participant: Yeah no, cause I had done a lot of research and so I kind of knew there were choices along the way. So this is, to show you how much of a project manager I was...

Jenny: Yeah, did you make this all yourself? Wow that is awesome!

Participant: Un uh, so this is a racy chart, this is a tool you use in business to say who has what roll.

Jenny: Um hmm 
Participant: The thing I wanted to be clear to everybody was I was making the decisions. And 90if I couldn't work with people, then I'd go find a new doctor.

Jenny: Yeah

Participant: So that was a real important criteria for me cause that original doctor, I mean it was just really clear that I didn't trust her to go through the process with. So I mean they all laughed at me and all kind of going okay you are really anal, but for me this was...

Jenny: That's how you understood it.

Participant: ... How I understood it and let's be clear I am making the decisions. I really really value your input and really want to work with you but at the end of the day I need to make that decision. And so based on having had that conversation and you know all my doctors were great, and really worked with me that way so it really was a partnership all along the way. You know, I 80would research thing and bring it in and ...

Jenny: And you had a good support group system from your friends, you said

Participant: Yeah, so I don't have family in the area and I am not married so you know it was kinda like oh okay. Umm but I had good friends and in fact I created another chart where it was like ok who's going ... because you know when you're on chemo you can drive yourself, so it's like how do you get to and from your secessions? So I created a chart and ask friends if they mind driving me to and from chemo. You know again had lots of great friends who rally around and.

Jenny: And you worked through, up until?

Participant: No, I didn't, I worked until chemo started.

Jenny: Ok

Participant: Because I was in a fairly high stress job and my boss and I talked about it and she said "I can't push you as hard as I need too, so I would rather you take a leave of absence". I had benefits where I had disability during that process. So I got to focus on going through the process.

Jenny: mmhm (sp?) what made you decide to change kind of your career, because you said now you are going to...

Participant: Well what happened is, it was interesting you talk about how did breast cancer change me and one of the things that happened for me is I don't take work so 
mentally any more. Before I would have been so totally consumed, you know because I was in middle management 100at Hulett Packard. You know I had a lot of responsibility, I was managing worldwide teams and but what happened for me it is all the sudden for me, it was like work was work and I could separate the two. But what happen in the end 2009 , is they basically said to keep my job I had to move to Texas and it was a case of I just didn't feel like that was the right move for me. So cancer for me had actually started to helped me separate, because I worked for HP 20 years, so me it really gave me this sense that there is more to life then work.

Jenny: Yeah, Ok and then so now you are going back to school for?

Participant: Yeah, So I have completed, as I have said the graduate student biomedical It's like how to I take all that experience and help health care as its going through all these major transitions that it has to go through, because you know the country can't afford the current model.

Jenny: and you would say your cancer diagnose, was that, did that have anything with you choosing anything in the medical... or not?

Participant: Yes and no, I mean I have a sister who's an emergency room nurse I have a bother-in-law who's a doctor, so there's always been medical. It was more of a case, where is there going to be jobs, where is there opportunities to contribute. For me, I call it cancer was a bump in the road, I didn't get obsessed about it, it was ok I got to go through this, got to manage it but when I was done, I was done.

Jenny: yeah and would you say you stayed relatively positive attitude wise through the whole?

Participant: yeah, yeah pretty much.

\section{Jenny: Yeah}

Participant: Yeah, I mean not working was really was really helpful because I had time to focus on it. You know when I had a day that I didn't have the energy, then...

Jenny: Then you didn't have to worry about that. And you say that you weren't worried about any of the side effects really or you didn't have?

Participant: Umm well I was aware of them. It was really interesting, like the first chemo I remember is I started throwing up and I couldn't stop. And so you know eventually I had to go back to the clinic and they gave me a shot because I took the oral medications and so you know that was manageable. The second one went pretty smooth, 
the third one was pretty interesting cause I actually looking back realized I was almost in a coma for like 36 hours, but I lived alone, so just like, it was a good thing I woke up. You know, but it was like, I am a person that has a strong faith tradition and I was really comfortable that I had done the best I could and so I was just trusting and going. So based on that, I didn't, it was like if something pops up I'll deal with it but I am not going to freak myself out, thinking about the what ifs.

Jenny: Yeah, did you worry about, cause these are the side effects right, did you worry about anything like long lasting side effects or like scaring or anything, well I guess not really, well I don't know much about chemo and how chemo actually works, can you explain it.

Participant: Yeah so the basic idea of chemo is, so cancer is a fast growing cell and so the idea is that chemo targets fast growing cells and kills them. So that's why you lose your hair, because what happens when you get your chemo, the cells that grow in that period, when the chemo in 140your system, the drugs that hair is really brittle so it breaks off basically and So that's why you lose your hair because the hair doesn't have any strength and so, I mean it was actually when I lost my hair a friend and I went down and picked out a wig and we cut my hair and did a Mohawk and you know all that kind of stuff and just had fun with it basically.

Jenny: Yeah

Participant: And so it was like I was aware of all these, you know some of them happened and some of them didn't. You know I quickly realized, you know cause I went through a lot of surgeries that you're always going to get that umm document that says you can die while we're doing this. Ok well if I do, I do. So like I said I am enough of a manager that I am aware that they have to do, you know it's risk management. They have to say that because people will sue if they don't say that, you know if something bad happens. You know I could separate the what is, they have to describe it all because it could happen to what is likely to happen, so the things that were really extreme I didn't bother with, I didn't worry about. You know so it was really interesting when I had the clot, a group of friends and I were flying down to Southern California, so I called my oncologist and I said I've got this funny symptom in my arm and actually I don't think I call him, I think I called the surgeon who put in the portacath(SP?) and I couldn't get a hold of him and so we flew off. We finally connected when I landed in LA and he was just freaked he's going "you need to go to an emergency room right now".

Jenny: Yeah. 
Participant: I was like ok. So we go to the emergency room and they admit me and it was like 160after 24 hours it was like this is stupid, why am I here, they wouldn't let me out.

Jenny: Really?

Participant: because you know they were concerned that the clot would break off and go to my lungs and kill me. If you get a pulmonary embolism it will kill ya. But and so they had to give me this anticoagulant basically to thin my blood and they gave me a shot in the morning and in the evening. Its like if I called my oncologist first, what happened cause it took a couple of weeks between that and getting the surgery, so I was giving myself shots within a couple days of coming back but the particular hospital that I went to had no mechanisms to do that. So my friends came, we were doing a quilting retreat so we took over the room at the hospital and brought the quilts in.

Jenny: Oh, nice!

Participant: and so it was just that sense of ok this is has happened, figure it out. What's real what's not real and then what do you do about it.

Jenny: and then so had, you called it a portacath?

Participant: It's a portacath.

Jenny: So where is that at?

Participant: So i'll show you, so that is scar. So what they do when you are getting chemo its intravenous and so they had, so rather than you know keep poking you every time, they put a portable catheter in so they just have to poke into that and it saves your veins basically. So I had one and what happened is that it had kinked in the vein and it created a clot. And so you could 180see, actually it was really cool I got to, this is the scientist / engineer, it was really cool. So when I was with the surgeon that was trying to clear the clot were sitting there and they didn't put me out, so I said "can I watch?" and so they had a television screen, so I am watching and he's putting the contrast fluid in and I could see that my veins had started to grow an alternate path.

Jenny: Wow

Participant: So the one was blocked to it had already built a whole series of new veins where it could go around the clot. So when you looking at it going man isn't the body cool. And then you, umm so anyway it was really funny about half way through what they do, is used, have you heard of angioplasty? 
Jenny: No

Participant: So if you have a clot in your heart they sensually take a little balloon, stick it up your vein and get to the clot and blow up the balloon and then they push. Just like a clot you'd have in your pipes they are trying to push the clot through and break it up. So anyway, he had pushed that up through here and you could watch it come up, and it blowup but he blew it up a little too far and it popped and it hurt. Ok and I am going ok ill take the pain meds now.

Jenny: Did it hurt?

Participant: Oh it hurt?

Jenny: Really?

Participant: Yeah, it really hurt

200Jenny: So you didn't have any pain medicine up until that point?

Participant: Not until that point, it was just like you know when you give blood, and you didn't need, but at that point it hurt. I was starting to feel on top of things.

Jenny: So what about pain did you have any other pain, as far as pain goes through the whole process?

Participant: No, I've got a pretty high pain tolerance so I mean, I had umm yeah it was more kinda the first four, so I had two regiments of chemo, the first four, you know two different drug sets, the first four was more nausea that I had to deal with and its like food tasted different I mean there was a lot of it that just didn't taste good.

Jenny: Yeah

Participant: The second four the issue was maropothy that's where your fingers go numb and your toes go numb that sort of stuff and so you know I had some of that that went on.

Jenny: Yeah but it was it was just more sort of discomforting kind of stuff?

Participant: Yeah, yeah I was never on pain meds, I didn't need them.

Jenny: What about, was radiation ever did you ever had to do?

Participant: Yeah I did radiation

Jenny: So what was that? How was that? 
Participant: So what they do is basically, so I've got four little tattoos, one here, two here and one here.

Jenny: mmhm

220Participant: So every time you get treatment they line you up so you are exactly the same umm but I really never got any symptoms from radiation. My skin didn't turn red, I basically said I need to give up ever getting a tan because it's like if I get intensive radiation and I don't change color, I am not going to get it with the sun, so.

Jenny: What about burns, did it burn? I've hear other women that I've interviewed said that radiation burns, that they got a really bad burn.

Participant: See I didn't get any of that.

Jenny: Nothing?

Participant: See and part of what was going on for me is, umm so in addition to the stuff that I was doing there, I was also using alternate methods. So I trained something its called Ke-a-so-ho (SP?). and it's a healing art it only taught here in Portland and in Japan.

Jenny: Wow

Participant: So what would happen is, so I had chemo scheduled on Thursday right so on Wednesday nights I would go to Ke-a-so-ho and they would press out all my organs and it's a matter of increasing your living energy. And So I do that, I get chemo on Thursday, Friday was usually a pretty good day, it would hit on Saturday, so Saturday was usually a bad day, go back on Sunday and get pressed again, by Monday or Tuesday I was fine.

Jenny: When you say "pressed" what do you mean, can you explain?

Participant: Yeah so if you think about here this is pressure, this is sending energy in and so there's all different kinds of ways, you can press your stomach, you can press all this sort of 240stuff, so chemo really kills a lot of stuff so part of what you have to do afterwards is you got get your health back. And So it was interesting as my stomach and all the organs down there started working again and you know. Medicine, western medicine gets you 80 percent whole, maybe 85 if you are lucky. But for that last 15 percent you got to own that, and so as you can tell I was just very proactive about it. Ok this is what I go to deal with and I am going to use all the tools that I have and I just worked through it. 
Jenny: Yeah it doesn't sound like you were brought down by it at all.

Participant: I mean I remember the first week or so it was like "wow I've got breast cancer and I've got to deal with it". You know so the first two to three weeks, maybe the first month as I was kind of figuring out the plan, was that was tough but it was like "ok".

Jenny: You just kind of had to deal with it.

Participant: You just worked through it because I've learned getting, you can deal with big problems just taking it one day at a time and saying what can I do today. So that's really that's the approach that I took.

Jenny: and then, I know, I've talked to other women, I went to a few young women's support groups and stuff like that and they, a lot of them talked about when they were diagnosed initially they felt like you know as a woman breast cancer it kind of changes you and they felt that some of them even felt, one girl she actually said "when I was initially diagnosed I felt like automatically felt like I was less of a woman, just because. Did you ever any feelings like that, not at all, yeah?

260Participant: I mean one of the things I was dealing with was that it could of put me in early menopause and you know as I looked at it I said I think, I don't think I want that have that happen. So during the chemo I was on drugs that would shut down my mental cycle so that I could reduce the likely hood that I would go into early menopause. And so, yeah I don't think I ever felt that way, yeah ok this is just something to deal with.

Jenny: So with where you are at today do you ever worry about it reoccurring or anything like that?

Participant: Yeah, no I mean it was funny my oncologist, so you have a medical oncologist and a radiation oncologist so the first year, you know after I fished everything I seeing each doctor every six months, so every three months I was seeing a oncologist. and after the first year, the radiation oncologist said "your good, see you later, don't need to see you again". My medical oncologist said well if he's not seeing you then I need to see you every three months. I am going "why?". Ha ha but it was basically you were so young when you got it that I just really want to follow you. I said "ok". So went through that, and we actually at one point I did the genetic testing to see if I had the BRCA, BRC I and II mutations, which I didn't, umm but so I met with him and it was about a year ago I kinda looked at him and said "I think, I think I can, I love spending time with you but I don't think I need to becoming anymore" and he kinda went "yeah, I think I agree".

Jenny: Ok 
Participant: So it was only a year or so ago that I, you know, I don't have another appointment 280with my medical oncologist.

Jenny: and you don't worry about it?

Participant: It kind of the thing is, I've had enough stuff in my life happen that worrying about it doesn't help you have to live with the cards your dealt but live 100 percent and move forward.

Jenny: Yeah

Participant: So if you get stuck and go man if this is going to happen or that is going to happen. So for me, lots of stuff has happened in my life but not the things that I would of predicted so I would rather just live life fully and say when it comes, cause I know other stuff will come, then I'll will work through it.

Jenny: That's amazing. I can't believe every woman I have interviewed has been so positive about their situation. You know what's funny is that every woman has taken like an independent like, like everyone have very good support groups like that but I feel like every woman just right when they get the diagnose there mind switches and their like "I have to take care of it". I don't think that any of the women that I've talked to have said well is it an option to not take care of it, and you know everyone said, know kinda like you said a bump in the road...

Participant: yeah

Jenny: Something that I am just going to have to deal with. And another woman too, she said that it just became, it was just a new lifestyle. It just became a different lifestyle, that I just had to adjust to and her life will always be that way. Umm okay, that was a very direct, I think I got everything that I needed to get thank you so much for...

300Participant: Sure...

Jenny: well hopefully that recorded because it never use to make that, well that makes me nervous but umm do you mind if I ask you.... end of audio. 